University of Louisville

ThinkIR: The University of Louisville's Institutional Repository

Electronic Theses and Dissertations

8-2004

\title{
Technological change, economic growth, and income inequality : MSA evidence from the 1990s.
}

Thomas Eric Lehman 1967-

University of Louisville

Follow this and additional works at: https://ir.library.louisville.edu/etd

\section{Recommended Citation}

Lehman, Thomas Eric 1967-, "Technological change, economic growth, and income inequality : MSA evidence from the 1990s." (2004). Electronic Theses and Dissertations. Paper 813.

https://doi.org/10.18297/etd/813

This Doctoral Dissertation is brought to you for free and open access by ThinkIR: The University of Louisville's Institutional Repository. It has been accepted for inclusion in Electronic Theses and Dissertations by an authorized administrator of ThinkIR: The University of Louisville's Institutional Repository. This title appears here courtesy of the author, who has retained all other copyrights. For more information, please contact thinkir@louisville.edu. 
TECHNOLOGICAL CHANGE, ECONOMIC GROWTH, AND INCOME INEQUALITY: MSA EVIDENCE FROM THE 1990s

\title{
By
}

Thomas Eric Lehman

B.S., Indiana Wesleyan University, 1992

M.A., Ball State University, 1994

\author{
A Dissertation \\ Submitted to the Faculty of the \\ Graduate School of the University of Louisville \\ in Partial Fulfillment of the Requirements \\ for the Degree of
}

Doctor of Philosophy

College of Business, Department of Urban and Public Affairs

University of Louisville

Louisville, Kentucky

August 2004 
Copyright 2004 by Thomas Eric Lehman

All rights reserved 
TECHNOLOGICAL CHANGE, ECONOMIC GROWTH, AND INCOME INEQUALITY: MSA EVIDENCE FROM THE 1990s

\author{
By
}

Thomas Eric Lehman

B.S., Indiana Wesleyan University, 1992

M.A., Ball State University, 1994

A Dissertation Approved on

July 6,2004

By the following Dissertation Committee:

Dissertation Chair / Director 


\section{DEDICATION}

To my loving wife Noelle Faith,

without whose support and encouragement

this journey would not have been possible;

and

With love to my special and wonderful daughters ("my sweeties"),

Amanda Noelle and Alyssa Nichole,

my other contributions to posterity. 


\section{ACKNOWLEDGEMENTS}

To call this research project "mine" would be true only in the sense that the labor of committing ideas, words and statistics to paper was mine alone. The labor itself, however, would have been wholly impossible without the gracious help of many others.

I would like to first thank the University of Louisville for the opportunity to pursue my life's dream in higher education in an exciting field of study that continues to fascinate and impassion me. More specifically I would like to thank my dissertation committee members for their tolerant assistance and keen insights, and for their diligence in seeing my research efforts through to completion: Steven Bourassa (chair), Paul Coomes, John Gilderbloom, Jay Vahaly, and Wayne Usui, all tremendous scholars from whom I have learned much.

Of course, I would never have made it to the dissertation stage of my Ph.D. program without the benevolence of my employer, Indiana Wesleyan University, who provided financial support, flexible working hours, generous time, wondrous office space, and countless lesser resources allowing me to complete this project and my degree. The barriers to the fulfillment of my professional goals were removed due to the caring encouragement and assistance of David Wright, Mark Smith, Bob Hamill, David Bartley and the late Glenn Martin, as well as through the help of Krista Brown, Brad Grubb, Jule Kind, Linda MacKay, Sheri McCoin, Beth Ohnesorge, Laryssa Solms, Keith Studebaker and Kathy Williams. To all these peers, friends and co-workers, I owe a huge debt of gratitude for their constant support and encouragement. Thank you! 
The data acquisition and processing requirements for this project were formidable, and would not have been possible without the help of two important collaborators. I would like to thank Martye Scobee of the Kentucky State Data Center, whose knowledge was invaluable in helping me to locate, interpret and weed through enormous amounts of Census Bureau and BEA data; and, my student assistant at Indiana Wesleyan University, Emily Lemasters, who did tedious work to provide me with highly accurate data from a variety of sources in an easy-to-analyze electronic format.

I would also like to thank my parents, Winston and Vicki Lehman, for their support and love over these many years. Since I was a boy, they have only ever offered their love and encouragement to whatever activity or endeavor struck my fancy, however incomprehensible or silly it might have seemed to them at the time. It is my hope that the completion of this project provides them with much pride for many years to come.

Additionally, I would like to acknowledge the love and gracious encouragement of my late grandmother, Freida L. Neuenschwander, whose passing came just 12 short hours after learning that I had successfully defended this dissertation and that her only grandson had earned the title of "doctor." Any successes I experience are, in part, a result of her lifelong strength and determination, and the importance she placed on education.

Finally, and most importantly, I would like to thank my beautiful wife, Noelle, and our precious daughters Amanda and Alyssa for their love, support, devotion, hard work and sacrifice throughout this long journey to the end of my little rainbow. Not only have you made the journey a possibility, but you have made the end of that journey all worth while for me. The hard times came, but you did not give up on me. I owe you 
more than I could ever repay in a lifetime for your steadfast loyalty and unconditional love.

Tom Lehman Marion, IN July 2004 


\begin{abstract}
TECHNOLOGICAL CHANGE, ECONOMIC GROWTH, AND INCOME INEQUALITY: MSA EVIDENCE FROM THE 1990s

Thomas Eric Lehman
\end{abstract}

August 2004

Employing a two-stage least-squares multiple regression technique using crosssectional data from metropolitan statistical areas (MSAs) as the unit of analysis, this study is designed to detect the indirect effect of skill-biased technological change (SBTC) on household income inequality through changes in the rate of per capita economic growth over the decade of the 1990s. If recent technological changes are skill-biased and tend to raise inequality, as much previous research has suggested, and if such technological changes are a relatively large determinant of economic growth, then we should be able to observe a positive association between technology-driven economic growth and income inequality, all else constant. However, the data and method employed here could not establish support for this hypothesis. Instead, the measures of technological change employed in this study are found to raise per capita economic growth, but economic growth is found to decrease, not increase, household income inequality.

In a related vein, this research study seeks to test the theory of an extended or reformulated Kuznets Curve Hypothesis in which economic growth and income inequality might be positively correlated due to structural changes in advanced post- 
industrial economies. This reformulated Kuznets Curve Hypothesis is linked to the theory that growth and inequality might both be related to SBTC resulting from structural shifts away from a mature industrial economy and toward the emerging information and knowledge economy of the 1990s and beyond. This theory, too, must be rejected based upon the findings presented here. Instead, economic growth is found to be negatively correlated with changes in household income inequality in metropolitan areas over the 1990s, confirming the original Kuznets Hypothesis that rising economic growth compresses the income distribution. Other variables are also found to explain variations in household income inequality in metropolitan areas over the decade, including changes in educational inequality, prpulation growth rates, and changes in black-nonblack housing segregation.

Overall, the findings presented here suggest that 1) further work must be done to substantiate the SBTC explanation for rising income inequality, 2) the effects of technological change may have little or no impact on inequality through economic growth, 3) the original Kuznets Curve Hypothesis appears to hold true even during periods of apparent structural change in an advanced post-industrial economy, and 4) numerous additional factors not identified by this study must be responsible for the variations in metropolitan household income inequality over the decade in question. 


\section{TABLE OF CONTENTS}

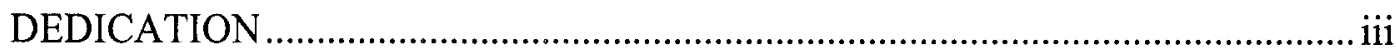

ACKNOWLEDGEMENTS .......................................................................... iv

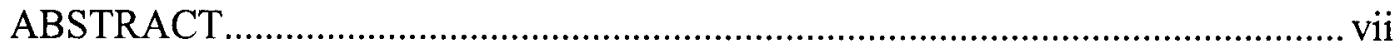

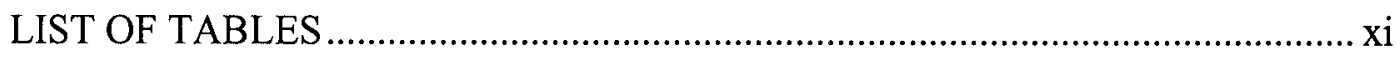

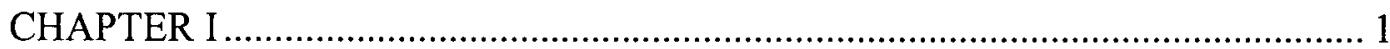

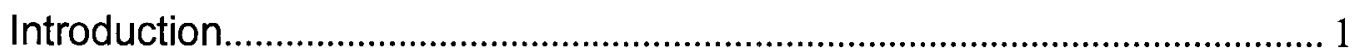

Background of the Research Question .............................................................. 1

Thesis Statement of the Problem and Research Questions................................... 7

Assumptions and Limitations of the Study ......................................................... 10

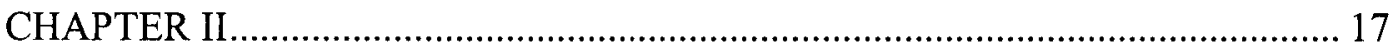

Literature Review: Growth, Technological Change, and Inequality ........... 17

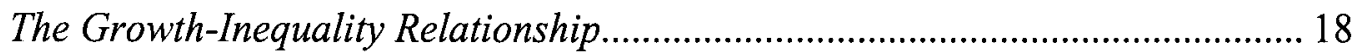

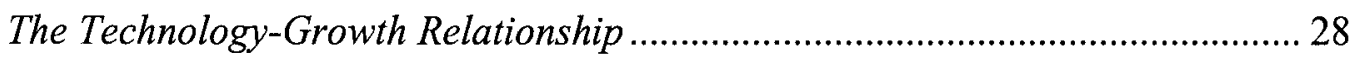

The Technology-Inequality Relationship ........................................................... 30

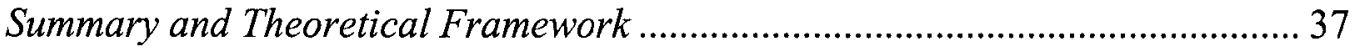

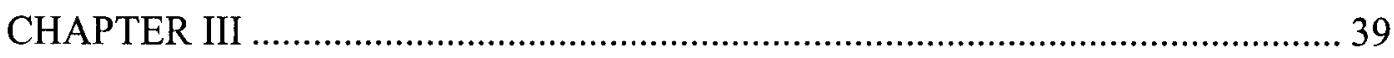

Methodology, Data and Formal Hypotheses ………................................. 39

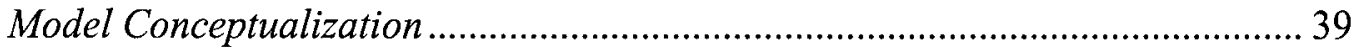

Operational Definitions, Variables, Hypotheses, and Data Sources..................... 43

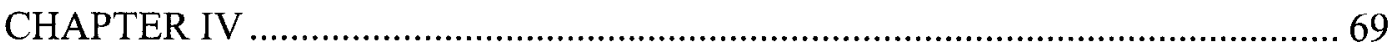

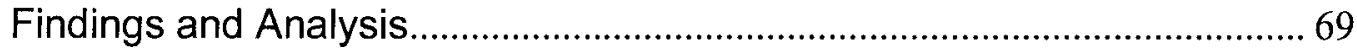


Description of Data and Univariate Analysis. 69

Effects of Technological Change on Per Capita Economic Growth .................... 78

The Question of Endogeneity: Per Capita Growth and Household Inequality .... 89

Effects of Per Capita Growth on Changes in Household Income Inequality ....... 93

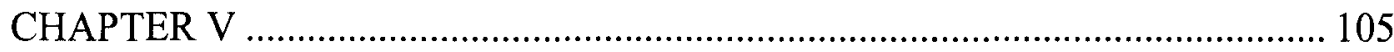

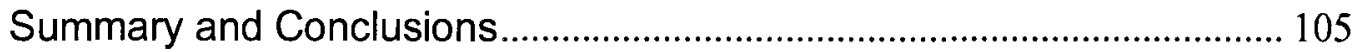

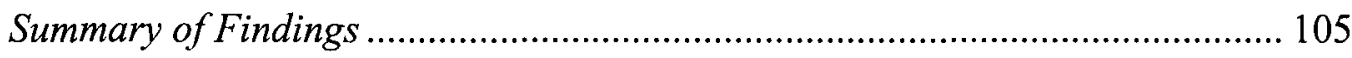

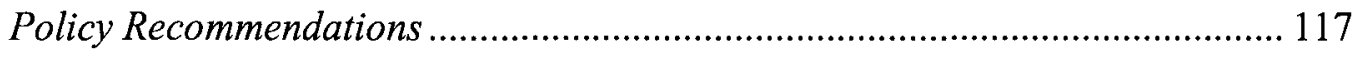

Weaknesses and Suggestions for Future Research .......................................... 127

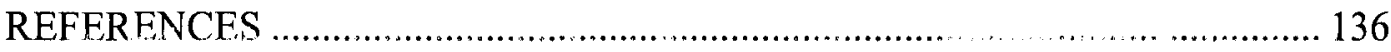

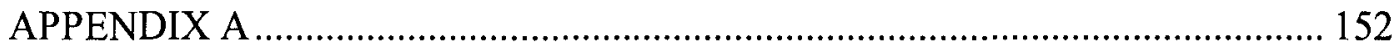

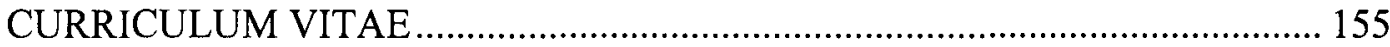




\section{LIST OF TABLES}

Table 1: Summary of variables in the first-stage regression estimating per capita growth.

Table 2: Summary of variables in the second-stage regression estimating inequality .68

Table 3: Univariate statistics for selected variables .72

Table 4: Summary of regression coefficients estimating real per capita GMP growth rates, 1990-2000 .78

Table 5: Summary of regression coefficients from Hausman's test of simultaneity between per capita real GMP growth rates and changes in metropolitan household income inequality. ... . .92

Table 6: Summary of regression coefficients estimating changes in the metropolitan household Gini index, 1990-2000.

Table 7: Summary of regression coefficients estimating changes in the metropolitan household Gini index, 1990-2000, including the direct effects of the measures of technological change. 


\section{CHAPTER I}

\section{Introduction}

\section{Background of the Research Question}

The experience of the U.S. economy in the late 1990s marks something of a watershed episode in terms of the trends in economic growth and labor productivity. The "productivity slowdown" of the 1973 to 1995 period, manifest in average annual productivity growth of less than two percent (see Wolff, 1985, 1996), was followed by a "productivity revival" beginning in 1996 which saw GDP and labor productivity growth climb to between three and four percent annually and as high as six or seven percent in some quarters (U.S Department of Commerce, BEA, 2003; U.S. Department of Labor, BLS, 2003). Rates of growth in real GDP also began to exceed trend-line expectations, leading to an accelerated rise in real output per capita thought to be driven, in part, by rapid technological advancements such as the PC and Internet "revolutions" (Brynjolfsson \& Hitt, 2000; Oliner \& Sichel, 2000). Apparently, the impact of the personal computer (finally) began to show up in the productivity and output numbers (Stiroh, 2001a, 2001b). ${ }^{1}$

While labor productivity and economic growth figures began to exhibit marked deviations from their secular trend, income inequality did not. The rise in income inequality beginning in the late 1970s and early 1980s (Levy \& Murnane, 1992;

\footnotetext{
${ }^{1}$ See Gordon (2000) for an alternative less sanguine view of the role of information technology in raising productivity and economic growth.
} 
Ryscavage, 1999) continued to increase, although at a less rapid pace (Autor, Katz \& Krueger, 1998; Card \& DiNardo, 2002). The household Gini coefficient is one of the most popular measures of income inequality (Ryscavage). According to Census Bureau data, the mean household Gini coefficient for the majority of Metropolitan Statistical Areas rose from .4291 in 1990 to .4429 in 2000, an increase of roughly 3.2 percent over the decade. ${ }^{2}$

Is there a relationship between economic growth and income inequality, and, if so, what explains the direction of this relationship? The formal investigation into the association between economic growth and income inequality began with Simon Kuznets' (1955) classic article relating the level of inequality to phases of industrialization and urbanization in various economies (specifically, Great Britain, Germany and the United States). In that article, Kuznets argued that economic growth exerts a loose causation on income inequality, and that at various stages of economic development (defined in terms of industrialization and urbanization levels), inequality would initially rise and then decline. This relationship came to be understood as the "Kuznets Curve Hypothesis," suggesting an inverted U-shaped curvilinear relationship between economic growth and income inequality. Kuznets claimed that in the early stages of industrialization and urbanization, economic development would accompany rising inequality due to the high returns to capital investment, earned largely by wealthy asset owners, and due to the

\footnotetext{
${ }^{2}$ It should be noted that research suggests that the rate of increase in income inequality and the acceleration in the wage gap beginning in the 1970s and 1980s began to subside somewhat during the 1990s (Card \& DiNardo, 2002). Ryscavage (1999, p. 34) reports that the household income Gini for the entire United States rose nine percent from 1979 to 1989 , a much larger jump than the 1990-2000 period reflected in the numbers reported above. Some research contends that this decline in the rate of increase in income inequality was largely a result of tight labor markets and strong economic growth (see Autor, Katz \& Krueger, 1998). However, Hill and Wolman (1997a) challenge this theory at the level of the city-suburb in metropolitan areas, finding that tighter labor markets may actually increase income inequality up to a point.
} 
geographic shifts in households from rural to urban areas induced by industrialization and economic growth. However, in the later stages of industrialization and urbanization Kuznets argued that inequality would abate, and that the forces of economic growth would exert downward pressure on inequality.

Since Kuznets' original article on the relationship between economic growth and income inequality, numerous studies have sought to substantiate the Kuznets hypothesis using cross-sectional or time-series data on various units of analysis ranging from developing and developed economies (Adelman \& Robinson, 1989; Aghion, Caroli \& Garcia-Penalosa, 1999; Anand \& Kanbur, 1993; Barro, 2000; Chang, 1994; Galbraith \& Kum, 2002; Glomm, 1997; Greenwood \& Jovanovic, 1990; Haslag, Fomby \& Slottje, 1988; Thornton, 2001; Vicente \& Borge, 2000) to regional, state, or local economies (Aigner \& Heins, 1967; Al-Samarrie \& Miller, 1967; Cloutier, 1997; Murray, 1969; Panizza, 2002). The results of these studies are mixed, and the findings are highly sensitive to the unit of analysis, the specific measure of inequality, and the time period to which the data apply. In particular, and relevant to the current study, the Kuznets inverted U-shaped relationship between inequality and growth appears to be evident in developing economies (Adelman \& Robinson; Haslag et al.; Greenwood and Jovanovic), while an uninverted $U$-shaped relationship may exist for advanced developed economies (Aghion et al.; Barro; Galbraith \& Kum; Glomm; Vicente and Borge). That is, the Kuznets relationship between inequality and growth appears to explain the behavior of developing economies where industrialization and urbanization lead first to a rise and then a decline in inequality. However, it fails to explain the more recent behavior of linked with falling rates of poverty, but says nothing about the effects, if any, on changes in inequality. 
developed economies where economic growth (even when below its secular trend) seems to be positively correlated with rising inequality, particularly since the late 1970 s in the U.S. (Levy \& Murnane, 1992; Ryscavage, 1999).

Taken together, this line of research suggests that the Kuznets inverted U-shaped curve can neither be fully rejected nor consistently confirmed. However, as Anand and Kanbur (1993), Barro (2000) and Vicente and Borge (2000) suggest, when developed and developing economies are analyzed in isolation from one another, different stages of the Kuznets process can be observed. The Kuznets Hypothesis may apply differently to different economies in different stages of economic development, and fitting the theory neatly to a broad spectrum of diverse economies may not be possible.

Further, the formal Kuznets' Curve may represent only a single stage or single oscillation in a long series of oscillations. That is, the initial curve proposed by Kuznets in his 1955 article may represent only one period in the longer term trajectory of economic growth, depending upon the stage of economic development exhibited by a given economy. If this is the case, then we would expect to see both positive and negative associations between economic growth and income inequality at various stages in the growth and development process, as implied by the research conducted to date. The implication for the original Kuznets Hypothesis is that the original proposed model positing a single inverse $U$-shaped relationship between per capita growth and income inequality needs to be extended or reconstructed. A reconstructed theory may included multiple oscillating Kuznets Curves that rise and fall according to different stages of industrialization-urbanization, post-industrialization and suburbanization, post-postindustrialization and post-suburbanization (whatever these might be), and so on. 
Another line of research into the relationship between economic growth and income inequality, connected to the Kuznets Hypothesis, involves the role of what has come to be known as "skill-biased technological change" (SBTC), particularly in developed economies and particularly embodied in the adoption and use of the microprocessor and personal computer (Autor, Katz \& Krueger, 1998; Block, 2000; Cappelli, 1996; Caselli \& Coleman, 2001; Galor \& Moav, 2000; Galor \& Tsiddon, 1997; Greenwood, 1999; Krueger, 1993; Levy \& Murnane, 1996; Nakamura, 2000). Periods of innovation and rapid technological change may lead to a higher demand for skilled labor in order to understand, implement, use and maintain new technologies in production. As the demand for skilled and educated labor rises, the returns to skill and education also rise, widening the income gap between the skilled and the unskilled. In theory, the result is that the increased pace of technological change raises the returns to human capital while also (eventually) increasing economic growth, leading to a positive relationship between growth and income inequality in developed economies.

Block (2000) and Nakamura (2000) argue that entrepreneurship and the "creative destruction" of a dynamic capitalist market play a critical role in this process. As entrepreneurial talent leads to innovations and technological breakthroughs, technologyled economic growth occurs simultaneous to a widening in the wage structure as entrepreneurs and those with large amounts of human capital are rewarded for their efforts, while those who possess human capital related to obsolete production methods see their incomes decline. According to this theory, we would expect growth and inequality to be positively correlated in advanced economies undergoing rapid technological change. 
Greenwood (1999) offers an interesting theory suggesting that the adoption of new technologies since the 1970s (and particularly microprocessor technologies) operates with a lag relative to economic growth, and thus explains both the rise in income inequality as well as the so-called "productivity slowdown" from roughly 1973 through 1994 (see also Wolff, 1996). As new technologies are developed, they take time to understand, implement, and use in a way that will eventually (but not immediately) raise labor productivity and economic output. However, new technologies also raise the demand for skilled and educated labor, both during and after the adoption phase, so that the returns to human capital increase, leading to a rise in the skilled-unskilled wage gap. Intuitively, this is an inviting theory. Galor and Moav (2000) and Galor and Tsiddon (1997) develop models that seem to confirm Greenwood's thesis: technological change can have simultaneous effects on economic growth and income inequality, leading to either a positive or negative association between growth and inequality depending upon the pace and stage of technological adoption.

The recent decade of economic growth and rising income inequality during the 1990s, and particularly the 1995 to 2000 period, offers an interesting and inviting backdrop for an empirical investigation into the relationship between economic growth and income inequality. If the new technologies of the "information economy" lead to both economic growth and growing income inequality, then economic growth and rising inequality should be positively correlated. An empirical test of this "reconstructed" Kuznets Hypothesis could be expected to reveal that income inequality is positively associated with (and is a function of) technological change and economic growth, when controlling for other plausible factors. 
One of the problems encountered when attempting to empirically test this theory on the international level (between countries) is the overall differences in the relevant economies, even among developed and/or post-industrial nations. In particular, the difficulty in finding a consistent and universal measure of inequality across various developed and developing economies has proven difficult (Chang, 1994; Deininger \& Squire, 1997; Forbes, 2000; Galbraith \& Kum, 2002), leading researchers to search for regional or local units of analysis (Aigner \& Heins, 1967; Al-Samarrie \& Miller, 1967; Cloutier, 1997; Panizza, 2002; Partridge, 1997). The degree of technological change may be difficult to measure and compare across different economies, and the influence of short-term business cycles impacts national economies at different times and to different degrees. Further, the availability of data covering enough countries to provide the minimum number of cases for a rigorous statistical analysis may be limited. As a solution, the data limitations of a cross-country analysis of growth and inequality might be partially overcome by utilizing city- or metropolitan-area data confined to a single national economy, particularly the United States where data on metropolitan economies, or MSAs, are widely available.

\section{Thesis Statement of the Problem and Research Questions}

The primary problem or question to be explored in the following research is to investigate the degree to which technology-driven economic growth may be responsible for rising household income inequality in the United States, especially during the productivity and growth "revival" of the 1990s. Does economic growth in an advanced, post-industrial economy (i.e., the United States) lead to rising income inequality via the medium of SBTC? Might the 1990s experience be evidence of the beginning of a new 
Kuznets Curve where technological change, ceteris paribus, leads to a positive association between economic growth and income inequality, even in advanced nations? If so, this would help form the theoretical basis for a "reconstructed" Kuznets Hypothesis, updated for post-industrial economies.

The primary thesis of the present research is that technological improvement leads to exogenous and/or endogenous economic growth ${ }^{3}$ (Lucas, 1988; Romer, 1986; Solow, $1956,1957)$, which in turn leads to rising household income inequality through the mechanism of non-neutral, SBTC (Berman, Bound \& Griliches, 1994; Berman, Bound \& Machin, 1998; Bound \& Johnson, 1992; Galor \& Moav, 2000; Johnson, 1997; Krueger, 1993; Murphy \& Welch, 1993a; Siegel, 1999). Non-neutral, SBTC can he said to be evident in new technologies that raise the productivity of (and thus demand for) highskilled educated labor, while reducing or leaving unchanged the productivity of (and demand for) low-skilled labor, providing relatively high returns to human capital. If this theory is correct, we would expect to see 1) a positive association between some measure of (skill-biased) technological change and per capita economic output, and, subsequently, 2) a positive association between per capita economic output and some measure of income inequality.

The importance of this line of research is profound in terms of its implications for public policies designed to address the perceived problem of income inequality. If growth and income inequality are positively correlated because of the presence of SBTC, then public policies designed to temper the rise in inequality must take economic growth

\footnotetext{
${ }^{3}$ For present purposes of investigating the effect of growth on inequality, it is not relevant to distinguish between exogenous economic growth as suggested in the Solow Neoclassical growth model, or endogenous economic growth as suggested by New Growth theorists such as Romer and Lucas. Whether technological
} 
into consideration. That is, public policies aimed at reducing inequality should also encourage productivity and economic growth, rather than forcing an "equity-efficiency tradeoff" between the two (Okun, 1975). If income inequality is a problem because of the social and political conflicts it engenders, as suggested by some authors (Alesina \& Rodrik, 1994; Dieckmann, 1996; Furman \& Stiglitz, 1998; Keefer \& Knack, 2002; Persson \& Tabellini, 1994; Rodriguez, 2000), and if it is positively correlated with growth, then a natural tension or dilemma exists in fashioning social policy designed to reduce income inequality (Lindbeck, 1998). The question becomes one of dealing carefully with income inequality that may be a function of technology-driven economic growth, without damaging or retarding that growth. What types of social and economic development policies may be adopted that help to promote (or at least preserve) economic growth, which is theoretically good for everyone ("a rising tide lifts all boats" $\{$ Freeman, 2003$\}$ ), and yet prevent a further widening of income inequality, which could potentially wreak social and political conflict that in turn retards growth? This is a particularly important question in light of the benefits that economic growth is found to have, even on the poor (Dollar \& Kraay, 2001; Lucas, 1988).

The present research proposes to accomplish three goals. First, to summarize and critique the recent literature on wage and income inequality, and, more specifically, review the possible theoretical arguments for the relationship between inequality and economic growth that may arise due to SBTC. Second, to analyze 1990 and 2000 data on U.S. Metropolitan Statistical Areas (MSAs) in order to investigate the possible association between economic growth, technological change, and income inequality that

change affects economic growth exogenously or endogenously is not as important to this research as is the effect of that change on the income structure. 
may have become apparent in this data over the decade of the 1990s. The dominant theory that will be tested is the degree to which technological change may spur economic growth, while also leading to rising labor market and household income inequality. If this is the case, we would expect to see a positive association between economic growth, as a function of technological change, and a concomitant widening of inequality.

The use of data from the 1990 s is particularly interesting in that this period witnessed a revival in productivity and economic growth, even as income inequality was thought to rise over most of the decade. The comparison of 1990 and 2000 MSA growth and inequality data will be a critical contribution of this paper. Because of the consistency, relative accuracy, and comparability of the data across a single homogenous developed economy, and because of the number of cases made possible by using MSAs as the unit of analysis, this study will fill an important gap in the literature on the growthinequality relationship.

A final goal will be to suggest policy recommendations that flow logically from the findings, and which may serve to both lessen the potential for social conflict stemming from inequality while also encouraging long-term economic growth and development. The key will be to develop social policy that deals carefully with inequality while preserving or even enhancing the prospects for economic growth and development (see Lindbeck, 1998).

\section{Assumptions and Limitations of the Study}

One of the dominant themes in the growth-inequality literature assumes that causation runs not from growth to inequality, as implied by Kuznets, but rather runs in the reverse direction, from inequality to growth. Based upon a "median voter" theory of 
political behavior, this line of research argues that growth in subsequent periods is a function of the level of inequality in previous periods, and that the sign on the coefficient is negative, meaning that the higher the level of initial inequality in income and wealth, the slower is the subsequent period of per capita growth (Alesina \& Rodrik, 1994; Dieckmann, 1996; Furman \& Stiglitz, 1998; Keefer \& Knack, 2002; Persson \& Tabellini, 1994; Rodriguez, 2000). The "median voter" theory of political behavior implies that if the income of the median voter coincides with the income of the mean voter (a "bell curve" income distribution), the median voter will prefer non-redistributive policies that enhance per capita economic growth. On the other hand, if the median voter is poorer than the mean voter (the income distribution is positively skewed and thus more unequal), then the median voter will prefer a progressive tax on investment designed to redistribute income and wealth through higher transfer payments, which may lead to slower per capita economic growth in some subsequent period. The greater the initial level of inequality, then, the more likely that the median voter will be in the lower half of the income distribution, and the higher the probability that he or she will vote for a redistribution of wealth and income from the top quintiles of the income distribution. Thus, inequality in wealth and income is argued to be negatively correlated with subsequent economic growth because inequality is conducive to the adoption of growthreducing public policies.

Several studies have countered or modified the "median voter" theory in the growth-inequality literature, arguing instead that initial levels of inequality may be unrelated to growth in subsequent periods (Forbes, 2000; Partridge, 1997), positively correlated with growth in subsequent periods (Li \& Zou, 1998; Sylwester, 1999, 2000), 
or that the growth-inequality relationship is indeterminate depending upon the dominance of opposing effects (Lee \& Roemer, 1998). In particular, these authors have challenged the assumption, implied by the "median voter" theory, that unequal income distribution has no impact on political participation, and that political participation is equal even when the income distribution is not. This is rarely the case. If income and political participation are positively correlated, then the political participation of lower-income voters is relatively less than that of higher-income voters, meaning that the median voter with relatively low income may have little if any impact on public policies or the distribution of income as determined by the political process. ${ }^{4}$

The assumption made by all of these studies is that causation runs from inequality to growth, and that initial levels of inequality may explain subsequent periods of economic growth and development. The assumption in the present research is just the opposite: economic growth exerts causation on income inequality, linked, as suggested above, through the mechanism of SBTC. This is not to argue that causation could not run in the opposite direction. However, one of the weaknesses in this line of research is the mixture of developed and developing economy data. Initial levels of inequality may lead to slower subsequent growth in developing economies, but the relationship may be just the opposite in developed economies, leading to mixed results (see especially Forbes, 2000, and Partridge, 1997).

Further, it has been shown that in spite of the relatively high levels of income inequality that prevail in the United States, social and political tolerance for inequality in the United States seems to be much higher than elsewhere (Austen, 1999; Konow,

\footnotetext{
${ }^{4}$ One recent study goes even further, suggesting that there is little if any difference between democratic and nondemocratic political regimes in terms of redistribution levels and policies designed to address issues of
} 
2003). ${ }^{5}$ If this is the case, then the inequality-to-growth direction of causation assumed by the "median voter" theory is likely to have very weak effects and is not likely to apply in the United States. The statistical methodology utilized in the present research will attempt to test for endogeneity between inequality and economic growth using a twostage least-squares regression model. This approach will permit us to investigate whether growth is endogenous to inequality in U.S. metropolitan economies, indirectly testing the median voter theory of income distribution.

The assumptions in the present research, then, are that 1) inequality is a function of technology-driven economic growth, and not vice versa, and 2) the results of the research may be generalized to developed economies (particularly the United States), but not necessarily to developing economies. The effect of inequality on economic growth will be tested using a two-stage least-squares regression model and Hausman's (1976) specification test for endogeneity.

A final, separate, assumption in the present research is that inequality, per se, should not be viewed as a problem, in and of itself (Welch, 1999). That is, the relative income levels of individuals and households, and the distribution of income, are not seen as being as important as the real purchasing power and standards of living of those same individuals and households as represented in measures of per capita economic output (Block, 2000; Feldstein, 1998). For example, if the income distribution is widening as a result of the top income quintile or top decile realizing more rapid income gains than the

\footnotetext{
inequality (Mulligan, Gil, \& Sala-i-Martin, 2004).

${ }^{5}$ In fact, Konow (2003) shows that inequality may be the normative condition preferred by a majority of people when the factors leading to inequality can reasonably be expected to be controlled by individuals themselves. In a summary of the literature on justice theories, Konow reveals that survey respondents are willing to tolerate relatively high levels of inequity when the choices leading to this inequity are attributable to the effort (or lack thereof) made by the parties in consideration.
} 
middle or lower quintiles or deciles, this does not mean that absolute poverty is rising, per se. Increases in inequality do not necessarily cause increases in poverty (Freeman, 2003). What matters is that the overall level of productivity, economic output and per capita growth move in the upward direction, and that the institutional framework of voluntary exchange embodied in a market economy is allowed to function. The standard of living, regardless the variance of the income distribution, can then be assumed to raise the living standards for the majority of the population, and income inequality, per se, is not necessarily detrimental for those at the bottom end of the income distribution. ${ }^{6}$

On the other hand, income inequality can and does become problematic when the social and political tolerance for it begins to wane, and when it leads to social conflict or political outcomes that threaten to retard or depress economic growth. As suggested by Austen (1999), we have apparently not yet reached this point in the United States. However, it is not inconceivable that if inequality continues to rise in the future as it seems to have risen since the 1970 s, we could reach the point where it becomes socially and politically intolerable, even in the United States. The message in the present research, then, is one of explaining the possible causes behind that rise in inequality, and in finding policy outlets for those who wish to address the concern of rising inequality without simultaneously harming the potential for economic growth.

In brief, the findings of the present analysis provide evidence that while technological change is positively correlated with economic growth, economic growth tends to reduce, not increase, income inequality. In the method employed here, the

\footnotetext{
${ }^{6}$ No normative statement is being made about the desirability or undesirability of inequality. See Rawls (1971). However, there is compelling evidence that real incomes at the bottom of the distribution have stagnated or dropped while those at the top have risen over the past two decades (Gottschalk, 1997; Levy \& Murnane, 1992; Murray \& Welch, 1992).
} 
theory that skill-biased technology-driven economic growth increases income inequality could not be supported. Further, evidence of an extended or reconstructed Kuznets Curve could not be found. The negative association found between measures of economic growth and income inequality, controlling for other factors, lends support for the original Kuznets Hypothesis. As economic growth and development improve, income inequality appears to decline, all else constant. These findings also challenge theories and previous research that focus on SBTC as an explanation for rising income inequality. If SBTC is to be empirically linked with rising income inequality in the United States over the 1990s, evidence for this relationship will need to pursue avenues of research other than those investigated here. In a recent paper, Card and DiNardo (2002) also question the explanatory power of the SBTC theory of rising wage and income inequality, pointing out that wage and income inequality began to stabilize in the 1990s even as technological change continued to accelerate. One explanation for this may be that technological change has become less skill-biased and more skill-replacing in recent years, particularly as personal computers and other technological advancements have become more "user friendly." If so, this would tend to (moderately) reduce the relative demand for skilled over unskilled labor, restraining the rise in wage and income inequality.

In the following section, I provide a detailed summary of the previous literature on the relationship between technological change, economic growth, and income inequality. Beginning with the work of Kuznets (1955), theoretical and empirical research pertaining to the growth-inequality relationship is discussed, followed by an investigation of the technology-growth relationship stemming from Solow $(1956,1957)$. These two strands of research are then linked theoretically by a discussion of the more 
recent studies on the relationship between SBTC and rising income inequality. Part III introduces the theoretical model that will be used to test the relationship between technological change, economic growth and income inequality, followed by a discussion of the research methodology, data, and statistical technique to be employed. Part IV provides a detailed summary of the data and the statistical findings, and Part V offers conclusions, policy recommendations and suggestions for further research. 


\section{CHAPTER II}

\section{Literature Review: Growth, Technological Change, and Inequality}

The thesis of the following research rests on three primary assertions relating growth, technological change, and inequality. The first is that growth and inequality may be positively or negatively correlated, depending upon the level of economic development exhibited by a given economy. Growth may impact or correlate with inequality differently at different points in the development process. This assertion builds upon the original work by Kuznets (1955), and makes predictions about the relationship between growth and inequality based upon the level of development and the pace of technological change. The second assertion is the relatively simple and wellknown idea that technological improvements encourage per capita economic growth (Lucas, 1988; Romer, 1986; Solow, 1956, 1957). The third assertion is critical to the main thesis and ties the first two assertions together to form the basis upon which the primary hypothesis rests: non-neutral, skill-biased technological change (SBTC) may explain any observed positive relationship between growth and inequality in developed economies. This assertion derives from the research on SBTC and inequality, and ties this literature to the growth-inequality relationship. The structure and format of the literature review follows the sequence and logic of these three primary assertions. 


\section{The Growth-Inequality Relationship}

In his 1955 article, Simon Kuznets made the argument that the direction of causation between inequality and growth ran from growth to inequality. That is, the stages of industrialization and urbanization (Kuznets' definition of "economic development") determined or influenced the level of inequality. More specifically, Kuznets posited an inverse U-shaped curvilinear relationship between these two variables. He suggested that in the early stages of industrialization and urbanization, economic development accompanied rising inequality. This was so for several reasons. According to Kuznets, high rates of return to capital investment during periods of rapid industrial growth lead to a widening gap between labor and the owners of capital (physical or financial). In addition, high rates of migration and urban population growth lead to greater inequality. According to Kuznets, because urban populations tend to exhibit greater income disparity than rural populations, migration of labor from rural to urban areas ("urbanization") would lead to an increase in the size of the population with the greatest inequality (the urban sector) and a concomitant reduction in the size of the population with the least inequality (the rural sector). Inequality would thus increase due to demographic shifts induced by economic growth. Finally, an underlying assumption in the Kuznets Hypothesis (more or less dormant in the 1955 article) is that urban labor markets exhibit higher levels of skill disparity than rural markets, thus leading to what more recent investigators have labeled "skill-biased" inequality (Bound \& Johnson, 1992; Johnson, 1997; Juhn, Murphy, \& Pierce, 1993; Levy \& Murnane, 1992; Murphy \& Welch, 1993b). 
In the later stages of industrialization and urbanization Kuznets argued that inequality would abate, and that the forces of economic growth would exert downward pressure on inequality. The continued increase in the supply of more highly skilled urban labor would compress wages and generate a more egalitarian income distribution. In addition, the high rate of turnover in a dynamic capitalist economy would lead to a high frequency of income mobility, in turn lowering inequality through Schumpeterian "creative destruction" (Schumpeter, 1976). Kuznets further argued that urban social policy would evolve to mitigate the effects of inequality. Particularly, social institutions would be forced to change in order to address the problem of growing inequality in an industrialized and urbanized economy under democratic capitalism. In come taxes would become more progressive, and social redistribution policies would become more popular, thus creating a more egalitarian distribution of wealth and income (Kuznets, 1955).

Given the time period in which Kuznets' article was written and published (1955), it is not difficult to understand why he reached these conclusions. In analyzing the predominantly developed economies of the United States, United Kingdom, and Germany, Kuznets observed economies coming to full industrial maturity at a time when the wage disparity was declining. As Goldin and Margo (1992), and Margo (1999) conclude, the wage structure during the 1940s and 1950s was narrowing during a period of rapid economic development. There were two predominant reasons for this in the United States, according to Goldin and Margo. First, the supply of skilled labor was rising due to the "high school movement:" the concerted social push for children to complete four full years of high school. The increased supply of high-school graduates had the effect of reducing the wage disparity between high-skilled labor (i.e., high school 
graduates) and low-skilled labor (i.e., those with less than a high school diploma). A simple supply and demand analysis illustrates that as high-skilled labor became more abundant relative to low-skilled labor, the wages of high-skilled labor were pushed down and the wages of low-skilled labor rose, leading to income convergence.

Secondly, the outbreak of World War II had the effect of increasing the demand for low-skilled labor relative to high-skilled labor, particularly in war-related production industries, further compressing the overall wage structure. However, even after the war, the wage structure remained stable and inequality was fairly subdued. Goldin and Margo (1992) argue that further industrialization, in combination with the G.I. Bill, raised the supply of educated and skilled labor, keeping wage disparities to a minimum on into the 1960s and 1970s, just as Kuznets had predicted. It is for this reason that Goldin and Margo refer to this period as the "Great Compression" in the wage structure. Margo (1999) argues that prior to this period, and during the earlier stages of U.S.

industrialization in the late $19^{\text {th }}$ and early $20^{\text {th }}$ century, wage inequality was much higher, owing to the greater demand for skilled labor arising from the introduction of new industrial technologies and mass production techniques.

These empirical findings seem to at least partially support the Kuznets Hypothesis that inequality will tend to decline as industrialization and urbanization occur in developed economies. On the other hand, the Kuznets curve, at least in its original form, appears not to have fared well in light of the more recent empirical evidence indicating rising inequality in the United States since at least the 1970s. Inequality in the United States did indeed decline during the first half of the $20^{\text {th }}$ century (Goldin \& Margo, 1992). However, beginning in the 1970 s and accelerating into the 1980 s, inequality began rising 
dramatically (Berman et al.,1994; Bound \& Johnson, 1992; Hyclak, 2000; Johnson, 1997;

Juhn, Murphy \& Pierce, 1993; Krueger, 1993; Levy \& Murnane, 1992; Murphy \&

Welch, 1992, Murphy \& Welch, 1993a, 1993b; Ryscavage, 1999). The more recent rise in inequality in the United States and, to a lesser degree, in other advanced industrial economies (Acemoglu, 2002b; DeNardi, Ren \& Wei, 2000; Galbraith \& Kum, 2002), leaves the original Kuznets Curve Hypothesis without firm empirical support. If inequality is predicted to decline in the advanced stages of economic growth, as Kuznets argued, then why do we seem to observe a marked widening in income inequality in the most advanced economies (Nickell \& Bell, 1996), and particularly the United States (Gottschalk, 1993, 1997; Gottschalk \& Smeeding, 1997)? Galbraith and Kum (2002) find confirmation for the original Kuznets Hypothesis across industrializing economies even as they find a worldwide trend toward rising inequality within nations. They argue that the rise in inequality is (mostly) independent of per capita GDP growth, and results instead from the independent effects of separate factors.

An alternative explanation, however, is that the original Kuznets Hypothesis was merely a description of the growth-inequality relationship at a precise period of economic development, specifically the period evidenced by the shift from a primarily agrarian and rural economy and culture to a primarily industrial and urban economic base.

These results could explain why inverted U-shapes prevailed using either old time-series [from developed economies] or LDCs [less developed countries] cross-sections, while uninverted U-shapes appear using recent data for developed economies. Kuznets' original hypothesis was formulated for a specific and unfinished growth process, whereas new data may be referred either to the end of that process or to new processes. That is why empirical studies on the inequality-growth relationship should specify which processes and which phases are being studied (Vicente \& Borge, 2000, p. 500; italics added). 
The implication is that the original Kuznets Hypothesis may apply differently to different economies in different stages of economic development, and fitting the theory neatly to a broad spectrum of diverse economies may not be possible. While Galbraith and Kum (2002) find general confirmation of the original Kuznets process, even they suggest that the growth-inequality relationship may reverse itself in the richest countries, with a turning point at some high level of income or per capita growth. Thus, in analyzing a developed economy entering a post-industrial period of growth, we may need to recast the Kuznets Curve into a broader theory that allows for multiple oscillating "waves" that reveal either a positive or negative association between inequality and growth depending upon the specific stage of economic development or technolngical advancement.

Research seeking to test the Kuznets Hypothesis suggests the need to apply the theory carefully depending upon the level and stage of economic development exhibited by given economies. Haslag, Fomby and Slottje (1988) tested the Kuznets Hypothesis on time-series data from the Mexican economy from 1951 through 1978. They find convincing evidence that 1) the direction of causation between inequality and growth runs from growth to inequality, as suggested by Kuznets, and 2) at early stages of economic development, inequality is higher, and at later stages of economic development, the Mexican economy exhibits lower levels of inequality. ${ }^{7}$ Specifically, the authors find that a permanent one percentage point increase in Mexican per capita real GDP leads to a permanent decrease in the Gini coefficient measure of expenditure inequality, confirming the Kuznets Hypothesis that at higher stages of economic growth,

\footnotetext{
${ }^{7}$ A key distinction of this study was the measure of inequality used. Instead of a more traditional measure of income inequality, the authors employed a Lorenz curve and Gini coefficient measuring consumption inequality. The authors believed this measure to be superior to the more traditional income Gini, and to provide a more realistic reflection of the inequality in living standards not captured by income alone.
} 
inequality tends to decline. The weakness in this research is that it cannot be generalized beyond the Mexican economy, or beyond a similar developing economy at the same stage of development experienced by the Mexican economy between 1951 and 1978 .

In a meta-analysis of the Kuznets Hypothesis, research findings reviewed by Adelman and Robinson (1989) confirm the Kuznets theory, at least for noncommunist developing economies between 1960 and 1980. The trends found by Adelman and Robinson indicate that in spite of rising inequality during this period in developing economies, the proportion of the households below the poverty line had been reduced. The authors conclude that economic growth in developing economies is positively correlated with rising inequality in the early stages of development, at least partially confirming the Kuznets Curve theory.

Anand and Kanbur (1993) test the Kuznets Hypothesis using cross-sectional data on sixty developing economies, employing six different measures of inequality to test for a relationship between the income distribution and economic development. When the sixty different countries are aggregated together, Anand and Kanbur find that all their measures of inequality are statistically insignificant, and that the coefficients reflect both positive and negative signs, suggesting no consistent direction of association between inequality and economic growth. Thus, when the data are aggregated, the authors cannot confirm the Kuznets Hypothesis. They are quick to point out, however, that their findings do not permit a rejection of the Kuznets theory, but instead suggest that different countries are at different stages along the growth-inequality continuum, and when data are aggregated across economies, the Kuznets Curve fails to fit the data. Anand and Kanbur, while failing to find a Kuznets Curve in their aggregated data, develop 
extensions of the Kuznets model to show that growth and inequality levels may vary at different points in the growth process, so that a modified Kuznets Hypothesis may indeed be plausible.

In another meta-analysis, Glomm (1997) finds convincing evidence that the Kuznets "process" exhibits a different direction of association between growth and inequality depending upon the time period and stage of economic development from which the data are taken. When data are taken from Post-WWII periods in developed economies, the Kuznets Curve appears to be uninverted, or right-side up, according to Glomm: as economic growth progresses, inequality first declines, then rises. But, when more recent data is taken on developing economies, the $K_{3}$ uznets Curve appears inverted, or upside-down, as predicted by Kuznets original theory: as economic growth progresses, inequality first rises, then declines. According to Glomm, then, the empirical evidence on the Kuznets Hypothesis is simply too varied and mixed to elevate the Kuznets Curve to the status of a "stylized fact." Glomm is one of the first authors to at least implicitly suggest the possibility of rising and falling levels of inequality over time based upon technological changes and subsequent migrations from one industrial sector to another, i.e., oscillating Kuznets Curves.

Barro (2000) draws similar conclusions to those suggested by Glomm. In an analysis of 84 countries with at least one comparable measure of inequality, Barro finds that the growth-inequality relationship is different depending upon the level of per capita GDP exhibited by the economy. For low GDP per capita countries, the association between inequality and growth is negative. However, in high GDP per capita countries, the association is positive. Barro concludes that the estimated relationship between 
growth and inequality found along an estimated Kuznets Curve reflects not just the influence of per capita GDP, but also reflects a dynamic effect related to the adoption of new technology, which may then have a transitory, Kuznets-like effect on the distribution of income. We would expect to see just this type of effect if the adoption of new technology is non-neutral or skill-biased.

Aghion et al. (1999), List and Gallett (1999), Thornton (2001) and Vicente and Borge (2000) all make similar diagnoses, implied or explicit, regarding the behavior of the Kuznets Curve over time. The growth-inequality relationship does not exhibit a onetime consistent single pattern that fits all nations, but rather applies differently to different nations at different points in time. A common theme in this body of research is that the original Kuznets Curve may potentially reverse course in developed economies, exhibiting a positive relationship between growth and inequality, particularly if SBTC is present. List \& Gallett, in particular, explicitly argue that the positive relationship between growth and inequality that they find is a result of structural shifts in advanced economies away from industrial manufacturing towards a post-industrial service and professional economic base. However, the uncertainty and inconsistency surrounding much of the data, and the difficulty in comparing international data sets (Deininger \& Squire, 1997; Galbraith \& Kum, 2002), makes any conclusion tentative at best. For this reason, research using consistent data from a single homogenous developed economy such as the United States may be a better method of testing the Kuznets Hypothesis.

The earliest tests of the Kuznets Hypothesis using U.S. state data were conducted by Aigner and Heins (1967) and Al-Samarrie and Miller (1967). Comparing state-level data from the 1950 and 1960 censuses, both sets of authors find that higher levels of 
economic development and economic growth are correlated strongly with declining inequality in the United States. In one of the first studies to test the Kuznets Hypothesis using data from Metropolitan Statistical Areas, Murray (1969) confirms the state-level findings of Aigner and Heins, and Al-Sammarie and Miller. Using MSA census data from 1960, Murray finds an inverse relationship between economic growth and inequality across U.S. cities, thus supporting the original Kuznets theory that inequality declines in the later stages of economic development. The research findings from this particular economic period in the U.S. are interesting in that they support the later findings by Goldin and Margo (1992) concluding that the U.S. economy passed through a period of rising equality and income compression during the middle of the $20^{\text {th }}$ century, owing largely to institutional and demographic factors. What Aigner and Heins, Al-Sammarie and Miller, and Murray may have been picking up was the negative growth-inequality correlation observed during the peak of manufacturing-based industrialization in the United States.

A mature industrial economy such as the United States in the 1950s, perhaps on the threshold of a technological revolution which might bring about large structural changes, could be expected to exhibit the predicted negative relationship between growth and inequality posited by the original Kuznets Curve. However, if technological change can bring about a change in the direction of the growth-inequality relationship, then we might expect the relationship between inequality and growth to exhibit a positive sign in some subsequent period. Using cross-sectional data on MSAs from the 1980 and 1990 censuses, Cloutier (1997) finds a curvilinear relationship between inequality and economic development that first declines and then rises. Using the squared value of 
median family income as the measure of economic development, Cloutier shows that as median income rises, income inequality initially decreases at a declining rate, but then begins to rise, indicating a positive growth-inequality relationship beyond a given level of development. This seems to confirm a "turning point" in the growth-inequality relationship in a developed economy, leading to a period of rising growth accompanied by rising inequality.

Several weaknesses plaguing Cloutier's study, however, make this conclusion somewhat tenuous. Cloutier's use of median family income as an operational definition of economic development, while consistent with the previous work by Aigner and Heins (1967), and Murray (1969), may not be the most accurate reflection of economic growth or total economic output. Some measure of per capita output, such as per capita Gross State Product or Gross Metropolitan Product, would seem to be a more accurate measure of true economic growth. Further, Cloutier uses no measure of technological change, per se, and does not test for the possibility that technological change may be "lurking" behind the turning point in the growth-inequality relationship. These are weaknesses upon which the present study hopes to improve.

Finally, a recent study by Wheeler (2004), also conducted using a sample of metropolitan areas as units of analysis, explores the relationship between three separate and distinct measures of urban economic growth (population, employment, and per capita income) and a variety of measures of income inequality between 1970 and 1990. Wheeler finds a negative relationship between all measures of urban growth and inequality, implicitly confirming the original Kuznets Hypothesis over the span of these two decades in the U.S. That is, metropolitan economies with a more rapid pace of 
economic growth and development from 1970 to 1990 also generally experienced a smaller increase or a larger decrease in measured inequality. However, like Cloutier (1997), Wheeler does not investigate the possibility of SBTC as a determinant of changes in metropolitan inequality, nor does he employ a measure of economic growth based directly upon per capita metropolitan output. Again, the present study seeks to extend this research by linking the Kuznets process with SBTC, and to provide updated results covering the decade of the $1990 \mathrm{~s}$.

\section{The Technology-Growth Relationship}

The relationship between technology and economic growth has a rich history. That technological advancements help to promote economic growth has been largely taken for granted by economists since the formal introduction of the discipline by Adam Smith. The general concept is that new technologies, either by themselves or embodied in new physical capital, raise the marginal product of labor (the additional output gained by the employment of an additional laborer) and thus increase output, thereby accelerating economic growth. The idea that technology and growth are interrelated is taken as a more or less "stylized fact" in the field of economics. ${ }^{8}$

In his groundbreaking work on economic growth, Robert Solow (1956) sought to improve upon the Harrod-Domar model of economic growth that emerged during the 1940s. The Harrod-Domar theory of economic growth argued that the output growth in an economy was always precariously positioned on a "knife edge" where any deviation

\footnotetext{
${ }^{8}$ For an interesting and easily readable discussion of technological change and global economic growth since the Industrial Revolution, see Robert E. Lucas (2004). Lucas explains global changes in economic growth and worldwide inequality as a function of the linkages between technological change, the returns to human capital, and fertility rates, suggesting that the explanatory power of competing theories of growth depend critically on the behavior of these factors.
} 
between the growth rate of the labor force and the growth rate of capital accumulation would throw the economy into a protracted period of slow or negative growth. With the assumption that "fixed proportions" of capital and labor cannot be substituted for one another, the Harrod-Domar model implies that the aggregate market economy is fragile and susceptible to "stalling out" if the growth rates of capital and labor are not equal, giving way to rising inflation or prolonged unemployment. In his path-breaking 1956 article, Solow argued that if the assumption of "fixed proportions" of capital and labor is relaxed, and the assumption made that capital and labor are substitutable, then the longrun economy can easily reach a "steady state" rate of growth and not be so susceptible to chronic bouts of unemployment or inflation. By demonstrating a positive relationship between per capita output and the capital-to-labor ratio, with the assumption of diminishing returns, Solow was able to revolutionize the field of economic growth by introducing the now-standard Aggregate Production Function that forms the basis for neoclassical growth theory.

In a follow-up article, Solow (1957) sought to build on his original theory by exploring more specifically the effects of technological change upon economic growth. Solow argued that "neutral" technological change would serve to shift the aggregate production function upward, thus increasing output per capita at any given capital-tolabor ratio. The critical link between Solow's 1957 article and the present paper is Solow's introduction of the concepts of "neutral" and "non-neutral" technological change. According to Solow, "[s]hifts in the production function are defined as neutral if they leave marginal rates of [technical] substitution [between capital and labor] untouched, but simply increase or decrease the output attainable from given inputs" 
(1957). In modern terms, "neutral" technological change would not change the diminishing marginal rate of technical substitution between capital and labor along the conventional isoquant line; the slope of the isocost line (the firm's budget constraint) remains constant, and new technology simply shifts the isocost line outward to a higher isoquant. That is, "neutral" technological change does not change the ratio of capital to labor, but applies equally to each and proportionately raises the productivity of each.

Although Solow does not offer a specific definition, the reader is left to conclude that "non-neutral" technological change would cause changes in the marginal rate of technical substitution between capital and labor, and even, possibly, between different types of capital or different types of labor. The introduction of "non-neutral" technological change, then, would presumably change the capital-to-labor ratio, raising the marginal productivity of one over the other. Further, and more specifically relevant to the current research, some types of "non-neutral" technology may raise the productivity of certain types of labor, say, high-skilled labor, while leaving the productivity of other less skilled labor either unchanged or marginally lower.

It is this notion of "non-neutral" technological change introduced by Solow that is critical to the present research. If technological change drives economic growth in a positive direction, but, at the same time, is non-neutral in a manner that differentially affects the productivity of different types of labor, then we could theoretically observe a positive relationship between economic growth and income inequality.

\section{The Technology-Inequality Relationship}

Various authors and researchers have together suggested several dominant factors that seem to explain the nationwide rise in inequality since the 1970s. Tinbergen (1975) 
has described rising inequality as a race between the supply of skilled labor and the demand for skilled labor. To the extent that the demand for skilled labor outpaces the supply, inequality will tend to accelerate. New technology that accelerates the demand for skilled and educated labor in excess of supply would thus lead to rising inequality. By far the most dominant theory that has emerged to explain the rise in inequality in the United States since the 1970s is based upon the concept of non-neutral skill-biased technology change (Acemoglu, 2002a; Berman et al., 1994; Bound \& Johnson, 1992, 1995; Goldin \& Katz, 1996, 1998; Johnson, 1997; Juhn, et al., 1993; Juhn \& Murphy, 1995; Kiley, 1997; Krueger, 1993; Murphy \& Welch, 1993a, 1993b; Siegal, 1999).

This theory rests on the notion that technological advancements are not neutral and do not have the same productivity impact on all types of labor. Rather, recent technological innovations (and especially the microprocessor and the personal computer) are particularly well-suited for an educated and skilled labor force (Autor, Katz \& Krueger, 1998; Krueger, 1993). These new innovations raise the productivity of skilled and educated labor, raising the demand for and wages of skilled and educated labor. However, these technological advancements may have little or no impact on low-skilled or less educated labor, and may not necessarily raise the productivity of the low skilled segment of the labor force (Levy \& Murnane, 1992). Thus, as new technologies are adopted by firms, the demand for and wages of low skilled and less educated labor decline. In other words, new technology is a complementary input to skilled labor, but a substitute input for unskilled labor. As the adoption of new technology occurs, the income gap between the skilled and the unskilled continues to widen. ${ }^{9}$

\footnotetext{
${ }^{9}$ It should be noted that non-neutral technological change need not necessarily be embodied in the adoption of new types of physical capital. Lindbeck and Snower (1996) and Snower (1998) make an intriguing case
} 
Theoretically, SBTC may be responsible for the observed changes in many other potential factors connected to rising inequality, including the decline in unionization, trade openness, and basic labor market supply and demand conditions. ${ }^{10}$ For example, unionization rates could have declined as new technology became cheap relative to semiskilled production labor. As blue-collar union labor pushed nominal wages higher through collective bargaining during the 1970s, firms could have found it in their interests to substitute more capital (and the new technology embodied in that capital) for semi-skilled union manufacturing labor, thus reducing the power of unions as the demand for union labor became more elastic, especially during the early 1980s (Asher \& DeFina, 1995; Fortin \& Lemieux, 1997; Freeman, 1996; Hyclak, 2000). The decline in the real costs of new technology (such as the microprocessor) and capital may have also contributed to this phenomenon (Greenwood, 1999).

In general, most studies have found trade alone to play a very minimal role in explaining the rising gap in the wage structure since the 1970s (Berman et al., 1994; Harrigan, 1997, 1998; Irwin, 2002). The dominant explanatory variable that appears repeatedly is technological change. To the extent that technological change interacts with trade openness and trade flows, the two variables may reinforce one another, with technological change playing the dominant role. New technology and trade openness may have interacted in one of two ways to raise inequality since the 1970 s. On the one hand, the introduction of new technologies may have been a result of increased foreign

\footnotetext{
that organizational restructuring at the firm level is a type of "technological change" that raises the productivity and demand for skilled and educated labor with specific multitasking and human relations skills, and argue that organizational restructuring explains the rise in inequality both within and between groups.

${ }^{10}$ Acemoglu (2002b) argues that the rise in wage and income inequality in Europe has been less acute than in the United States and the United Kingdom because European labor market institutions encouraged
} 
trade, in which case these two factors (technology change and trade openness) might have interacted to raise the income gap over time (Brauer \& Hickok, 1995; Harrigan, 1997; Leamer, 1996). Greater trade openness may have induced the adoption of new technologies. As manufacturing firms struggled to compete for global market share with lower-cost competitors in the 1970s and 1980s, they certainly would have considered adopting new technologies as a means of enhancing their efficiency and competitiveness. If these new technologies were substitutes for low-skilled union labor, firms could have seen an opportunity to raise productivity and lower costs by restructuring their production around more capital-intensive techniques combined with high-skilled labor (Bhagwati, 1995).

On the other hand, SBTC may have been the driving force underlying the sectoral shift in trade flows. In other words, the adoption of new technologies in the United States may have induced an increase in imports of labor-intensive goods from abroad, particularly durable goods. If technological change in the U.S. caused the shift in imports toward durable goods as the U.S. economy moved toward the production of hightechnology services and goods not classified as "durable," then increased technological change may have led to the change in trade flows and the level of imports as a percentage of GDP. The shift in trade flows brought about by new technology may have indirectly impacted wage inequality by lowering the demand for less skilled labor (Borjas \& Ramey, 1994; Irwin, 2002). ${ }^{11}$

European firms to adopt technologies that were less skill-biased and more skill-replacing, thus raising the productivity of less skilled workers in these economies compared to the U.S. and UK economies.

${ }^{11}$ For further investigations into the linkages between trade openness, immigration and U.S. income inequality see Borjas (1995), Freeman (1995), Harrigan (1997, 1998), Johnson and Stafford (1993), Lawrence (1995), Leamer (1996), Revenga (1992), Richardson (1995), and Wood (1995). 
The introduction of non-neutral skill-biased technology may also underlie supply and demand factors in labor markets (Katz \& Murphy, 1992; Murphy \& Welch, 1992; Topel, 1997). SBTC may explain the shift in demand for skilled labor, and may explain why, in the face of a rising supply of educated workers since the 1970s, the demand for skilled labor continues to push up the wages of the more educated segment of the labor force (Levy \& Murnane, 1992). The more popular view is that SBTC had its greatest impact on labor demand, as explained here. That is, new innovations and the introduction of new technologies are exogenous to the conditions of supply and demand in labor markets, and these new innovations, once they exist, then lead to a marked increase in the demand for skilled labor and a marked decrease in the dcmand for unskilled labor.

However, Acemoglu (2002a) and Kiley (1997) make an interesting case for endogenous SBTC that presents problems for the demand-side theory. These authors focus on the supply of skilled labor as the impetus to SBTC and innovation. Acemoglu and Kiley ask whether the increase in the supply of skilled and educated labor since the 1970s might not have induced firms to begin producing new types of capital that take advantage of higher levels of education and skills. This is, in some sense, a "supplycreates-its-own-demand" type of theory, and is a complete inversion of the more popular demand-side exogenous theory of SBTC. According to Acemoglu, technical change is driven by the profit motive, and firms can only profit from developing new technologies if these new technical inputs are complimentary to or compatible with the skills of the labor market. Thus, prior to the $20^{\text {th }}$ century, technologies were skill-replacing (rather than skill-biased) because the overwhelming proportion of the labor market was 
unskilled. That is, firms developed technologies that could increase the productivity of the low-skilled labor force of the time period. But, with the growth of more educated and skilled labor during the $20^{\text {th }}$ century, and particularly since WWII, new technologies are able to take advantage of the greater supply of skilled labor, and are now more profitable to implement, leading to endogenous skill-biased technical change, and a rise in labor market earnings inequality driven from the supply side rather than by demand.

While this theory is certainly plausible and intriguing, it fails to explain clearly why a relatively moderate and stable increase in the supply of skilled and educated labor since WWII would result in such a marked surge in the demand for skilled and educated labor beginning in the 1980s. Why the delay? Why, according to Goldin and Margo (1992), do we observe wage compression in the 1940s and a stable wage distribution from the 1950s to the 1970s if the rising supply of skilled labor is responsible for the rise in inequality? Acemoglu (2002a) attempts to answer these criticisms by positing an "acceleration hypothesis" relative to the demand for skills, but the argument remains somewhat unconvincing. At any rate, he fails to identify why the demand for skills has far outpaced the supply of skills if it is truly the supply-side that drives the demand for technological change. Should not the two rise in equal magnitude together? If not, why not?

While it remains the dominant explanation for the rise in inequality since the 1970s, the demand-side SBTC theory is not without critics. Card and DiNardo (2002) question the explanatory power of the SBTC theory of rising wage and income inequality, pointing out that wage and income inequality began to stabilize in the 1990 s even as technological change (apparently) continued to accelerate. One explanation for 
this may be that technological change has become less skill-biased and more skillreplacing in recent years, particularly as personal computers and other technological advancements have become more "user friendly." If so, this would tend to (moderately) reduce the relative demand for skilled over unskilled labor, restraining the rise in wage and income inequality by perhaps raising the productivity of less skilled laborers.

Others have argued that while SBTC may explain some of the rise in wage and income inequality since the 1970 s, other factors such as trade openness and immigration (Borjas, 1995; Borjas \& Ramey, 1994; Johnson \& Stafford, 1993; Revenga, 1992; Richardson, 1995; Wood, 1995), and institutional changes such as the level of unionization and minimum wages (Asher \& DeFina, 1995; Fortin \& Lemieux, 1997; Freeman, 1996; Hyclak, 1996, 2000) are also independently responsible. These authors argue that trade and institutional factors, rather than simply interacting with technological changes, have had a moderate impact on wage and income inequality independent of the effects of SBTC.

The most difficult and troubling aspect of the research on the relationship between SBTC and income inequality has been the difficulty in identifying an appropriate measure of technological change. The literature on growth theory has also struggled to more specifically define technological change other than to label it as the "Solow Residual." Krueger (1993) attempted to operationally define technological change in terms of the use of personal computers in the workforce. However, this leaves much technological change unmeasured, and most authors have simply treated technology as a left-over "residual" that "falls out" after other factors have been accounted for (Berman et al., 1994). This leaves much to be desired, and is one of the reasons that the SBTC 
theory of inequality is treated as somewhat tenuous. Given the research efforts to date, we can conclude that SBTC seems to account for the majority of the rise in inequality simply by ruling out other factors that are relatively weak in explanatory power. However, the inability to identify a variable that measures the concept we label "technological change" has proven frustrating. The present research hopes to partially remedy this problem in attempting to employ a valid measure of SBTC.

\section{Summary and Theoretical Framework}

Research to date suggests that the growth-inequality relationship first posited by Kuznets varies over time and depends upon the stage of economic development, the state and pace of technological change, and the measures of growth and inequality used in the analysis. The evidence suggests that, at least for developed economies such as the United States, the maturation of industrialization and urbanization during the 1950s and 1960s may have witnessed the end of a period of negative association between inequality and growth, and that the 1970s and 1980s may have been a turning point beyond which the growth-inequality relationship becomes positive, at least for a time (even if the rate of growth is below its secular trend, such as during the productivity slowdown from 1973 to 1994). Can we observe this turning point in the Kuznets Curve empirically? If so, what might explain it? If technological improvements enhance economic growth by raising the productivity of labor and thus output per capita, we can expect new technologies to account for increased economic growth, particularly during the 1990s. And, if new technologies are non-neutral in their impact on labor productivity, then this may also account for the rise in inequality. Thus, any observed turning point in the Kuznets Curve in developed, post-industrial economies might be explained by the existence of SBTC. 
The present research seeks evidence in support of this theory by investigating the relationship between technological change and growth, and between growth and changes in inequality. If both of these relationships are found to be positive, it would seem to lend support to the SBTC theory of rising inequality, and would also demonstrate a possible reformulation of the original Kuznets Hypothesis. 


\section{CHAPTER III}

\section{Methodology, Data and Formal Hypotheses}

\section{Model Conceptualization}

The conceptual framework of the research model rests on two primary hypotheses relating three constructs: technological change, per capita economic growth, and income inequality, in that order. The first hypothesis is that technological change and per capita economic growth are positively correlated, and that technological change exerts a causal influence on per capita output. This assertion is based upon the relatively simple and well-known idea that technological improvements encourage per capita economic growth (Lucas, 1988; Romer, 1986; Solow, 1956, 1957). The theoretical neoclassical growth model is given in Equation 1, below, where $Y / N$ is the output-per-capita ratio, $K / N$ is the capital-to-labor ratio, and $A$ and $H$ are exogenous factors representing the level of technology and human capital development, respectively. The functional form of the technology-growth relationship to be tested in the present research is given in Equation 2 where $\psi$ is the change in per capita economic growth, $\tau$ is a vector of variables measuring technological change, $\sigma$ is a measure of human capital improvement, $\gamma$ is population growth, and $\varepsilon$ is an error term $\left(\alpha_{1}, \alpha_{2}, \alpha_{3}\right.$ and $\alpha_{4}$ are estimated coefficients):

$$
\begin{aligned}
& Y / N=f\{(K / N), A, H\} \\
& \psi=\alpha_{0}+\alpha_{1} \tau+\alpha_{2} \sigma+\alpha_{3} \gamma+\varepsilon
\end{aligned}
$$


The second hypothesis is that technology-driven per capita economic growth will be positively correlated with income inequality if technological change is non-neutral or skill-biased in some way and is a strong determinant of growth. That is, non-neutral, SBTC may explain any observed positive association between growth and inequality if new technologies raise the productivity of high-skilled labor disproportionately to lowskilled labor. This assertion derives from the research on SBTC and inequality, and ties this literature to the growth-inequality relationship. Thus, technological change may drive per capita economic growth, and economic growth, in turn, may partially explain rising inequality in urban economies. The functional form of the growth-inequality relationship to be tested in the present research is given in Equation 3, below, where $\phi$ is the change in inequality, $\psi$ (from Equation 2 ) is real per capita economic growth, $\lambda$ represents decennial changes in a vector of control variables, and $v$ is an error term $\left(\theta_{0}\right.$, $\theta_{l}$, and $\theta_{2}$ are estimated coefficients):

$$
\phi=\theta_{0}+\theta_{1} \psi+\theta_{2} \lambda+v
$$

\section{Justification of Statistical Estimation Method}

To test for the potential determinants of inter-metropolitan or inter-urban household income inequality, previous research has relied overwhelmingly on standard OLS multiple regression techniques, typically utilizing cross-sectional Census data with Metropolitan Statistical Areas (MSAs) as the primary unit of analysis. This method of exploring the potential determinants of inequality is rooted in the work of Aigner and Heins (1967) and Al-Sammarie and Miller (1967) who employed this approach to investigate state-level Census data on a number of factors hypothesized to explain the observed variation in inequality between U.S. states. This method was developed and 
applied to MSAs by Mooney (1967) to investigate the relationship between unemployment and urban poverty. In his landmark work on urban inequality, Betz (1972) employs a series of standard OLS multiple regressions in a path analysis model, and, by the mid-1970s and early 1980s, OLS regression methods had become the standard statistical technique in a series of research papers investigating the relationship between city population size and household inequality (Burns, 1975; Danziger, 1976; Farbman, 1975; Garofalo \& Fogarty, 1979; Haworth, Long \& Rasmussen, 1978, 1979; Hirsch, 1982; Kennedy \& Nord, 1984; Long, Rasmussen \& Haworth, 1977; Nord, 1980a, 1980b; Yinger \& Danziger, 1978). More recent research employing this method to investigate explanations of metropolitan inequality, income growth, unemployment and/or economic growth can be found in Chakravorty (1996a), Cloutier (1997), Drennan, Tobier \& Lewis (1996), Galster (1989), Glaeser \& Mare (2001), Madden (2000), and Moomaw \& Shatter (1996).

The present research will use a method similar to that cited in the above literature, employing a two-stage least-squares multiple regression model to first investigate the effect of technological change on per capita metropolitan economic growth and, second, the effect of per capita economic growth on metropolitan household income inequality. As mentioned above, the two-stage regression model is being employed to test for endogeneity of the economic growth variable in the second-stage income inequality equation. By employing a two-stage regression model in combination with Hausman's (1976) specification test for simultaneity, we can answer the question as to whether 
inequality has any causal effect on economic growth, as suggested by the median voter theory of the growth-inequality relationship. ${ }^{12}$

The unit of analysis, as in previous research, will be the MSA/CMSA, and the present study will compare the change in cross-sectional MSA/CMSA data from 1990 through 2000. (PMSAs, per se, were excluded in favor of the larger CMSAs as units of analysis in this study because CMSAs are thought to offer a better geographic definition of a cohesive singular economy without the theoretical problems of spillovers between PMSAs due to their close proximity to each other.) All MSA/CMSA 1990 data have been updated to reflect changes in the geographic definitions of MSAs or CMSAs between 1990 and $2000 .^{13}$

Based upon the literature review and theories set forth above, measures of technological change over this decade should exhibit a positive relationship to per capita urban economic growth over the same time period, suggesting that metropolitan areas with relatively greater levels of technological advancement will experience higher per capita economic growth. More importantly, based upon the research linking SBTC with widening inequality, we might also expect that predicted or actual levels of decennial per capita economic growth emerging from the first regression to be positively and significantly correlated with changes in a given measure of metropolitan household income inequality over the same decade as predicted in the second regression. By demonstrating a positive relationship between technology-driven economic growth and income inequality, while properly controlling for a number of additional variables that have also been shown to account for the variation in the household income distribution,

\footnotetext{
${ }^{12}$ For further explanation of the Hausman simultaneity test, see Gujarati, 1995, pp. 669-671.
} 
this finding would enable us to lend greater weight to the theory that SBTC indirectly accounts for growing inequality in urban economies in the United States.

\section{Operational Definitions, Variables, Hypotheses, and Data Sources}

The uniqueness of the present research, and what sets it apart from prior investigations into the determinants of inequality or the relationship between inequality and growth, is the use of distinct and innovative measures of both economic growth and technological change. An additional improvement is the use of MSA/CMSA economic units with many more cases and much more reliable and comparable data than can be obtained in cross-sectional or panel data across highly diverse developing or developed economies.

Technological change has been an elusive and difficult-to-define concept plaguing previous investigations. That is, the inability to operationally define and measure the concept of "technology" has weakened the case for the theory of non-neutral SBTC as an explanation for rising inequality. The present research hopes to at least partially remedy this weakness in the literature by offering measurable definitions of technology and technological change. ${ }^{14}$ There are good theoretical and empirical reasons to believe that the measures of technological change used in the present research will be positively correlated with metropolitan economic growth over the decade in question, and that they may also be (indirectly) linked to rising income inequality.

Additional weaknesses have plagued prior research on the relationship between inequality and growth. The definition of economic growth used in previous research has

\footnotetext{
${ }^{13}$ Specifically, the 1990 data from the Census Bureau have been updated by Geolytics, Inc. to conform to Census 2000 geographic boundaries.
} 
been limited to median household income levels per MSA rather than a closer measure of total economic output for the entire metropolitan economy. The present research uses a distinct indicator of metropolitan economic growth designed to measure real output per capita, further improving weaknesses in previous research relating inequality to economic growth.

The first-stage regression will use multiple independent variables measuring technological change and the level of human capital development as predictors of real per capita metropolitan economic growth. The dependent variable in the model is a measure of metropolitan economic growth, and will be operationally defined as the percentage change in real per capita Gross Metropolitan Product (GMP) from 1990 to $2000 .{ }^{15}$ GMP is a concept analogous to Gross Domestic Product (GDP), the commonly accepted metric of a nation's total economic output (U.S. Conference of Mayors, 2001). By utilizing a measurable concept that captures the value of all final economic output in a given area over a specified time period, this variable provides a much more specific and widely accepted definition of economic growth than has been employed in previous studies. Real per capita GMP captures an estimate of the total constant-dollar ${ }^{16}$ production output of a metropolitan economy, something distinctly absent from measures such as real median household income levels used in previous studies. This lesser measure may

\footnotetext{
${ }^{14}$ Although no claim is made here regarding whether these measures of technological change are necessarily skill-biased, skill-neutral or skill-replacing, a point that is relevant to the findings, below.

${ }^{15}$ The GMP data source is from Global Insight (formerly Standard \& Poor's DRI-WEFA) and the United States Conference of Mayors. The data can be found at http://www.usmayors.org/uscm/news/press releases/documents/npc 071001.asp

${ }^{16}$ All variables with dollar figures for both regression equations in the present research are expressed in constant, inflation-adjusted 2000 dollars. The nominal dollar figures for each of these variables were adjusted using the national CPI-U (the consumer price index for all urban consumers) reported by the Bureau of Labor Statistics. Nominal dollar figures for 1990 were adjusted to constant inflation-adjusted 2000 dollars using the following CPI-U index numbers for each year, respectively: 130.7 and 172.2 (base year $1982-1984=100$ ). The precedent for employing the nationwide CPI-U rather than individual
} 
provide information about the household income levels of the persons who reside in the metropolitan area, and we would generally expect it to be correlated with per capita output, but it is less able to capture the full economic output and productivity of that urban economy. ${ }^{17}$

The measure of per capita economic growth utilized in this research is not without weaknesses, however. Gross Metropolitan Product (GMP) is computed as a derivative of Gross State Product (GSP) data provided by the Bureau of Economic Analysis. For each state, GSP is allocated by industry to the counties and metropolitan areas within that state. This allocation is done based upon the relative concentrations of these industries in the metropolitan areas as measured by employment and labor market concentrations in these industries and within each county. The distribution of GSP to each county is based upon the employment weighting of each industry in that county according to the first two digits in the SIC occupational categories. ${ }^{18}$ Thus, the relative labor concentration of employment in a given industry and county determines the amount of GSP that is appropriated to each county and/or MSA/CMSA. This approach, while perhaps offering the most plausible estimate of metropolitan per capita output, is not exact and is subject to error. However, the weaknesses of this estimate are thought to be a reasonable tradeoff in obtaining a new and innovative measure of economic growth at the metropolitan level.

metropolitan consumer price indexes to adjust nominal dollar values can be found in Drennan, Tobier and Lewis, 1996.

${ }^{17}$ In a separate test, the percentage change in real per capita GMP from 1990 to 2000 was found to be positively and significantly correlated with the percentage change in metropolitan real median household income from 1989 to 1999 , indicating some similarity in these two measures of economic growth. The bivariate correlation between these two variables is statistically significant at the 99.9 percent confidence level ( $\mathrm{p}$-value $\leq .001$ ). This suggests that these two measures of income (one per capita, the other per household) are capturing similar effects or are measuring roughly similar patterns of output and/or income.

${ }^{18}$ Email from statistician at Global Insight, Inc., dated December 23, 2003. 
Per capita metropolitan economic growth from 1990 to 2000 will be regressed on two independent variables measuring technological change. The first measure of technological change will be operationally defined as the percentage change in per capita utility patent approvals per MSA/CMSA from 1990 to $1999 .{ }^{19}$ Utility patent approvals have been shown to be an important indicator of technological advancement (Worgan \& Nunn, 2002), although their association with economic growth is less well understood. Theoretically, we would expect that urban areas with relatively greater levels of per capita patent approval could also experience relatively higher levels of per capita growth, all else constant. Although not all patents are useful patents leading to new innovations or to increased economic output (Griliches, 1990), general utility patents per MSA might be expected to reveal something about the pace of technological development that could raise economic growth.

Higgs (1971) first used state per capita patent data as an operationalization of the concept of inventiveness (or entrepreneurship) to test for the relationship between the level of inventiveness and economic growth. In his original investigation, Higgs found that states with higher levels of urbanization also exhibited relatively more patents per capita than other states. Higgs' conclusion was that urbanization has technological spillover effects due to agglomeration economies and advantages of proximity, leading to higher levels of economic growth in more urbanized states. This nuanced use of utility

\footnotetext{
${ }^{19}$ The MSA general utility patent data source is the United States Patent Office. A "utility" patent is granted to inventors of new and useful improvements, machines, or processes. The utility patent is overwhelmingly the most common type of patent issued by the USPO. The utility patent is distinct from design, plant, reissue and statutory patents because it is granted solely for new inventions and processes (see Worgan and Nunn, 2002, p. 230).

At the time of this writing, the U.S. Patent Office had not yet compiled MSA-level utility patent data for the year 2000. 1999 utility patent approvals per MSA were the latest patent data available. Thus, in computing per capita utility patent approvals per MSA/CMSA for the year 2000, 1999 utility patent
} 
patent approval data in Higgs' research was an important contribution, and opened up the possibility of measuring the concept of technological change.

Griliches (1990), building on the previous work of Schmookler $(1954,1957)$, evaluates the pros and cons of the use of patent data as an indicator of a variety of economic concepts including economic growth, technological change, the competitive position of firms and economies, and the level of inventiveness in specific geographic regions. Griliches points out a number of weaknesses in the use of patent statistics. First, general utility patents are difficult to classify in terms of the inventions to which they lead. Do we assign the invention indicated by the patent to the industry in which it was discovered, to the industry that is likely to produce the new invention, or to the industry that is likely to use the invention in producing other goods and services? This is a dilemma because the firm or geographic location from which the patent originates may benefit little or not at all from the productivity advantages of the patented invention. Additionally, many patents may not lead to any useful inventions or have any meaningful economic impacts. Some products or processes that are patented may have little or no economic value, thus inflating the measure of inventive activity expressed in patent data. On the other hand, some products or processes may have enormous economic value, but are not patented because the inventor(s) did not want to disclose information required to obtain the patent. This would tend to deflate the measure of inventive activity reflected in patent data.

Despite the weaknesses of patent data, Griliches concludes that patent data are generally a "good" indicator of technological change and the level of inventiveness,

approval data from the U.S. Patent Office were divided by 2000 metropolitan population level data from the U.S. Census Bureau. 
particularly in the absence of any reasonable substitute (such as the specific levels of R \& D spending by firms or R \& D spending in specific geographic locations). In spite of these difficulties, patent data remain a unique and valuable resource for the analysis of the processes of technological change and inventiveness, according to Griliches. In a more recent article, Worgan and Nunn (2002) find support for Griliches' conclusions regarding the validity of patent data as a measure of economic change and innovation. In related work, Nunn and Worgan $(2001,2002)$ employ patent data to demonstrate the importance of its use as a gauge of economic development and innovation in urban economies.

A variety of published research in the past decade has made use of patent data as an indicator of technological change and inventiveness. Jaffe, Trajtenberg, and Henderson (1993) use patent data to measure the association between inventiveness and locational spillovers in urban economies. Using patent citation statistics, these authors find that later patents tend to emanate from geographic locations that are in close proximity to the previous patents they cite, suggesting self-reinforcing inventiveness owing to localized technological spillovers. O'hUallachain (1999) finds a similar pattern in patent data. He employs patent data as a measure of technological change and finds a strong positive association between patent frequency and population size in MSAs. In a similar research vein, Carlino (2001) uses patent data to investigate the determinants of the levels of inventiveness in urban areas, with patents per capita as the dependent variable in his model. 
The second measure of technological change will be operationally defined in terms of the change in the proportion ${ }^{20}$ of laborers employed in professional-, managerial-, and technology-related jobs per MSA/CMSA from 1990 to $2000 .^{21}$ The proportion of workers employed in professional-, managerial-, or technology-intensive jobs in a local economy could also have a strong linkage to urban economic growth. The growth or contraction in the proportion of professional and managerial positions, or in technology-related jobs in the computer sciences, health sciences, engineering, and research and development industries should be a valid indicator of technological change in the urban economy, and one we would theoretically expect to co-vary with the change in metropolitan economic output.

This measure is also a staple in the research on economic growth and innovation in urban areas. O'hUallachain (1999) uses a similar measure as a control variable in his investigation of innovation and city size, finding a strong positive association between the proportion of the labor force in high-technology jobs and the level of economic innovation. Other researchers make similar findings when employing some measure of

\footnotetext{
${ }^{20}$ For many of the variables used in this study, the decision was made to employ the change in the proportion of the population with a given characteristic, as opposed to the percentage rate of change in the raw number of people with that attribute over the decade in question. The latter measure would have ignored overall MSA/CMSA population changes (growth or contraction) that might have effected the number of people in the given categories. That is, for example, the percentage change in the absolute number of people in technology-intensive occupations per MSA might have been influenced by a corresponding change in the MSA/CMSA population over the decade. On the other hand, the former measure using the change in the proportion of the population in technology-intensive occupations allows us to control for population changes by using a proportionate rather than an absolute measure. This methodology is employed throughout.

${ }^{21}$ The data source for the number of workers in professional-, managerial-, and technology-related jobs per MSA/CMSA in both 1990 and 2000 is from the Bureau of the Census, 1990 and 2000 Summary File 3.

This measure includes: managerial, business and financial occupations, including business managers and financial specialists; computer and mathematical occupations, architecture and engineering occupations, legal and educational/training occupations; art, entertainment and media occupations; and health technologist and technician occupations. This broad category (defined by the Census Bureau) includes occupations that are most likely to be considered "high skilled." By definition, these occupations would be considered "skill-biased" and would be most likely to be complimentary with technological advancements
} 
labor market structure that accounts for employment in technology-related or other highskilled sectors (Carlino, 2001; Cloutier, 1997; Hyclak, 1996).

Florida (2004) argues that growing urban economies are marked by an increasing contingent of professionals who generate new technologies and new ideas through networks of creativity within an urban economy. He suggests that this "creative class" of workers, instilled with a high level of diversity, individuality, intelligence, education, drive, and creativity, are one of the primary forces behind why some urban and regional economies experience rapid development and economic growth. The variable used here to measure the proportionate change in technology and professional occupations per MSA/CMSA may be expected to capture elements of this "creative class," allowing us to empirically test Florida's theories on metropolitan economic growth and development.

If both of these measures of technological change have the expected influence on metropolitan economic growth, then we are led to the following hypotheses: There is a statistically significant positive relationship between the percentage change in per capita utility patent approvals per MSA/CMSA from 1990-1999 and the growth rate of per capita real GMP from 1990 to 2000; and, there is a statistically significant positive relationship between the change in the proportion of laborers employed in professional-, managerial-, and technology-related jobs per MSA/CMSA from 1990 to 2000 and the growth rate of per capita real GMP from 1990 to 2000.

The third independent variable in the first-stage regression will be a measure of metropolitan human capital development, operationalized as the 1990 to 2000 change in the proportion of the MSA/CMSA population age 25 and over with a four-year degree or

in the workplace. They are also most likely to include and be consistent with Richard Florida's (2003) definition of the concept of a "creative class" of workers. 
beyond. ${ }^{22}$ Becker's (1961) classic work on human capital theory suggests that the improvement of human capital is critical to economic development, and Romer (1986) and Lucas $(1988,2004)$ both include human capital as an important ingredient to economic growth in their theoretical research. In a recent cross-country comparison, Barro (2001) finds a strong positive relationship between human capital levels, operationalized as years of education, and economic growth. Barro's findings confirm that both the quantity and the quality of education promote economic growth. Goldin and Katz (2001) make similar conclusions about the United States economy over the $20^{\text {th }}$ century (see also Glomm \& Ravikumar, 1992). Gottlieb and Fogarty (2003) find a statistically significant positive relationship between a level of educational attainment, measured as the percentage of the metropolitan population with a four-year degree in 1980, and subsequent metropolitan per capita income growth rates from 1980 to 1997. Based upon findings from previous research, then, we would expect MSAs and CMSAs with a more rapid increase in human capital development to exhibit a higher level of output per capita. All else constant, we expect a statistically significant positive relationship between the change in the proportion of the MSA/CMSA population with a four-year degree or more from 1990 to 2000 and the growth rate of per capita real GMP from 1990 to 2000 .

A fourth and final variable will be included in the first-stage regression to control for the broad effects of population growth on MSA/CMSA per capita economic output. O'hUallachain (1999) shows that population growth and size play a large role in the level of inventive activity and technological change. His findings imply that there may be a

\footnotetext{
${ }^{22}$ The data source on MSA education levels in 1990 and 2000 comes from the Bureau of the Census, 1990 and 2000 Summary File 3.
} 
two-way causation between these concepts: as population grows, inventive activity rises, but as inventive activity rises, population may grow in response.

Population change will be operationally defined as the population growth rate per MSA/CMSA from 1990 to 2000 (the percentage change in metropolitan population from 1990 to 2000), and this factor will be used as a fourth control variable in the first-stage regression model. ${ }^{23}$ We expect a statistically significant positive relationship between the MSA/CMSA population growth rate from 1990 to 2000 and the growth rate of per capita real GMP from 1990 to 2000.

A summary of the variables included in the first-stage regression is provided in Table 1, below. The first-stage estimating equation is specified in Equation 4,

$$
\psi=\beta_{0}+\beta_{1} \tau_{1}+\beta_{2} \tau_{2}+\beta_{3} \sigma+\beta_{4} \gamma+\mu
$$

where $\psi$ is the estimated value of real per capita GMP growth from 1990 to $2000, \tau_{l}$ is the percentage change in per capita utility patent approvals per MSA/CMSA from 1990 to $1999, \tau_{2}$ is the change in the proportion of the MSA/CMSA population employed in technology-related jobs per MSA/CMSA from 1990 to $2000, \sigma$ is the change in the proportion of the MSA/CMSA population holding a four-year degree or beyond from 1990 to 2000 , and $\gamma$ is the MSA/CMSA population growth rate from 1990 to 2000 . $\beta_{0}$, $\beta_{l}, \beta_{2}, \beta_{3}$ and $\beta_{4}$ are estimated coefficients from the data, and $\mu$ is an error term.

\footnotetext{
${ }^{23}$ The data source on MSA population growth from 1990 to 2000 is from the Bureau of the Census, 1990 and 2000 Summary File 3.
} 


\begin{tabular}{lll}
\hline & Variable Name & Expected Correlation \\
\hline$\psi$ & $\% \Delta$ in real per capita GMP 1990- \\
& 2000 \\
& $\% \Delta$ in per capita utility patent \\
& approvals per MSA/CMSA 1990- \\
& 1999 & \\
& $\Delta$ in proportion of MSA/CMSA \\
& population in professional-, \\
& managerial-, and technology-related \\
$\tau_{2}$ & jobs 1990-2000 \\
& $\Delta$ in proportion of MSA/CMSA \\
& population with a four-year degree or \\
& more 1990-2000 \\
& $\% \Delta$ in MSA/CMSA population \\
& $1990-2000$ \\
\hline
\end{tabular}

The second-stage regression model will regress a standard measure of household income inequality on a number of different independent variables. The second-stage model will be designed to permit an investigation of the determinants of the variation in household income inequality in metropolitan areas from 1990 to 2000 . The dependent variable employed to measure the change in the level of urban household income inequality will be operationally defined as the point change in the household gross income Gini coefficient (the Gini index) per MSA/CMSA from 1990 to 2000.

The household income Gini index is one of the most popular measures of income inequality in use today, and is widely accepted as a valid and reliable measure of the variance in the income distribution. The Gini index measures the level of income inequality across cumulative income quintiles, or cumulative income fifths, as they are plotted along a Lorenz Curve from the lowest fifth (or quintile) to the highest fifth (Gastwirth, 1972; Ryscavage, 1999). The Gini coefficient is a measure between 0 and 1, where 0 indicates perfect equality of incomes across all quintiles, and 1 indicates perfect inequality of incomes with the top household possessing 100 percent of all income. As an example of the use of this index in the present study, the Gini coefficient for the entire 
United States stood at 0.376 in 1979 , and had risen to 0.410 by 1989 , indicating a 0.034 point increase, or an increase of roughly nine percent, over this ten-year period (Ryscavage, 1999).

The Gini index is not the only measure of income inequality available,${ }^{24}$ and it exhibits certain weaknesses and advantages when compared to other measures. For example, changes in the Gini index are most sensitive to income changes or transfers taking place in the middle of the income distribution. An income transfer of a given amount will have a larger impact on the middle of the income distribution as measured by the Gini, whereas other measures of inequality may reflect a larger change at the upper or lower tails of the income distribution resulting from the same income transfer (Levy \& Murnane, 1992; Ryscavage, 1999). The choice of any income inequality measure is fraught with tradeoffs. In a comparison of normative and descriptive measures of inequality, Kaplow (2002) argues that the Gini index is a "useful" descriptive indicator of inequality, but how useful depends on its specific application and the accompanying theoretical framework in which it is used. Nonetheless, the Gini index is one of the most widely accepted, valid, and reliable measures of income inequality, and is chosen for use in the present research because it is easily comparable with previous inequality research using this measure (Al-Samarrie \& Miller, 1967; Betz, 1972; Burns, 1975; Chakravorty, 1996a; Cloutier, 1997; Danziger, 1976; Farbman, 1975; Galster, 1989; Garofalo \& Fogarty, 1979; Haworth et al., 1978; Hirsch, 1982; Kennedy \& Nord, 1984; Madden,

\footnotetext{
${ }^{24}$ See Nelson and Lorence $(1985,1988)$ for research on urban inequality using an alternative measure of inequality.
} 
2000; Nord, 1980a, 1980b). The Gini index is also the most easily obtainable measure of household income inequality for MSAs and CMSAs. ${ }^{25}$

The Gini coefficient for each MSA/CMSA will be computed from 1990 and 2000 Census data, ${ }^{26}$ and the point difference between the 1990 and 2000 Gini coefficient will serve as the dependent variable in the second-stage regression. That is, if the Gini coefficient rises from, say, 0.425 in 1990 to 0.490 in 2000, for example, the point change in the Gini coefficient would be 0.065 , and this point change value would serve as the dependent variable in the regression. If the point change in the MSA Gini index is positive, this will indicate an increase in metropolitan household income inequality over the decade. Conversely, if the point change in the MSA Gini index is negative, this will indicate a decrease in metropolitan household income inequality over the decade. The point change in the Gini index will be regressed on a number of independent variables to investigate the possible determinants of rising or falling income inequality from 1990 to 2000. (Unless otherwise explicitly noted, the data for all of the independent variables used in the second-stage regression model are also from the Bureau of the Census, 1990 and 2000 Summary File 3.)

The first regressor in the second-stage equation will be the actual or predicted growth rate of per capita real GMP from 1990 to 2000, depending upon the results of the first regression and the Hausman's specification test for simultaneity (Hausman, 1976;

\footnotetext{
${ }^{25}$ See Galbraith and Kum (2002), Gastwirth (1972), Kaplow (2002), Levy and Murnane (1992) and Ryscavage (1999, pp. 33-44) for further descriptions of the Gini index, how it is calculated, pros and cons of the Gini, and alternative measures of inequality.

${ }^{26}$ Gini coefficients used in the current study were computed by the Census Bureau, Special Tabulations Division, based upon household income reported on the 1990 and 2000 Census "long form." The smallest unit of analysis for which long form data are directly and openly available from the Census Bureau is the census block-group level. The Gini computations were therefore performed by the Special Tabs Division of the Census Bureau because the author does not have access to individual or household level long-form Census data.
} 
see above). A preliminary second-stage regression will be run including both predicted economic growth and its residual (from the first-stage model) as independent variables. If the residual variable is found to be statistically significant in this preliminary secondstage model, then this tells us that both the residual and actual economic growth are endogenous to inequality, thus suggesting two-way causality between inequality and economic growth. In this case, we will use the predicted growth rate of per capita real GMP from 1990 to 2000 in the actual second-stage regression model. On the other hand, if the residual variable from the first-stage model is not found to be statistically significant, then this suggests that endogeneity of economic growth to inequality is not a problem, and we will use actual values of the growth rate of per capita real GMP from 1990 to 2000 in the actual second-stage regression model. ${ }^{27}$

It is this growth-inequality relationship that is most critical to the present research, and it is anticipated that we will observe a positive relationship between the growth rate in real per capita GMP and point changes in the Gini index measure of metropolitan household income inequality if SBTC is a factor. If we find that the level of per capita economic growth as predicted by technological change is positively and statistically significantly related to the change in household income inequality, we can begin to substantiate the claim that, ceteris paribus, technology-driven growth indirectly leads to higher levels of inequality, at least over this decade in the United States' economy. This would further suggest a possible "turning point" in the Kuznets curve in developed economies as discussed above. If no significant relationship is found, or if a significant negative relationship is observed, this would allow us to question the proposition that

\footnotetext{
${ }^{27}$ For further clarification of this specification technique in testing for simultaneity problems, see Hausman, 1976, and Gujarati, 1995.
} 
technology-driven growth raises inequality. This leads us to the following hypothesis:

We expect a statistically significant positive relationship between the growth rate of real per capita GMP from 1990 to 2000 and the change in MSA/CMSA household income inequality from 1990 to 2000 , all else constant.

The second independent variable in the second-stage regression will be the change in MSA/CMSA educational inequality from 1990 to 2000 . Educational inequality will be operationally defined as the change in the proportion of the MSA/CMSA population in the extreme tails of the educational distribution: those with either less than a high school diploma, or a graduate/professional degree or more. ${ }^{28}$ Previous research suggests a positive relationship between the level of educational inequality and the level of income inequality (Burns, 1975; Cloutier, 1997; Danziger, 1976; Garofalo \& Fogarty, 1979; Levy, 1995). As the distribution of education becomes more unequal, the income distribution also tends to become more unequal (see also Bishop, 1996; Kain \& Singleton, 1996; Kane \& Rouse, 1995; Lynch, 1995). It is expected that metropolitan areas with a growing proportion of people in the extreme tails of the educational distribution would also exhibit higher levels of household income inequality, all else constant, a finding that would specifically support the research findings by Cloutier (1997). A positive relationship between this variable and the change in the Gini coefficient is therefore expected: There is a statistically significant positive relationship

\footnotetext{
${ }^{28}$ As indicated above, the decision was made to employ the change in the proportion of the population in the extreme tails of the educational distribution as a measure of educational inequality, as opposed to the percentage rate of change in the number of people in the extreme tails of the educational distribution over the decade in question. The latter measure would have ignored overall MSA/CMSA population changes (growth or contraction) that might have effected the number of people in the extreme educational categories. That is, the percentage change in the absolute number of people in, say, the upper category of the educational distribution might have been influenced by a corresponding change in the MSA/CMSA population over the decade. On the other hand, the former measure using the change in the proportion of
} 
between the change in the percentage of the population in the extreme tails of the educational distribution per MSA/CMSA from 1990 to 2000 and the change in MSA/CMSA household income inequality from 1990 to 2000.

Racial segregation and the problem of "spatial mismatch" in urban areas may also play a role in explaining metropolitan income inequality. If African-American households are geographically separate from white households due to discrimination in residential housing markets, and if this leads to barriers to employment and income opportunities for black minority workers as numerous studies have suggested (Chakravorty, 1996b; Holzer, 1987; Holzer \& Ihlanfeldt, 1996; Ihlanfeldt \& Sjoquist, 1990; Kain, 1968; Massey \& Denton, 1987; Wilson, 1987), this may, in turn, explain observed levels and changes in inequality in metropolitan areas. Massey and Eggers (1993) suggest that the metropolitan spatial concentration of affluence and poverty began to accelerate in the 1970s. This is consistent with the time period during which it has been found that income inequality also began rising (Levy \& Murnane, 1992; Ryscavage, 1999). If the spatial concentration of higher and lower income households breaks down along racial lines, then there may be a link between racial segregation and the rise in income inequality. Additionally, industrial restructuring and suburbanization may have led to employment mismatches for African-American residents isolated in central cities (Moore \& Laramore, 1990), perhaps leading to further inequality. ${ }^{29}$ An independent variable is therefore included to test for the relationship between the change in racial segregation and changes in metropolitan income inequality from 1990 to 2000 . The

the population in the extreme education categories allows us to control for population changes by using a proportionate rather than an absolute measure.

${ }^{29}$ For a further investigation of urban spatial and residential effects on income, unemployment, and inequality see Kodrzycki (1996), Mayer (1996), O’Regan and Quigley (1996) and Taylor and Ong (1995). 
change in racial segregation will be operationally defined in terms of the point change in Massey and Denton's (1987) Dissimilarity Index per MSA/CMSA from 1990 to 2000.

The dissimilarity index is a measure of the percentage of African-Americans that would need to relocate across census tracts to get a perfectly equal proportion of black residents across the entire MSA (Glaeser and Vigdor, 2001). ${ }^{30}$ If racial segregation of residential housing plays a role in metropolitan household income inequality, we would expect to observe a positive relationship between the point change in the Massey and Denton dissimilarity index and the point change in the Gini index per MSA/CMSA from 1990 to 2000 , all else equal: There is a statistically significant positive relationship between the change in racial housing segregation per MSA/CMSA from 1990 to 2000 and the change in MSA/CMSA household income inequality from 1990 to 2000 .

Several studies on urban income dispersion have tested for the effects of government transfer payments on household income inequality (Cloutier, 1997; Danziger, 1976; Farbman, 1975). The findings from these studies are mixed, with some research finding a negative association between transfer payments and inequality (Cloutier) while others find a positive association (Danziger). Farbman finds no relationship between inequality and transfer payment levels per MSA. Theoretically, we

\footnotetext{
${ }^{30}$ Dissimilarity index data for 1990 and 2000 are from the study by Glaeser and Vigdor, 2001, which also includes a computational summary of the exact calculations used to compute the dissimilarity index. For additional information on the precise calculations used to compute the dissimilarity index, see Massey and Denton (1987). Of the 260 MSAs used in the current study, 238 of these metropolitan areas reflect the 1990 dissimilarity indexes computed by Glaeser and Vigdor in their Census Bureau study. The 1990 dissimilarity indexes for the remaining 22 MSAs were computed by the present author using the same methodology employed by Glaeser and Vigdor, and include the following cities: Appleton-OshkoshNeenah, WI; Bangor, ME; Bellingham, WA; Billings, MT, Bismarck, ND; Brownsville, TX; Casper, WY; Dover, DE; Dubuque, IA; Eau Claire, WI; Fargo-Moorehead, ND-MN; La Crosse, WI-MN; Laredo, TX; Lewiston-Auburn, ME; Medford-Ashland, OR; Provo-Orem, UT; Rochester, MN; Sante Fe, NM; Sheboygan, WI; Sioux Falls, SD; St. Cloud, MN; and Wausau, WI. For the 2000 data, dissimilarity indexes for 250 of the total 260 MSAs used in the current study are from Glaeser and Vigdor, and the remaining 10 were computed by the present author, including the following: Bangor, ME; Billings, MT;
} 
might expect transfer payment levels to reduce inequality by raising the incomes of the lowest quintile in the income distribution. However, if relatively larger transfer payment levels (or large increases in transfer payment spending) accompany a relatively larger number of low-income welfare-dependent households in the metropolitan area, higher levels of transfer payments might coincide with higher levels of inequality.

To measure the effect of changes in transfer payments on changes in household income inequality, we will include a variable capturing the percentage change in real per capita total transfer payment spending per MSA/CMSA from 1990 to $2000 .^{31}$ The expected direction of correlation between the percentage change in real per capita transfer payments and the point change in the Gini index is indeterminate. Our hypothesis is thus correlational but not directional: There is a statistically significant relationship between the percentage change in real per capita transfer payment expenditures per MSA/CMSA from 1990 to 2000 and the change in MSA/CMSA household income inequality from 1990 to 2000.

Five additional control variables will be included to test for the impact of various demographic changes on metropolitan household income inequality: 1) the change in the proportion of the black (including Hispanic) population per MSA/CMSA from 1990 to $2000,2)$ the change in the ratio of female head-of-household families to population per MSA/CMSA from 1990 to 2000,3$)$ the change in the proportion of the population aged 65 and over per MSA/CMSA from 1990 to 2000,4 ) a regional dummy variable for MSAs and CMSAs in the South Census Region of the United States, and 5) the

Bismarck, ND; Casper, WY; Dubuque, IA; Eau Claire, WI; Laredo, TX; Lewiston-Auburn, ME; MedfordAshland, OR; and Sante Fe, NM.

${ }^{31}$ Data for total real per capita transfer payments per MSA/CMSA from 1990 and 2000 are from the Regional Economic Information System (REIS) produced by the Bureau of Economic Analysis (BEA). 
population growth rate per MSA/CMSA from 1990 to 2000. Previous research suggests that most of these control variables are correlated with household income inequality in some way, some stronger, others weaker.

Aigner and Heins (1967), Al-Sammarie and Miller (1967), Betz (1972), Burns (1975), Cloutier (1997), Danziger (1976), Farbman (1975), Garofalo and Fogarty (1979), Haworth et al. (1978), Kennedy and Nord (1984), Long et al. (1977), Murray (1969), and Nord (1980a and 1980b) all find overwhelmingly that the larger the nonwhite proportion of the population, the higher the levels of income inequality. Nelson and Lorence (1985, 1988) find no relationship between the proportion of nonwhite population and inequality in metropolitan economies when controlling for other factors. ${ }^{32}$ And, Madden (2000), in her study of metropolitan household inequality change from 1980 to 1990 , finds that the percentage growth in MSA nonwhite population did not significantly impact the changes in income inequality over this period. However, most studies seem to indicate that the urban income distribution may be heavily influenced by racial composition, with nonwhites comprising a majority of the low-income quintiles and whites comprising a majority of the high-income quintiles. Thus, in general, we would expect that cities with an expanding African-American population from 1990 to 2000 would also exhibit relatively larger increases in income inequality over this same period, all else constant: There is a statistically significant positive relationship between the change in the proportion of African-American population per MSA/CMSA from 1990 to 2000 and the change in MSA/CMSA household income inequality from 1990 to 2000.

\footnotetext{
${ }^{32}$ This may be due to the peculiar choice of inequality measure in the Nelson and Lorence studies. Rather than using the traditional Gini index measure of income inequality, the two Nelson and Lorence studies use the Thiel "information-based" inequality coefficient. The sensitivity of the Thiel index to urban racial
} 
Likewise, findings by Chakravorty (1996a), Cloutier (1997), Haworth et al., (1978), Madden (2000), Nord (1980a, 1980b), and Ryscavage (1999) suggest that cities with higher levels of female heads-of-household also exhibit higher levels of income inequality (see also Hyslop, 2001). Single mothers typically earn relatively low incomes and could be expected to make up a significant proportion of low-income quintiles of the income distribution. Thus, we would expect that MSAs/CMSAs with a growing contingent of female head-of-household families from 1990 to 2000 would exhibit a relatively greater increase in household income inequality over this decade, all else constant: There is a statistically significant positive relationship between the change in the ratic of female-headed households to population per MSA/CMSA from 1990 to 2000 and the change in MSA/CMSA household income inequality from 1990 to 2000.

In similar fashion, the proportion of elderly households on a fixed retirement and/or Social Security income could easily impact the level of metropolitan income inequality. Chakravorty (1996a), Cloutier (1997), Garofalo and Fogarty (1979), Kennedy and Nord (1984), and Madden (2000) have all found that income inequality is positively associated with a higher proportion of elderly in the urban population (aged 65 and above). We would expect that MSAs or CMSAs with gains in the proportion of the population aged 65 and over to also experience a more rapid increase in income inequality. Although the elderly may have a large stock of accumulated assets and wealth, their relatively low and fixed retirement incomes may tend to put them in the lowest income quintiles of the income distribution, theoretically leading to higher levels of income inequality the larger the proportion of elderly in the metropolitan population:

composition may be weaker than the Gini index, thus explaining the insignificant finding by Nelson and Lorence. 
There is a statistically significant positive relationship between the change in the proportion of the elderly population (age 65 and over) per MSA/CMSA from 1990 to 2000 and the change in MSA/CMSA household income inequality from 1990 to 2000 , all else constant.

Regional effects have been found to result in peculiar outcomes related to metropolitan inequality in previous studies, most of which find higher levels of inequality in the South than in other regions, all else constant (Chakravorty, 1996a; Cloutier, 1997; Kennedy \& Nord, 1984; Nelson \& Lorence, 1985). Thus, we will also test for this regional effect by including a similar dummy variable for MSAs/CMSAs in the South Census Region in 1990. We would expect MSAs and CMSAs located in this region in 1990 to exhibit a stronger rise in household income inequality from 1990 through 2000 than other regions, all else constant: There is a statistically significant positive relationship between the regional location of MSAs and CMSAs in 1990 and the change in MSA/CMSA household income inequality from 1990 to 2000, with MSAs and CMSAs in the South Central Census Region exhibiting larger increases in inequality.

Finally, MSA population growth rates and MSA population levels have been found to be an important factor related to household income inequality in metropolitan areas (Alperovich, 1995). Moreover, the use of metropolitan growth rates can serve as a (loose) proxy for Kuznets' (1955) concept of "urbanization" as a determinant of income inequality, allowing us to test for the effects of late-stage urbanization on income inequality in advanced economies.

The research on city size (as measured by population level) and income inequality was first advanced by Michael Betz (1972) and Irving Hoch (1972) and continued by 
numerous researchers throughout the 1970s and 1980s (Burns, 1975; Farbman, 1975;

Garofalo \& Fogarty, 1979; Haworth et al., 1978, 1979; Hirsch, 1982; Kennedy \& Nord, 1984; Long et al., 1977; Nord, 1980a, 1980b; Walker, 1979; Yinger \& Danziger, 1978). The tenuous conclusions of this body of research (relying heavily on cross-sectional decennial census data) suggest that the relationship between city size (population level) and household income inequality is reflected in a curvilinear U-shaped pattern.

Relatively smaller cities appear to experience higher levels of inequality. Cities with moderate-to-high levels of population appear to experience lower levels of inequality up to a point. And, beyond some threshold population level, income inequality once again appears to be higher in the largest of cities. This tentatively supports the theory of oscillating Kuznets' Curves along the urbanization dimension.

Several hypotheses have been advanced to explain this nonlinear relationship. Murray (1969) shows that as cities grow in size, median income rises, raising the incomes of the lower-income households and leading to lower inequality. However, Danziger (1976), Farbman (1975), and Long et al (1977) show that city size leads to widening skill differentials in a more diverse urban population mix, which in turn leads to rising inequality. Burns (1976) however raises a human capital counter-argument suggesting that as city size increases and population levels rise, opportunities for human capital development (education and training) will increase in urban areas, raising skills across the board and leading to a decline in urban inequality.

Haworth et al (1978) posit a "monopoly hypothesis" and argue that the principle beneficiaries of rising urban size will be those individuals and groups that hold assets and have monopoly positions in the delivery of goods and services, so that the benefits of 
increasing city size will be unequally distributed, leading to rising inequality.

Specifically, Haworth et al. argue that holders of land assets will see wealth appreciation through capital gains resulting from an increase in the population, and that this increase in wealth will lead to gains in income that will be disproportionate to non-asset holders in the city, thus creating higher levels of inequality at higher population levels.

Garofalo and Fogarty (1979) advance a "productivity-agglomeration hypothesis." They argue that the productivity advances resulting from urban agglomeration economies and spillover knowledge accrue almost fully to higher skilled labor. Thus, productivity increases with city size due to agglomeration economies, spillovers, and external economies of scale, but these factors serve to raise the productivity of high skilled urban labor only, leaving low skilled urban labor unaffected and resulting in widening inequality. (Another label for this phenomenon might be "non-neutral skill-biased agglomeration change.") Garofalo and Fogarty also offer a secondary explanation for rising inequality and city size, particularly in the largest cities: the "amenitycompensation" theory. Garofalo and Fogarty argue that higher aggregate urban income leads to a broader tax base and a higher quality of public goods and amenities in the city. This, in turn, tends to attract higher-skilled labor, initially resulting in an increasing supply of high-skilled labor that reduces the wage premium for skills and reduces overall inequality. However, once city population (and income) grow beyond a certain point, market failures caused by congestion externalities result, and higher-skilled workers must be compensated for these social costs with a wage premium in order for urban firms to retain them as employees. Lower-skilled urban labor cannot command this higher wage premium to compensate for the social costs of congestion, according to Garofalo and 
Fogarty, leading to a rising skilled-unskilled income gap as the city population grows beyond a certain threshold.

Nord and Kennedy (1984) analyze 167 MSAs using census data from the 1950 to 1970 time period to explore the possible theories on the relationship between city size and the income distribution. They break city population levels into three ranked size categories and analyze all three categories for the 1950,1960 and 1970 decennial censuses. They control for a number of additional variables as well, and their findings confirm some of the previous theories on city size and inequality while rejecting others. In cities over 500,000 in population (the largest of the three class size categories), the coefficient on city size and household income inequality is positively and statistically significant. For cities less than 500,000 in size, the coefficient is positively correlated, but not significant. This tentatively confirms the "monopoly-benefits" theory and the "amenities-compensation" hypothesis of Garofalo and Fogarty (1979), and suggests that city size as measured by population level raises inequality, but only in the largest class of cities. Otherwise, it has little or no effect. For the smaller class of cities, however, the "human capital" theory of Burns (1975) is tentatively supported, suggesting that as cities grow in size, opportunities for human capital development become more available, leading to an increase in the supply of skilled and educated labor and reducing inequality. Additionally, Nord and Kennedy find that population growth rates in the previous decade had no statistically significant effect on income inequality in either direction. This challenges previous research and suggests that urban population growth rates have little impact on inequality in the lagged time period. 
Based upon the foregoing summary of somewhat inconclusive literature exploring the relationship between population levels or population growth rates and inequality, the direction of the relationship between MSA/CMSA population growth rates and the change in MSA/CMSA inequality over the 1990 to 2000 period cannot be predicted $a$ priori. The indeterminacy of this relationship leads to the following correlational hypothesis: There is a statistically significant relationship between 1990 to 2000 population growth rates per MSA/CMSA and the change in MSA/CMSA household income inequality from 1990 to 2000 .

A summary of the variables included in the second-stage regression are listed in Table 2, below. The second-stage regression equation is specified in Fauation 5,

$$
\begin{gathered}
\phi=\theta_{0}+\theta_{l} \psi+\theta_{2} \lambda_{1}+\theta_{3} \lambda_{2}+\theta_{4} \lambda_{3}+\theta_{5} \lambda_{4}+\theta_{6} \lambda_{5}+\theta_{7} \lambda_{6} \\
+\theta_{8} \lambda_{7}+\theta_{9} \lambda_{8}+\mu
\end{gathered}
$$

where $\phi$ is the estimated point change in the Gini coefficient measure of income inequality per MSA/CMSA from 1990 to $2000 . \psi$ is real per capita GMP growth (the dependent variable from the first regression equation), and $\lambda_{l}$ through $\lambda_{8}$ are control variables discussed above and listed below. $\theta_{0}$ through $\theta_{9}$ are predicted coefficients from the data, and $\mu$ is an error term. 
Variable Name

estimated point change in Gini index coefficient 1990-2000

actual (or predicted) $\% \Delta$ in real per capita GMP per MSA/CMSA 19902000

$\lambda_{1}$

$\lambda_{2}$

$\lambda_{3}$

$\lambda_{4}$

$\lambda_{5}$

$\lambda_{6}$

$\lambda_{7}$

$\lambda_{8}$ $\triangle$ in educational inequality per MSA/CMSA 1990-2000 ( $\triangle$ in proportion in extreme tails of the education distribution)

point change in Massey and Denton's racial dissimilarity index from 1990 2000

$\% \Delta$ in real per capita total transfer payments per MSA/CMSA from 1990-2000

$\Delta$ in proportion of black (including Hispanic) population per MSA/CMSA from 1990-2000

$\Delta$ in the ratio of female-headed households to population per MSA/CMSA from 1990-2000

$\Delta$ in proportion of population age 65 and above in MSA/CMSA population 1990-2000

dummy variable for MSA/CMSA in

South Census Region in 1990

$\%$ growth in population per MSA/CMSA 1990-2000
Expected Correlation

$+$

$+$

Indeterminate

$+$

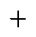

$+$

$+$

Indeterminate 


\title{
CHAPTER IV
}

\section{Findings and Analysis}

\author{
Description of Data and Univariate Analysis
}

The units of analysis for the present research are Metropolitan Statistical Areas (MSAs) and Consolidated Metropolitan Statistical Areas (CMSAs). MSAs are urban areas with a population of 50,000 or more in the central city and geographically defined by the Bureau of Census to include the central city plus the surrounding metropolitan counties and suburbs. CMSAs are larger super-metropolitan areas comprised of a grouping of smaller cohesive individual MSAs (called Primary Metropolitan Statistical Areas or PMSAs). Both MSAs and CMSAs are considered stand-alone urban economies defined by geographic boundaries determined not by political jurisdictions but by commuting patterns and the relationship of other economic activity to the central urban location (Mills \& Hamilton, 1994, pp. 5-7).

PMSAs, per se, were excluded from the present study (and the larger CMSA metropolitan units used instead) because the goal is to analyze single stand-alone economies uninfluenced by the possible economic spillovers from other cities in close geographic proximity. The CMSA is thus the preferred economic-geographic unit of analysis in the largest metropolitan areas (i.e., Boston, Chicago, Los Angeles, New York City, etc.) where numerous smaller PMSAs may not be so easily analyzed in isolation due to the potential spillover influence between and among these smaller economic units. 
There were $276 \mathrm{MSAs} / \mathrm{CMSAs}$ in the United States as of the 2000 Census. The

Census Bureau was able to provide 1990 and 2000 household income Gini coefficients for 260 of the total 276 MSAs/CMSAs existing in 2000. 1990 household Gini coefficients for the remaining sixteen MSAs were not able to be provided because these urban areas did not exist as a classified MSA in $1990 .{ }^{33}$ Because of the problem of missing values for these sixteen cases, the decision was made to drop them from the analysis. Despite their relatively new status as MSAs over the 1990 to 2000 time period, the sixteen cases excluded from the analysis were found to be random relative to most of the variables in both the first- and second-stage regressions. ${ }^{34}$ Because the sixteen cases dropned comprise less than six percent of the total population of 276 cases, their exclusion is considered small enough to be of negligible consequence. The findings from the analysis of the remaining 260 cases should be valid and largely unbiased, and the generalizability of the results should be unaffected.

All other variables are complete and do not suffer from any missing values, leaving a total sample size of $n=260 \mathrm{MSAs} / \mathrm{CMSAs}$ for which data are available and which are thus included in the study. ${ }^{35}$ The use of $n=260$ cases is thought to provide a

\footnotetext{
${ }^{33}$ The sixteen specific MSAs for which there were missing values on the 1990 Gini coefficient include: Auburn-Opelika, AL; Barnstable-Yarmouth, MA; Corvallis, OR; Flagstaff, AZ-UT; Goldsboro, NC; Grand Junction, CO; Greenville, NC; Hattiesburg, MS; Jonesboro, AR; Missoula, MT; Myrtle Beach, SC; Pocatello, ID; Punta Gorda, FL; Rocky Mount, NC; San Luis Obispo, CA; Sumter, SC.

${ }^{34}$ In a simple difference of means $t$-test of significance, the sixteen excluded cases were found to have significantly different means $(\mathrm{p} \leq .05)$ on only two variables included in the two separate regression equations. The sixteen excluded cases exhibited statistically significantly higher means on the percentage point change in professional-, managerial-, and technical-sector jobs from 1990-2000 and the percentage point change in the number of elderly $65+$ from $1990-2000$.

${ }^{35}$ One caveat should be mentioned. In calculating the percentage change in per capita utility patent approvals per MSA/CMSA from 1990-1999 (an independent variable in the first-stage regression), the author discovered that two MSAs (Jacksonville, NC and McAllen, TX) had zero utility patent approvals in 1990, and one and five utility patent approvals in 1999 respectively, making a percentage rate of increase calculation impossible for these two cases (computing a percentage change from zero yields an error and thus a missing value in this variable for these two cases). In order to avoid excluding these two cases, and because the relative increase in per capita patent approvals was so small for these two cities, the decision
} 
sufficiently large enough sample size for use in standard multiple regression analysis

given the number of independent variables to be included in both the first- and secondstage regression equations. ${ }^{36}$

The data for each of the variables were checked for normality, linearity, homoscedasticity, and multicollinearity before interpreting the results of either of the two regressions. The two critically important dependent variables were found to be normally distributed, allowing us to assume that the error terms or residuals are normally distributed as well, an important criterion of multiple regression analysis (Berry, 1993). The percentage change in real per capita GMP from 1990 to 2000 (the dependent variable in the first-stage regression) exhibited slight negative skewness of. .492 with a skewness z-score of -3.26. The point change in the Gini coefficient from 1990 to 2000 (the dependent variable in the second-stage regression) exhibited minimal positive skewness of +.068 with a skewness z-score of $+.450 .{ }^{37}$

The data in all variables were also visually inspected for linearity and homoscedasticity using bivariate scatterplots of the relationships between all independent

was made to arbitrarily set the percentage increase in per capita utility patent approvals at 0 percent for McAllen, TX (from 0 in 1990 to 5 patents in 1999), and at 0 percent for Jacksonville, NC (from 0 in 1990 to 1 patent in 1999).

${ }^{36}$ Tabachnick and Fidell (2001, p. 117) suggest that the ratio of cases to independent variables can follow a simple rule-of-thumb formula: $\mathrm{N} \geq 50+8 m$ (where $m$ is the number of independent variables). With 260 cases, this rule of thumb would permit a maximum of $m=26$ independent variables in either of the multivariate regression equations. Neither regression equation in the present study includes this many independent variables.

${ }^{37}$ All skewness $\mathrm{z}$-scores were calculated by dividing the skewness statistic by its standard error. A skewness z-score between \pm 2.33 is considered good, and a skewness z-score between \pm 2.33 and \pm 3.29 is considered marginal but acceptable (Tabachnick and Fidell, 2001, p. 67). The distribution of both dependent variables are within this range of acceptance, indicating only a slight or moderate deviation from normality in this data. The decision was made not to $\log$ or otherwise transform these variables due to the relatively large sample size and the assumptions of normality that can be made with larger samples. Additionally, the degree of skewness in these two dependent variables is not considered severe enough to warrant a transformation of the data that would render interpretation of the results more difficult. Retaining the data in these variables in their untransformed state was thought to be an acceptable tradeoff to ease of interpretation. See Tabachnick and Fidell (2001, pp. 72-77), for further discussion of the assumptions of 
variables and the dependent variable in each regression. Based upon a visual inspection of these scatterplots, there do not appear to be any nonlinear relationships. Where a bivariate pattern between the dependent and independent variables is evident, it appears to be linear. Other scatterplots where patterns are not evident reveal slight

heteroscedasticity but no curvilinearity. Heteroscedasticity problems were not severe enough to warrant a transformation of the relevant variables, and multiple regression and correlation analysis is thought to be a robust enough statistical technique to overcome moderate heteroscedasticity and still render valid results. ${ }^{38}$

Table 3: Univariate statistics for selected variables

\begin{tabular}{|c|c|c|c|c|}
\hline & Mean* & Median & Minimum & Maximum \\
\hline 1990 real GMP (billions) ** & $24.2(4.1)$ & 7.3 & 1.5 & 751.7 \\
\hline 2000 real GMP (billions) & $32.3(5.2)$ & 10.3 & 1.7 & 940.6 \\
\hline 1990 per capita GMP ** & $28,620(5,983)$ & 28,131 & 12,310 & 61,121 \\
\hline 2000 per capita GMP & $34,310(6,684)$ & 34,274 & 16,627 & 59,026 \\
\hline 1990 Gini coefficient & $.4291(.0251)$ & .4278 & .3688 & .5141 \\
\hline 2000 Gini coefficient & $.4429(.0251)$ & .4419 & .3794 & .5179 \\
\hline 1990 total population & $\begin{array}{c}756,468 \\
(1,817,842)\end{array}$ & 260,490 & 56,735 & $19,549,615$ \\
\hline 2000 total population & $\begin{array}{c}861,317 \\
(2,020,748)\end{array}$ & 298,046 & 57,813 & $21,199,865$ \\
\hline 1990 patents per capita & $0.00016(0.00013)$ & 0.00012 & 0 & 0.00086 \\
\hline 1999 patents per capita & $0.00024(0.00028)$ & 0.00016 & 0 & 0.00253 \\
\hline 1989 median hhld. inc. ** & $41,023(6,590)$ & 40,427 & 24,591 & 65,374 \\
\hline 1999 median hhld. inc. ** & $40,860(6,158)$ & 39,897 & 25,699 & 64,109 \\
\hline$\% \Delta$ per capita GMP & $20.4(8.6)$ & 20.8 & -19.5 & 42.1 \\
\hline$\% \Delta$ utility patent per capita & $55.4(98.0)$ & 34.8 & -100.0 & 812.1 \\
\hline$\Delta$ in $\%$ tech. $\&$ prof. jobs & $1.6(0.93)$ & 1.5 & -0.87 & 4.69 \\
\hline$\Delta$ in $\%$ pop. 4-yr. degree + & $2.5(1.1)$ & 2.6 & -0.53 & 6.06 \\
\hline point $\Delta$ Gini coefficient & $0.0138(0.0101)$ & 0.0130 & -0.0167 & 0.0502 \\
\hline$\% \Delta$ median hhld. income & $-0.1(5.3)$ & -0.3 & -14.4 & 16.6 \\
\hline$\Delta$ in $\%$ educ. inequality & $-2.3(1.5)$ & -2.4 & -6.4 & 3.8 \\
\hline point $\Delta$ dissimilarity index & $-0.061(0.054)$ & -0.052 & -0.400 & 0.050 \\
\hline$\% \Delta$ per capita transfer pmt. & $24.4(10.6)$ & 23.8 & -0.8 & 83.3 \\
\hline$\Delta$ in $\%$ black population & $0.50(1.08)$ & 0.31 & -3.45 & 6.38 \\
\hline$\Delta$ in $\%$ female $\mathrm{HOH}$ & $0.35(0.28)$ & 0.33 & -0.40 & 1.33 \\
\hline$\Delta$ in $\%$ population $65+$ & $0.30(0.88)$ & 0.28 & -2.31 & 3.26 \\
\hline$\% \Delta$ total population & $13.3(12.3)$ & 12.0 & -7.4 & 83.3 \\
\hline
\end{tabular}

* standard deviations are in parentheses

** Note: all dollar values are expressed as constant, inflation-adjusted 2000 dollars

univariate normality in regression analysis. See also Berry (1993, pp. 6-12), Gujarati (1995, pp. 101-107), and Kennedy (1997, pp. 42-47). 
Table 3, above, reveals relevant univariate statistics on selected variables including means, standard deviations, medians, and minimum and maximum values.

The mean level of real GMP rose over the decade, as did the mean level of real GMP per capita. It is noteworthy (but not necessarily surprising) that the top five cities with the highest levels of real GMP were the same in 2000 as they were in 1990, and were ranked in the same order at the end of the decade as at the beginning: 1) New York, NY, 2) Los Angeles, CA, 3) Chicago, IL, 4) San Francisco, CA, and 5) Washington, D.C.-Baltimore, MD (all CMSAs). Additionally, three of the five metropolitan areas with the lowest real GMP levels in 1990 were also ranked in the bottom five metropolitan areas in this category in 2000: Enid, OK; Great Falls, MT; and Pine Bluff, AR. (Enid, OK, had the lowest level of real GMP in both Census years.)

A similar pattern appears when we look at the rankings of per capita real GMP from 1990 to 2000. Four of the top five metropolitan areas ranking highest in per capita real GMP in 1990 were also in the top five in this category in 2000: Hartford, CT; Pittsfield, MA; Roanoke, VA; and Springfield, IL. Three of the five lowest ranked cities in per capita real GMP in 1990 were also among the five lowest in 2000: Jacksonville, NC; Las Cruces, NM; and Yuma, AZ. Taken together, this would seem to suggest that while mean economic growth increased over the decade (as measured by either the level of real GMP or per capita real GMP), there were few changes in the rankings of metropolitan areas during that time.

Perhaps the most interesting finding revealed in Table 3 is that while real per capita GMP appears to have increased rather substantially on average from 1990 to 2000 ,

\footnotetext{
${ }^{38}$ For each of the two regression models, a formal Breusch-Pagan-Godfrey test of heteroscedasticity was conducted (see Gujarati, 1995, pp. 377-378). The null hypothesis of homoscedasticity could not be rejected
} 
real median household income remained constant or declined just slightly on average over this period. What specifically explains the deviation between these two similar measures of income is unknown. However, as mentioned earlier in this study, there is a positive bivariate correlation between the percentage change in real per capita GMP from 1990 to 2000 and the percentage change in real median household income from 1989 to 1999 , and the relationship is statistically significant at the 99.9 percent confidence level ( $\mathrm{p}$-value $\leq .001)$. This suggests that these two measures of income (one per capita, the other per household) are capturing similar effects or are measuring roughly similar patterns of output and/or income. Frequency distributions and skewness statistics for these measures indicate that they are both normally distributed with very few outliers or extreme values. We can only conclude that while real per capita output rose, on average, rather substantially over the decade, real median household income appears to have stagnated. This may be so for several reasons.

First, this apparent anomaly may be a function of the way in which these two variables have been computed and/or the specific differences in what they are measuring: median household income versus per capita production output. Second, surges in immigration into U.S. metropolitan areas by low-income Hispanic families over the decade may be responsible for putting downward pressure on median household income. The purported and widely acknowledged increase in low-income Hispanic immigration over the 1990s may have kept real median household income growth down even as output per capita rose over the same period (Brookings Institution, 2001). Finally, the decline in household size may explain the fall in real median household income alongside a rise in real per capita GMP. Census Bureau data show that the mean household size in 
1990 was 2.63 , while dropping to 2.59 in 2000 , a decline of 1.5 percent over the decade. ${ }^{39}$ This decline in the number of members in the household, and thus the number of earners contributing to household income, would tend to reduce median household income over this period even if real individual earnings and/or per capita GMP were rising. At any rate, the finding seems to suggest that, for a variety of possible reasons, the potential labor earnings from per capita output are not reflected in the measure on median household income despite the statistically significant positive correlation found between the two measures.

The percentage change in per capita utility patent approvals as a measure of technological change is positively skewed by some metropolitan areas with a very large jump in utility patents, as suggested by the data in Table 3 (most notably Boise, ID, and Killeen, TX, with 812 percent and 553 percent rates of growth, respectively).

Nonetheless, the data seem to indicate that, on average, the U.S. Patent Office approved more utility patents in 1999 than in 1990 . Theoretically, this may be a result of at least two factors: 1) there were relatively more unique discoveries and inventions in 1999 than in 1990; and/or 2) the U.S. Patent Office became more lenient in granting utility patent approvals over the decade. We have no obvious evidence that the U.S. Patent Office made significant changes to the way in which it awarded utility patent grants from 1990 to 1999 (Nunn and Worgan, 2002; Worgan and Nunn, 2002), so we can reasonably conclude that technological progress or some other exogenous factor led to an increase in metropolitan innovations and discoveries from 1990 to 1999 (see also Wessel, 2003).

Other findings in Table 3 generally reveal expected trends and patterns in the data. Household income inequality as measured by the Gini coefficient rose modestly

\footnotetext{
${ }^{39}$ Data from U.S. Census Bureau Census 1990 Summary File 3 and Census 2000 Summary File 3.
} 
over the decade as suggested by other research (Ryscavage, 1999). A detailed investigation of the data on inequality reveals no distinct pattern of the metropolitan areas with either the highest or the lowest changes in the Gini coefficient. The two metropolitan areas with the highest Gini coefficient in 1990, Bryan, TX, and Naples, FL, are also ranked first and second, accordingly, in 2000. However, beyond this similarity in the Gini coefficient rankings, no other obvious trends or patterns appear.

Metropolitan population increased strongly over the decade but at rates that we would expect (Glaeser and Shapiro, 2001), reflecting the continuing trends toward urbanization and suburbanization and away from rural life. Again, as discovered for other variables, there does not appear to have been a noticeable degree of change in the rankings over the decade. The five metropolitan areas with the highest population levels were the same in 1990 and 2000, and were ranked in the same sequence: 1) New York, NY, 2) Los Angeles, CA, 3) Chicago, IL, 4) Washington, D.C.-Baltimore, MD, and 5) San Francisco, CA. Likewise, at the other end of the spectrum, the bottom five metropolitan areas with the lowest levels of population were the same in 2000 as in 1990: Casper, WY; Cheyenne, WY; Enid, OK; Great Falls, WY; and Victoria, TX.

The number of metropolitan professional- or technology-related jobs and the number of people with a higher education also increased over the decade, reflecting gains in human capital and the rise in skilled occupational positions in the metropolitan labor force. The metropolitan areas that exhibited the largest increases in the proportion of skilled labor and education categories over the decade were found almost exclusively in the Midwest, South and East, including cities such as Lawrence, KS, BloomingtonNormal, IL, Wausau, WI, Wilmington, NC, Portland, ME, and Burlington, VT. 
As life spans continue to increase, we would expect to find an increase in the elderly population aged 65 and above. And, as the population becomes more diverse, we would also expect to see an increase in African-American population levels. Both of these expectations are confirmed in Table 3. Additionally, as the African-American population in metropolitan areas has increased, we observe a moderate decline in blacknonblack housing segregation, on average, as reflected in the drop in the dissimilarity index. This further confirms the work of Glaeser and Vigdor (2001) who also find an overall drop in dissimilarity indexes across a large majority of metropolitan areas. The metropolitan areas with the largest increases in the dissimilarity index (and by extension the largest increase in racial housing segregation) are found in the Southeast and Northeast: Biloxi, MS, Cumberland, MD, Hickory, NC, Jacksonville, NC, and New London-Norwich, CT-RI. The metropolitan areas with the largest declines in the dissimilarity index over the decade are located primarily in the Southwest and West: Brownsville, TX, Great Falls, MT, Laredo, TX, and Provo-Orem, UT. This also confirms the research by Glaeser and Vigdor who find relatively higher dissimilarity indexes in older eastern cities, and relatively lower dissimilarity indexes in younger western cities.

Educational inequality (the proportion of the metropolitan population with either a graduate degree or less than a high school diploma or equivalent) appears to have declined somewhat, on average, over the decade, perhaps owing to fewer individuals in the bottom of the educational distribution with less than a high school education. Indeed, the median number of individuals per MSA/CMSA with less than a high school diploma declined by 10.4 percent from 1990 to 2000 , even as the median number of individuals 
per MSA/CMSA with a graduate degree increased by 41.3 percent. Because the former category is a much larger segment of MSA/CMSA population than the latter category, its drop had a greater impact on the overall distribution of education, thus explaining the convergence we see in education levels in Table 3.

\section{Effects of Technological Change on Per Capita Economic Growth}

Table 4 summarizes the findings on the relationship between each independent variable in Equation 4 and the growth rate of real per capita GMP from 1990 to 2000, including partial coefficients with their standard errors, t-values, significance levels and $R^{2}$ coefficient of determination. An analysis of the findings follows the table.

Table 4: Summary of regression coefficients estimating real per capita GMP growth rates, 1990-2000 (standard errors are in parentheses, $t$-values in brackets)

\begin{tabular}{lcc}
\hline & Model 1 & Model 2 \\
\hline y-intercept (constant) & 16.434 & 18.307 \\
$\% \Delta$ per capita utility patent approvals $1990-2000$ & .006 & $.012^{* *}$ \\
& $(.005)$ & $(.005)$ \\
& {$[1.198]$} & {$[2.203]$} \\
$\Delta$ in proportion of population in prof. / mgmt. / & $5.362^{* * *}$ & \\
tech. jobs $1990-2000$ & $(.652)$ & \\
& {$[8.225]$} & $1.054^{* *}$ \\
$\Delta$ in proportion of population with a 4-yr. degree & $-1.732^{* * *}$ & $.482)$ \\
or more 1990-2000 & $(.547)$ & {$[2.188]$} \\
& {$[-3.169]$} & $-.093^{* *}$ \\
$\% \Delta$ total population $1990-2000$ & -.023 & $(.043)$ \\
& $(.039)$ & {$[-2.144]$} \\
$F$ & {$[-.589]$} & 4.302 \\
$R^{2}$ & 20.980 & .048 \\
adjusted $R^{2}$ & .248 & .037 \\
$n$ & .236 & 260 \\
\hline$* * *$ significance level $\mathrm{p}<.01$ & 260 & \\
$* *$ significance level $\mathrm{p}<.05$ & & \\
$*$ significance level $\mathrm{p}<.10$ & &
\end{tabular}

Model 1 is the complete model including all four independent variables. Model 2 removes the secondary measure of technological change measuring the change in the proportion of professional-, managerial- and technological-sector occupations since this 
variable appears to be so strong that it masks (or distorts) the independent effects of the other three variables in Model 1.

Clearly, Model 1 is the strongest of the two models. As indicated by the coefficient of determination, changes in the combination of the four independent variables in this model explain roughly one quarter of the variation in real per capita GMP growth from 1990 to 2000 . Additionally, the secondary measure of technological change (the change in the proportion of the population in professional- or technologysector jobs) is clearly the strongest and most statistically significant predictor of real per capita GMP, and the sign on the coefficient is in the expected positive direction. The coefficient on this variable indicates that a one percentage point increase in the proportion of the metropolitan population employed in professional-, managerial- or technology-sector jobs raises real per capita GMP by more than five percent over the decade. We can therefore reject the null hypothesis that no relationship exists, and assert that there is a statistically significant positive association between the growth rate in the proportion of the metropolitan population in high-skilled occupations and the growth rate in real per capita metropolitan economic output.

Florida (2004) argues that growing cities are marked by an increasing contingent of professionals who generate new technologies and new ideas through networks of creativity within an urban economy. He suggests that this "creative class" of workers, instilled with a high level of diversity, individuality, intelligence, education, drive, and creativity, are one of the primary forces behind why some urban and regional economies experience rapid development and economic growth. The results found in Table 4 can be interpreted as a (tentative) confirmation of this theory if we accept that the variable 
measuring proportionate changes in technical and professional occupations captures some of this "creative class," which is plausible.

Models 1 and 2 in Table 4 reveal two unexpected findings and one apparent anomaly. First, the primary variable measuring technological change (the growth rate in per capita utility patent approvals) is only weakly related to real per capita economic growth in the expected positive direction. Second, population growth is found to be significantly and negatively correlated with the growth rate in real per capita output in Model 2, opposite the expected positive relationship. And, finally, the sign on the coefficient of the variable measuring the growth rate in the proportion of the population with a four-year degree nr more changes from negative (unexpected) to positive (expected) between the two models, but remains statistically significant in both. In Model 1, the coefficient on the educational attainment variable indicates that a one percentage point increase in the proportion of the metropolitan population with a fouryear degree or above is significantly correlated with a 1.7 percent drop in real per capita GMP. Yet, in Model 2, with the secondary measure of technological change omitted, the coefficient on the educational attainment variable indicates that a one percentage point increase in the proportion of the metropolitan population with a four-year degree or above is significantly correlated with a one percent increase in real per capita GMP. These findings are discussed in more detail below.

Table 4 indicates that the primary variable measuring technological change (the percentage change in per capita utility patent approvals per MSA/CMSA, 1990 to 1999) is, at best, weakly related to the metropolitan growth rate in real per capita output in the expected (positive) direction. Even then, the correlation is significant only under 
conditions where the measure on occupational change is omitted in Model 2. And, Model 2 is relatively weak with a coefficient of determination of just .04 , indicating that changes in the three independent variables retained in this model explain less than five percent of the variation in metropolitan per capita economic output, even though each of the three independent variables are statistically significant. The coefficient on the patent per capita measure of technological change indicates that a one percentage point increase in per capita utility patent approvals is correlated with only a .01 percent increase in real per capita GMP from 1990 to 2000; not a large impact. Patent data thus appear to be a weak predictor of economic growth in metropolitan areas, at least over the time period investigated here. This is an important finding. This weak or negligible association between patent data and economic growth may result for several reasons.

First, while utility patent grants may be a good indicator of inventiveness or entrepreneurship in urban areas (Higgs, 1971), or may give good indications of metropolitan technological spillovers in close geographic proximity (Carlino, 2001; Higgs, 1971; Jaffe, Trajtenberg \& Henderson, 1993), they may simply be a poor predictor of economic growth. As a measure of technological change, utility patent data apparently do not correlate well with real per capita output in metropolitan areas. This does not imply that the findings presented here are in contradiction to the uses of patent data as measures of inventiveness or technological spillovers in the previous research cited above. Patent data may measure variations in these concepts quite well, yet fail to perform well as a predictor of economic growth. Not all inventive activities necessarily create economic growth (Griliches, 1990). 
Second, utility patents approved at a given geographic location may not have any growth-inducing impact at that location. This is consistent with one of the major critiques of the use of patent data by Griliches (1990). The growth impacts of the inventions linked to utility patent approvals, if there are any, might be felt at an entirely different geographic location. The metropolitan area to which the utility patent approval is assigned may not benefit economically from the invention to which the patent is linked, particularly if the patented invention is more productive or useful in an industry that is unrelated to the industry to which the original patent was granted. The industry that generates the patented invention may not be the industry that uses the patented invention. If so, then the patented invention may generate no observable economic benefits for the geographic location to which the utility patent was originally granted or assigned. There may be a disconnect between the industry and location where the patent was originally granted and the industry and location where the patented invention is actually used, making it difficult to trace the economic benefits from patented inventions using only geographically-based per capita utility patent approval rates.

Jaffe, Trajtenberg and Henderson (1993) attempt to trace the effects of patents geographically to understand how patent approvals in one period and in one location affect patent approvals in a later period at that same location. These authors find that later patents tend to emanate from geographic locations that are in close proximity to the previous patents they cite (or to which they are linked in terms of their inventive genealogy), suggesting self-reinforcing inventiveness due to localized technological spillovers. However, this says nothing about the impact of successive patents on the level or rate of growth in economic output at those geographic locations. One can easily 
hypothesize two distinct metropolitan economies in different locations. One economy engages in large amounts of $\mathrm{R} \& \mathrm{D}$ and generates many new patented inventions. Perhaps a research university is located within its boundaries or it is characterized as an incubator economy or "nursery city" (Duranton \& Puga, 2001). The other metropolitan area simply imports the inventions and ideas generated by the first, putting them to use increasing productivity and the output of goods and services. Indeed, Duranton and Puga argue that many cities can be characterized by one of the two alternatives suggested in this scenario, depending upon the stage of product life cycles. In this scenario, it is reasonable to assume that measures of economic growth such as the growth rate in per capita GMP would register stronger output growth in the second economy than in the first. Perhaps it is for this reason that the findings in Table 4 do not reveal a strong relationship between per capita patent approval rates and the rate of per capita economic growth in metropolitan economies over the 1990s.

Finally, as Griliches (1990) also points out, there is much inventive activity that is not patented due to concerns over trade secrecy and innovation concealment between rivals. Perhaps inventive activity that is not patented (and thus concealed) has a much greater impact on economic output in a given geographic location than do the patented inventions in these same locations. If so, this would further explain the weak association between utility patent approvals and per capita economic growth in metropolitan economies that we find here.

As discussed above, the second variable measuring technological change (the change in the proportion of professional-, managerial-, and technology-sector occupations per MSA/CMSA, 1990 to 2000) is positively and significantly related to the 
growth rate in real per capita output, as expected, and has a much stronger influence than the growth rate in utility patent approvals. The occupational change variable may simply do a better job of capturing the concept of technological change than the patent data variable. In fact, as indicated in a comparison of Model 1 and Model 2, the strength and significance of this variable eliminates any relationship between the growth rates in per capita utility patent approvals and real per capita GMP. When controlling for the change in the proportion of the population with a professional-, managerial-, or technologyrelated occupation from 1990 to 2000 , the percentage change in per capita utility patent approvals fails to be significantly correlated with the growth rate in per capita GMP. The apparent relationship between real per capita GMP growth rates and the first measure of technological change (per capita utility patent approvals) found in Model 2 is likely a result of omitted variable bias: it disappears once we control for the effects of skilled occupational change.

This stronger association between the occupational measure of technological change and per capita economic growth may result for several reasons. First, metropolitan labor market composition is itself a function of GMP given the methodology used by the BEA in computing GMP (see above explanation). If GMP is derived from GSP (gross state product) and assigned back to metropolitan areas based upon the proportion of metropolitan workers in distinct industrial categories, then changes in GMP should be logically related to changes in labor market composition. Thus, it is not surprising to find a correlation.

Further, labor market measures are geographically fixed and thus not separable from their metropolitan location. Where patented inventions in one area can be easily 
drawn into use at another location, labor market occupational change is fixed to the geographic area by which it is defined. Thus, it should be expected to relate to changes in economic growth in that metropolitan area.

The second unexpected finding in Table 4 pertains to the effects of population growth on per capita output. As revealed in Model 2, while the patent and education measures exhibit the expected positive sign on the coefficient, the population growth rate variable is negatively correlated with real per capita GMP growth, a somewhat unexpected finding. Model 2 suggests that when controlling for the effects of per capita utility patent growth rates and proportionate changes in educational attainment, a one percent increase in population growth leads to a .09 percent decline in the growth rate of real per capita GMP from 1990 to 2000 . While this is not a large effect, it is statistically significant, and the direction of the relationship is intriguing.

One explanation for the negative relationship found between growth rates in population and real per capita economic output may be congestion externalities and/or a deficiency in the rate of growth in public infrastructure in metropolitan areas experiencing relatively higher population growth. That is, metropolitan areas with high rates of population growth from 1990 to 2000 may have experienced congestion externalities and other spillover costs associated with rapid growth that, in turn, slowed the rate of growth in real per capita output. If this explains the negative relationship between per capita output and population growth, it would question conclusions reached in previous research on the relationship between city size, city growth, and income and productivity (Hoch, 1972, and Sveikauskas, 1975). 
A second and equally plausible explanation is simply that population growth rates exceeded the growth rates in real GMP over this period. Because real GMP per capita depends not only upon the level of real GMP in its determination, but also upon population levels, metropolitan areas where decennial population grew rapidly would have had greater difficulty increasing real per capita GMP; even if the overall level of real economic output was rising, the denominator was simply rising faster than the numerator in the GMP-to-population ratio.

However, this theory is difficult to rectify with the univariate findings in Table 3 where both the mean and median growth rate in real per capita GMP outpaced the mean and median growth rate in metropolitan population over the decade. As Table 3 indicates, the median growth rate in real per capita GMP from 1990 to 2000 was 20.8 percent while the median metropolitan population growth rate was 12 percent. The negative relationship between population growth rates and real per capita GMP growth rates in Table 4 cannot be reconciled simply by reference to "the denominator rising faster than the numerator in the GMP-to-population ratio." Indeed, further investigation of the data reveals that conditions were just the opposite. Median real GMP in 1990 was approximately $\$ 7.3$ billion (in constant 2000 dollars), and median real GMP in 2000 was $\$ 10.5$ billion, a rate of increase in the median level of real GMP equal to 43.8 percent. On the other hand, the median population level in 1990 stood at 260,490, and the median population level by 2000 had risen only 14.4 percent to 298,046 .

Clearly, then, real economic output rose, on average, by a larger magnitude than population levels over the decade, meaning that the negative relationship found between population growth rates and per capita output growth rates is not a function of population 
levels rising faster than real output levels. Something else is going on, and explaining the inverse relationship between population growth rates and per capita economic output growth rates found here provides fertile ground for future research. One place to begin would be the theory suggested above: fast-growing metropolitan populations may experience slower per capita economic growth due to congestion externalities and/or an insufficient growth rate in public goods and public infrastructure necessary to support rapid population growth. In either case, we can reject the null hypothesis that there is no correlation between population growth rates and the growth rate in real per capita GMP.

Finally, the apparent anomaly in Table 4 is the change in the sign on the coefficient for the measure of growth in educational attainment between Model 1 and Model 2. The dominant influence of the professional- and technology-sector job change variable in Model 1, combined with the unexpected negative sign on the educational attainment variable, led to the subsequent regression omitting the occupational change variable, the results of which are shown in Model 2. Interestingly, when utility patents per capita and population growth rates are held constant in Model 2, the change in the proportion of the population with a four-year degree or more becomes positively and significantly related to per capita GMP, just as human capital theory would predict (i.e., an increase in overall education level should raise labor productivity and thus per capita economic growth). A one percentage point increase in the proportion of the metropolitan population with a four-year degree or more is significantly associated with a roughly one percent increase in the growth rate of real per capita GMP, significant at the 95 percent confidence level. When the occupational change variable is omitted, the change in the proportion of the population with higher educational attainment switches from being 
negatively and significantly correlated to per capita output in Model 1 to positively and significantly related to per capita output in Model 2, as we would expect. This is somewhat surprising, but may be a result of nothing more than the relatively high statistical collinearity between these two independent variables in Model 1. The change in the proportion of the population in professional- or technology-sector jobs and the change in the proportion of the population with a four-year degree or more were found to exhibit relatively high positive collinearity. The Pearson's $r$ coefficient of correlation between these two variables is .604 , and the correlation is positive and statistically significant at the 99.9 percent confidence level $(p<.001)$. The dominance of the occupational change variahle in the model may cause the sign on the educational attainment variable to become negative in Model $1 .^{40}$

Based upon Table 4, we can make the following tentative conclusions regarding the relationship between educational attainment and per capita economic growth: The change in the proportion of the metropolitan population with a four-year degree or more from 1990 to 2000 (employed as a measure of human capital development) is statistically significantly related to real per capita GMP growth rates, but the relationship is

\footnotetext{
${ }^{40}$ This discovery suggests a possible interaction between changes in the proportion of metropolitan professional-, managerial- and technology-sector occupations and changes in the proportion of metropolitan educational attainment. That is, professional- and technology-sector occupational changes may play an indirect role in determining the influence of educational attainment on real per capita GMP growth rates. If so, there may be an interaction between the proportionate change in professional and technology jobs per MSA and the proportionate change in the MSA population with a bachelor's degree or more, such that the change in educational attainment exhibits a greater or lesser impact on real per capita GMP growth rates conditional on the proportionate rise or fall in technology-sector occupations. This theory was tested by creating a continuous-by-continuous interaction term to determine the level of influence that the educational attainment growth rate exerts upon real per capita GMP at various levels of professional-, managerial- and technology-sector occupational change. The interaction term was found to be statistically significant but with a negative sign, further confounding any plausible interpretation of the effects of growth in educational attainment on per capita economic growth rates. The most appealing conclusion, therefore, is that growth in educational attainment has a small positive impact on economic growth that can only be observed when the occupational change variable is excluded from the model due to collinearity concerns.
} 
contingent on changes in the proportion of the population in professional-, managerial- or technology-intensive jobs. We can therefore reject the null hypothesis that there is a zero correlation between growth in the proportion of the metropolitan labor force with a higher education and per capita economic growth rates. Yet, the correlation found in Model 1 is at odds with expectations, and likely a result of statistical collinearity between educational change and skilled occupational change. The (minor) positive effect of changes in educational attainment on real per capita GMP, then, is perhaps best indicated by Model 2.

\section{The Question of Endogeneity: Per Capita Growth and Household Inequality}

As mentioned in the literature review above, some researchers have suggested that economic growth is endogenous in a model of income inequality. Moreover, it has also been suggested that a more plausible direction of causation would run from inequality to economic growth, rather than from economic growth to inequality, as posited by the Kuznets Hypothesis. To repeat this theory briefly, the most popular argument is based upon the median voter theory of income distribution applied primarily to developing economies. If the income distribution is positively skewed and income inequality is relatively high, then the median voter is likely to be found in the lower half of the income distribution and will tend to vote for growth-retarding transfer payments paid for by taxes on capital investment. On the other hand, if the income distribution is less positively skewed or normally distributed, income inequality would tend to be relatively low. In this scenario, the median voter would be more likely to be in the upper half of the income distribution, and thus less likely to vote for growth-retarding taxation of capital investment. The conclusions of this research, then, suggest that (developing) economies 
with relatively low inequality in period $t$ will exhibit relatively higher levels of economic growth in subsequent time period $t+1$, while economies with higher inequality in the earlier period will see slower or negative growth in the subsequent period (see especially Allesina \& Rodrik, 1994, and Persson \& Tabellini, 1994).

To test this theory on (developed) U.S. metropolitan economies and to ensure that the growth-to-inequality causal relationship assumption of the Kuznets Hypothesis is correct (since it is this assumption on which the present analysis rests), the endogeneity of metropolitan household income inequality and metropolitan economic growth was tested using Hausman's specification test for simultaneity (see Gujarati, 1995, and Hausman, 1976). This test fits with the methodology used in the present analysis, and is the basis for the two-stage standard least-squares technique used here. ${ }^{41}$

The predicted values of the growth rate in per capita real GMP and the residuals from the first-stage regression (Equation 2)

$$
\psi=\alpha_{0}+\alpha_{1} \tau+\alpha_{2} \sigma+\alpha_{3} \gamma+\varepsilon
$$

were saved and inserted into the second-stage regression estimating the change in household income inequality (Equation 3).

$$
\phi=\theta_{0}+\theta_{1} \psi+\theta_{2} \lambda+v
$$

\footnotetext{
${ }^{41}$ For a two-stage least-squares regression, the Hausman specification test tests the endogeneity between the dependent variable in the first-stage regression and the dependent variable in the second-stage regression when the dependent variable in the first-stage equation will be used as a predictor in the secondstage equation. The residual and the predicted values of the dependent variable from the first-stage equation are inserted into the second-stage equation, and the second-stage regression is run. If the residual from the first-stage regression is found to be a statistically significant predictor of the dependent variable in the second-stage equation, then the null hypothesis that there is no endogeneity must be rejected. That is, if the residual from the first-stage regression is statistically significant, then the residual and the actual values of the dependent variable from the first-stage equation are endogenous with the dependent variable in the second-stage equation, and two-way causality is possible. If this is the case, then the predicted value of the dependent variable (as opposed to the actual values) from the first-stage equation must be employed as predictors in estimating the dependent variable in the second-stage regression. On the other hand, if the first-stage residual is not found to be statistically significant in the second-stage regression, then the null
} 
Equation 6 is a modified version of Equation 3 which includes the predicted value of the per capita real GMP growth rate $(\hat{\psi})$ and the residual $(\chi)$ from the first-stage regression of Equation $2:^{42}$

$$
\phi=\theta_{0}+\theta_{l} \hat{\psi}+\theta_{2} \chi+\theta_{3} \lambda+v
$$

Table 5, below, summarizes the results of the regression on Equation 6 including partial unstandardized coefficients with their standard errors, t-values, significance levels and $R^{2}$ coefficient of determination:

hypothesis of no endogeneity can be accepted, and the actual values of the dependent variable from the first-stage equation may be used to estimate the dependent variable in the second-stage regression.

${ }^{42}$ In the methodology description, above, the 1990-to-2000 metropolitan population growth rate is listed as a predictor variable in both the first-stage and second-stage regression equations. Its use as a predictor of per capita real GMP growth rates in the first-stage model could result in specification errors when also included in the second-stage model testing for simultaneity, because the predicted value of the per capita real GMP growth rate is itself included as an estimator of the change in metropolitan household income inequality. Thus, to avoid potential specification errors in the Hausman's simultaneity test, the metropolitan population growth rate variable was excluded. As discussed below, the results for the Hausman test show no endogeneity or simultaneity problems between per capita real GMP growth rates and changes in metropolitan household income inequality, permitting the re-insertion of the population growth rate variable into the full second-stage model (because the actual values, rather than the predicted values, of per capita real GMP growth rates will be used as a predictor in the second-stage estimating equation). 
Table 5: Summary of regression coefficients from Hausman's test of simultaneity between per capita real GMP growth rates and changes in metropolitan household income inequality (standard errors are in parentheses, $t$-values in brackets)

\begin{tabular}{|c|c|}
\hline & Model 3 \\
\hline \multirow{4}{*}{$\begin{array}{l}\text { y-intercept (constant) } \\
\text { predicted value of per capita real GMP growth rate 1990-2000 from } \\
\text { first-stage regression }\end{array}$} & .0251 \\
\hline & $-.0005 * * *$ \\
\hline & $(.000)$ \\
\hline & {$[-2.903]$} \\
\hline \multirow{3}{*}{$\begin{array}{l}\text { residual of per capita real GMP growth rate 1990-2000 from first-stage } \\
\text { regression }\end{array}$} & -.0001 \\
\hline & $(.000)$ \\
\hline & {$[-.657]$} \\
\hline \multirow{3}{*}{ proportionate $\Delta$ in educational inequality $1990-2000$} & .0005 \\
\hline & $(.000)$ \\
\hline & {$[1.225]$} \\
\hline \multirow[t]{3}{*}{ point change in dissimilarity index $1990-2000$} & $.0311^{* *}$ \\
\hline & $(.012)$ \\
\hline & {$[2.522]$} \\
\hline \multirow[t]{3}{*}{$\% \Delta$ in per capita total real transfer payments $1990-2000$} & .0001 \\
\hline & $(.000)$ \\
\hline & [.615] \\
\hline \multirow[t]{3}{*}{$\Delta$ in proportion of black population (including Hispanic) $1990-2000$} & -.0001 \\
\hline & $(.001)$ \\
\hline & {$[-.183]$} \\
\hline \multirow[t]{3}{*}{$\Delta$ in ratio of female heads-of-household to population $1990-2000$} & .0013 \\
\hline & $(.003)$ \\
\hline & [.441] \\
\hline \multirow[t]{3}{*}{$\Delta$ in proportion of elderly population age $65+1990-2000$} & .0011 \\
\hline & $(.001)$ \\
\hline & {$[1.231]$} \\
\hline \multirow{3}{*}{ dummy for South census region } & -.0023 \\
\hline & $(.002)$ \\
\hline & {$[-1.516]$} \\
\hline$F$ & 3.776 \\
\hline$R^{2}$ & .120 \\
\hline adjusted $R^{2}$ & .088 \\
\hline$n$ & 260 \\
\hline
\end{tabular}

As Table 5 reveals, the coefficient on the residual of per capita real GMP growth from the first-stage regression is not significant, allowing us to accept the null hypothesis that no endogeneity or simultaneity exists between the predicted or actual values of per capita real GMP growth and metropolitan household income inequality. That is, the changes in household income inequality are uncorrelated with the error term in the firststage equation, ruling out the possibility of simultaneity between changes in metropolitan household income inequality and changes in per capita real GMP from 1990 to 2000 . We can tentatively conclude, then, that endogeneity between economic growth and changes 
in income inequality is not evident in U.S. metropolitan economies, and that the direction of causation between the two variables may be assumed to run from growth to inequality in this data. This permits us to reject the inequality-to-growth direction of causation suggested by the median voter theory, at least for U.S. metropolitan economies in the 1990s. ${ }^{43}$ This finding also allows us to proceed with the test of the relationship between growth and inequality assumed in the extended or reformulated Kuznets Curve Hypothesis: at different stages of economic development and growth, economic growth may exert a different causal influence on income inequality.

\section{Effects of Per Capita Growth on Changes in Household Income Inequality}

Table 6 summarizes the findings for the second-stage regression on Equation 5 estimating the effect of changes in economic growth on changes in household income inequality from 1990 to 2000 in metropolitan areas, including partial unstandardized coefficients with their standard errors, t-values, significance levels and $R^{2}$ coefficient of determination. Model 4 is the full second-stage regression model including all predictors. Model 5 repeats the second-stage regression but without the inclusion of the unrelated predictor variables in Model 4. A discussion of the results follows the table.

\footnotetext{
${ }^{43}$ This is consistent with the findings by Forbes (2000) and Partridge (1997). See also Block (2000).
} 
Table 6: Summary of regression coefficients estimating changes in the metropolitan household Gini index, 1990-2000 (standard errors are in parentheses, $t$-values in brackets)

\begin{tabular}{|c|c|c|}
\hline & Model 4 & Model 5 \\
\hline$y$-intercept (constant) & .0236 & .0244 \\
\hline \multirow[t]{3}{*}{$\% \Delta$ actual per capita real GMP $1990-2000$} & $-.0002^{* *}$ & $-.0002 * *$ \\
\hline & $(.000)$ & $(.000)$ \\
\hline & {$[-2.087]$} & {$[-2.395]$} \\
\hline \multirow[t]{3}{*}{ proportionate $\Delta$ in educational inequality $1990-2000$} & $.0014^{* * *}$ & $.0014 * * *$ \\
\hline & $(.000)$ & $(.000)$ \\
\hline & [2.754] & [3.218] \\
\hline \multirow[t]{3}{*}{ point change in dissimilarity index $1990-2000$} & $.0245^{*}$ & $.0272^{* *}$ \\
\hline & $(.013)$ & $(.012)$ \\
\hline & [1.951] & {$[2.302]$} \\
\hline \multirow[t]{3}{*}{$\% \Delta$ in per capita total real transfer payments $1990-2000$} & -.0001 & \\
\hline & $(.000)$ & \\
\hline & {$[-.430]$} & \\
\hline \multirow{3}{*}{$\Delta$ in proportion of black population $1990-2000$} & -.0004 & \\
\hline & $(.001)$ & \\
\hline & {$[-.628]$} & \\
\hline \multirow[t]{3}{*}{$\Delta$ in ratio of female heads-of-household to population $1990-2000$} & .0016 & \\
\hline & $(.003)$ & \\
\hline & {$[.571]$} & \\
\hline \multirow[t]{3}{*}{$\Delta$ in proportion of elderly population age $65+1990-2000$} & .0012 & \\
\hline & $(.001)$ & \\
\hline & {$[1.367]$} & \\
\hline \multirow[t]{3}{*}{ dummy for South census region } & .0010 & \\
\hline & $(.002)$ & \\
\hline & [.605] & \\
\hline \multirow[t]{3}{*}{$\%$ population growth rate $1990-2000$} & $-.0002 * * *$ & $-.0002 * * *$ \\
\hline & $(.000)$ & $(.000)$ \\
\hline & {$[-2.661]$} & {$[-3.312]$} \\
\hline$F$ & 4.019 & 8.164 \\
\hline$R^{2}$ & .126 & .114 \\
\hline adjusted $R^{2}$ & .095 & .100 \\
\hline$n$ & 260 & 260 \\
\hline
\end{tabular}

The most important result in Table 6 is the coefficient revealing the association between the growth rate of real per capita GMP and the point change in the household Gini index. While the relationship between changes in real per capita economic growth and household income inequality is found to be statistically significant at the 95 percent confidence level $(\mathrm{p} \leq .05)$, the negative sign on the coefficient is opposite expectations. The results summarized in Table 6 indicate that a one percent increase in real per capita GMP from 1990 to 2000 leads to a decline in the Gini index measure of household income inequality of roughly .0002 points over this same time period. In other words, 
ceteris paribus, an increase in real per capita economic growth at the metropolitan level leads to a modest decline in household income inequality, which contradicts the theory that growth and inequality are positively correlated due to technological and structural changes in post-industrial economies. On the contrary, the data used here suggest that real economic growth is significantly but negatively correlated with household income inequality in metropolitan economies over the 1990s, supporting similar findings by Wheeler (2004) for the 1970 to 1990 period. We can reject the null hypothesis that there is no correlation between changes in real per capita economic growth and changes in household inequality, but conclude that this correlation is contrary to the expected finding. This, in turn, forces us to reject the two separate but inter-linked theories on the growth-inequality relationship stemming from the literature.

First, the findings from this data force us to reject the hypothesis that income inequality and economic growth are positively correlated through SBTC. This is not to suggest that SBTC does not play a role in raising the wage dispersion or household income inequality. However, to the extent that new technology is skill-biased on the wage or household income structure, it apparently has its effect apart from economic growth. The association between the measures of technological change and economic growth found in the first-stage regression in Table 4, combined with the findings on the second-stage regression presented in Table 6, suggest 1) that SBTC has no impact on income inequality through economic growth, or 2) that the variables we have chosen to operationalize these concepts fail to adequately measure the relationship. If it is the latter, then the variables used to measure technological change in the present study may be invalid. If, on the other hand, they are valid, the technological change they reflect may 
not be skill-biased (i.e., perhaps patented inventions or changes in labor market composition reflect technological change that is, on balance, skill-neutral rather than skill-biased). Further, even if the measures of technological change are both valid and skill-biased, their impact on economic growth may be so weak as to be unable to indirectly impact income inequality. At the very least, the findings in Table 4, Model 2, suggest this. In any case, we simply cannot substantiate the theory that SBTC explains rising inequality by observing a positive association between economic growth and income inequality; such an association does not exist as evidenced by the findings presented here. ${ }^{44}$

Second, the theory of an extended or reformulated Kuznets Curve Hypothesis related to the growth-inequality relationship also cannot be supported by the evidence presented here, and is thus also weakened. To the extent that a growth-inequality relationship exists, the data used here support the original Kuznets Hypothesis that rising economic growth leads to a reduction in income inequality, controlling for other factors, as suggested by the negative sign on the real per capita GMP coefficient in Table 6. The measures used in the present research fail to find any evidence of a Kuznets Curve indicating a $U$-shaped or positive association between growth and inequality during periods of economic structural shifts or post-industrial (skill-biased) technological

\footnotetext{
${ }^{44}$ In fact, the implications for the SBTC theory of rising income inequality go beyond the findings summarized in Table 6 . The design of the present research study was to detect the indirect effect, if any, of skill-biased technological change on rising income inequality through changes in economic growth. In the method employed here, support for this theory cannot be established. In addition, in results summarized in Appendix A, Table 7, a standard OLS multivariate regression testing the direct effect between the two measures of technological change and income inequality reveals no association between these two measures of technological change and changes in income inequality. When controlling for the effect of decennial changes in real per capita GMP, neither the growth rate in per capita patent approvals nor the change in skilled and technical occupational composition register a significant association with changes in household inequality. These findings further weaken support for the SBTC explanation for rising
} 
change. Apparently, economic growth reduces household inequality not only during the middle and later stages of industrialization, say, during the 1940s and 1950s in the United States, but continues to put downward pressure on household inequality even when a mature industrial economy begins a structural shift toward a post-industrial economic base. This finding bolsters support for the original Kuznets Curve theory and forces us to caution theoretical and empirical research arguing against it. What is surprising is the fact that this relationship prevails even in an advanced economy like the United States, at least at the metropolitan area level. While Galbraith and Kum (2002) find general confirmation of the original Kuznets process, even they suggest that the growthinequality relationship may reverse itself in the richest countries, with a turning point at some high level of income or per capita growth. The findings presented here appear to indicate otherwise (or at least suggest that U.S. metropolitan economies have not reached this turning point yet), although the relatively weak association between growth and inequality force us to interpret these findings with caution.

Most of the previous growth-inequality research uses cross-sectional data at a point-in-time to test the relationship between the level of real median household income (an alternative measure of economic growth) and the level of household income inequality. This is slightly different from the present study using cross-sectional data over a period-of-time (1990 to 2000) to test the relationship between changes in household income inequality and changes in real per capita GMP. Nonetheless, the findings are similar, indicating that real per capita economic growth explains variations in household income inequality, and, at least in metropolitan areas during the 1990s, this

inequality, with the caveat that we assume these two measures of technological change are valid and skillbiased rather than skill-neutral. 
association is negative. The most apparent explanation for this negative association is that rising real per capita output may reflect increases in real income for the households that make up the lowest end of the income distribution. As the lowest household incomes rise, and provided they rise more rapidly than households in the upper end of the distribution and/or comprise a larger proportion of the distribution, the overall household income distribution becomes less dispersed and thus less unequal. This is a somewhat counterintuitive finding given the fact that overall inequality during the 1990s appears to have increased, as indicated by the Gini coefficient comparisons in Table 3. However, the independent effect of real per capita economic growth may restrain the rise in household income inequality even as other factors work to increase it. This conclusion is much more plausible when we consider the low $R^{2}$ on Model 4 in Table 6 . The variables in this model, including the rate of economic growth, explain less than 13 percent of the variation in household income inequality. Clearly, economic growth may mildly reduce the rise in inequality while some other omitted variable(s) has (have) a much larger counteracting effect.

Additionally, the coefficient on the MSA/CMSA population growth rate reveals a significant and negative correlation with the point change in the Gini index of household income inequality from 1990 to 2000, again confirming Kuznets' (1955) original theory that advanced-stage urbanization would tend to reduce income inequality (if we permit metropolitan population growth to approximate the concept of "urbanization"). When controlling for other factors, Model 4 indicates that a one percentage point increase in metropolitan population growth from 1990 to 2000 is associated with a .0002 point decline in the Gini index measure of household inequality, and this correlation is 
statistically significant at the 99 percent confidence level $(\mathrm{p} \leq .01)$. Population growth, then, appears to (mildly) reduce or suppress changes in household income inequality in metropolitan areas, at least during the $1990 \mathrm{~s}$.

This finding is distinct from previous studies on the metropolitan populationinequality relationship since the genesis of this line of research began during the 1970 s. Most of the previous research exploring the association between urban population and inequality makes use of metropolitan cross-sectional data on population and inequality levels, as opposed to population and inequality growth rates as employed in the present research. In a path analysis model, Betz (1972) finds only an indirect positive relationship between population levels and levels of household income inequality through an endogenous industrial diversification variable. Farbman (1975) divides metropolitan areas into four distinct categorical (ordinal) rankings based upon population level and also finds a positive relationship between population and household income inequality levels. Burns (1975) is one of the first studies to test the association between population growth rates and household income inequality levels. Using cross-sectional census data from 1950 and 1960, Burns finds no relationship between population growth rates over this decade and the level of household income inequality in 1960. Long, Rasmussen and Hayworth (1977) find a statistically significant positive association between population levels and household income inequality levels in cross-sectional Census data in 1970. These same authors repeat this study with a follow-up 1978 paper in which they find a positive and statistically significant association between the 1960 to 1970 metropolitan population growth rate and 1970 household income inequality levels (Hayworth, Long \& Rasmussen, 1978). 
Subsequent research on the urban population-inequality relationship continues to confirm the positive association found by most studies between population levels or population growth rates and the level of household income inequality during the $1960 \mathrm{~s}$, 1970s and 1980s (Galster, 1989; Garofalo \& Fogarty, 1979; Kennedy \& Nord, 1984; Nelson \& Lorence, 1985; Nord, 1980a, 1980b). More recently, using cross-sectional Census data from 1980 and 1990, Chakravorty (1996a) finds metropolitan population levels to be positively associated with the level of household income inequality, but finds population growth rates from 1980 to 1990 to be negatively correlated with the level of household income inequality in 1990. When contrasted with the research by Hayworth, Long and Rasmussen (1978) for 1960 and 1970 data, Chakravorty's finding suggests a change in the way in which population growth rates impact household income inequality levels from the 1960s to the 1980s. Finally, Cloutier (1997) uses cross-sectional Census data from 1980 and 1990 to test the association between population levels and decennial population growth rates on household income inequality in 1990 . He finds no significant effect of population level and decennial population growth rates on household income inequality levels in 1990.

This leaves only the present study, then, to test for the unique relationship between decennial population growth rates and changes in household income inequality from 1990 to 2000 . The negative and significant association found between these two variables in Model 4 provides a preliminary basis for future research in this area. One possible extension in this line of research would be to control for the effects of population levels in the regression model to determine if population growth remains significantly correlated with changes in household inequality. Additionally, the use of an interaction 
term between metropolitan population growth rate and population level may provide further evidence on the effect of metropolitan population growth conditional on population levels.

Two final predictors of changes in metropolitan household income inequality are consistent with expectations in Model 4. Holding other factors constant, the measure on educational inequality is positively associated with changes in household income inequality, as we would expect, and is statistically significant at the 99 percent confidence level $(\mathrm{p}<.01)$. For each one percentage point increase in the proportion of the metropolitan population with educational achievement below a high-school diploma and above a bachelor's degree, the change in the Gini index measuring household income inequality rises by .0014 points. As the disparity in education levels rises, household income disparity also rises.

This is not an unexpected finding, and much prior research has suggested that educational inequality will lead to wage and income inequality (Glomm \& Ravikumar, 1992; Levy, 1995; Lynch, 1995). Conversely, greater equality of educational opportunity and education levels will tend to lead to greater equality of wages and incomes over the long run (Goldin \& Katz, 2001; Goldin \& Margo, 1992; Margo, 1999). If education and income levels are positively associated, as is widely understood (Bound \& Johnson, 1992; Levy, 1995; Levy \& Murnane, 1992; Murphy \& Welch, 1993), then a rise in the proportion of the population in the extreme tails of the educational distribution (those with graduate or professional degrees plus those with less than a high school diploma) should be expected to lead to an increase in income disparity measured by the household Gini coefficient. 
Finally, changes in the racial dissimilarity index measuring racial housing segregation are also positively and significantly correlated with changes in household income inequality in metropolitan economies, as expected. Although this association is relatively weak, metropolitan areas with increases in racial housing segregation also tend to experience rising household income inequality. This supports the hypothesis that changes in housing segregation along racial lines (which is often a proxy for income segregation as well) may play a minor role in explaining changes in metropolitan household income inequality, controlling for other factors.

This finding lends tentative support to the literature on the spatial mismatch hypothesis (Chakravorty, 1996b; Hill \& Wolman, 1997a; Hill \& Wolman, 1997b: Holzer, 1987; Holzer \& Ihlanfeldt, 1996; Ihlanfeldt \& Sjoquist, 1990; Kain, 1968; Massey \& Denton, 1987; Massey \& Eggers, 1993; Mayer, 1996; O'Regan \& Quigley, 1996; Taylor \& Ong, 1995; Wilson, 1987). Spatial housing segregation between blacks and nonblacks may isolate blacks in urban areas that lack access to information about job opportunities or employment that would match their skill levels. If so, it would explain why blacks, as a group, have lower incomes than nonblacks, in turn exacerbating overall household income inequality in metropolitan areas. Nonblack households with rising incomes may locate in the suburbs in closer proximity to employment opportunities that match their education level and/or skill set. Additionally, nonblack households may have greater access to private transportation in the form of automobiles than black households (Taylor and Ong), permitting them greater mobility in finding and traveling to and from jobs. Black households, on the other hand, may have lower incomes and lack the means to relocate closer to jobs that fit their education levels or skill sets. This may isolate black 
households in inner-city neighborhoods where they lack information about job opportunities and also private transportation (an automobile) that could get them this access. In theory, then, spatial mismatch may lead to a combination of rising nonblack household income with falling or stagnant black household income that could, in turn, widen income disparities and lead to a larger rise in income inequality (Mayer). Based upon the findings in Table 6 revealing a positive association between changes in the dissimilarity index and changes in the Gini coefficient, it seems reasonable to conclude that spatial segregation between black and nonblack households (spatial mismatch) plays some limited role in explaining rising household income inequality in metropolitan areas from 1990 to 2000 , all else constant. ${ }^{45}$

None of the other predictors in Model 4 were found to be significantly associated with changes in the Gini index of household income inequality from 1990 to 2000 . The percentage change in per capita real transfer payments from 1990 to 2000 was found to be unrelated to changes in household inequality over this period. And, changes in the additional demographic, household structure, and regional control variables were also found to be uncorrelated with changes in household income inequality over this period.

Overall, Model 4 is statistically significant. However, as mentioned above, the model exhibits weak explanatory power with a relatively low $R^{2}$ coefficient of determination. The variables included in this model explain only 10 to 13 percent of the variation in the decennial change in the Gini index of household income inequality, leaving much of the change in household income inequality from 1990 to 2000 largely unexplained. We can only conclude that some other variable or variables excluded from

\footnotetext{
${ }^{45}$ Some research indicates a reinforcing effect of both educational inequality and spatial mismatch on income inequality. Spatial mismatch may reinforce educational inequality, which in turn leads to greater
} 
the present study is (are) responsible for the changes in metropolitan household income inequality over this period, providing fertile ground for future research. 


\section{CHAPTER V}

\section{Summary and Conclusions}

\section{Summary of Findings}

One of the initial noteworthy findings in the present research is that technological change defined as the percentage rate of growth in metropolitan per capita utility patent approvals from 1990 to 1999 has only a weak positive association to metropolitan economic growth, operationalized as the rate of increase in per capita real GMP from 1990 to 2000. Patent data, therefore, may be a poor indicator of the effects of technological change on economic growth, at least at the metropolitan area scale. This is an important finding in the present research related to the use of patent data as a predictor of growth. This relatively weak association may result for several reasons.

First, while utility patent approvals may be a good indicator of inventiveness or entrepreneurship in urban areas (Higgs, 1971), or may give good indications of metropolitan technological spillovers in close geographic proximity (Carlino, 2001; Higgs; Jaffe, Trajtenberg \& Henderson, 1993), they may simply be a poor predictor of economic growth. As a measure of technological change, utility patent data apparently do not correlate well with real per capita output in metropolitan areas. This does not imply that the findings presented here are in contradiction to the uses of patent data as measures of inventiveness or technological spillovers in the previous research cited above. Patent data may measure variations in these concepts quite well, yet fail to 
perform well as a predictor of economic growth. Not all inventive activities necessarily create economic growth.

Second, utility patents approved at a given geographic location may not have any growth-inducing impact at that location. This is consistent with one of the major critiques, by Griliches (1990), of the use of patent data. The growth impacts of the inventions linked to utility patent approvals, if there are any, might be felt at different geographic locations. The metropolitan area to which the utility patent approval is assigned may not benefit economically from the invention to which the patent is linked, particularly if the patented invention is more productive or useful in an industry that is unrelated to the industry to which the original patent was granted. Further, the industry that created the patented invention may not be the industry that uses the patented invention. If so, then the patented invention may generate no observable economic benefits for the geographic location to which the utility patent was originally granted or assigned. In other words, there may be a disconnect between the industry and location where the patent was originally granted and the industry and location where the patented invention is actually used, making it difficult to trace the economic benefits from patented inventions using only geographically-based utility patent approval rates.

Jaffe, Trajtenberg and Henderson (1993) attempt to trace the effects of patents geographically to understand how patent approvals in one period and in one location effect patent approvals in a later period at that same location. These authors find that later patents tend to emanate from geographic locations that are in close proximity to the previous patents they cite (or to which they are linked in terms of their inventive genealogy), suggesting self-reinforcing inventiveness due to localized technological 
spillovers. However, this says nothing about the impact of successive patents on the level or rate of growth in economic output at those geographic locations. One can easily hypothesize two distinct metropolitan economies in different locations. One economy engages in large amounts of R \& D and generates many new patented inventions. Perhaps a research university is located within its boundaries or it is characterized as an incubator economy or "nursery city" (Duranton \& Puga, 2001). The other metropolitan area simply imports the inventions and ideas generated by the first, putting them to use increasing productivity and the output of goods and services. Indeed, Duranton and Puga argue that many cities can be characterized by one of the two alternatives suggested in this scenario, depending upon the product life cycle stage. In this scenario, it is reasonable to assume that measures of economic growth such as the growth rate in real per capita GMP would register stronger output growth in the second economy than in the first. Perhaps it is for this reason that the findings in Table 4 do not reveal a strong relationship between patent approval rates and the rate of per capita economic growth in metropolitan economies over the 1990s.

Finally, as Griliches (1990) also points out, there is much inventive activity that is not patented due to concerns over trade secrecy and innovation concealment between rivals. Perhaps inventive activity that is not patented (and thus concealed) has a much greater impact on economic output in a given geographic location than do the patented inventions in these same locations. If so, this would further explain the weak association between utility patent approvals and per capita economic growth in metropolitan economies that we find here. 
An equally important finding in the present research is that technological change defined as the change in the proportion of professional- and technology-sector occupations per metropolitan area from 1990 to 2000 is positively associated with the rate of increase in per capita real GMP from 1990 to 2000. The much stronger association between the occupational measure of technological change and per capita economic growth (as compared to the results on the patent data measure) may result for several reasons. First, metropolitan labor market composition is itself a function of GMP given the methodology used in computing GMP. If GMP is derived from GSP (gross state product) and assigned back to metropolitan areas based upon the proportion of metropolitan workers in distinct industrial categories, then changes in GMP should be logically related to changes in labor market composition. Thus, it is not surprising to find a correlation.

Second, labor market measures are geographically fixed and thus not separable from their metropolitan location. Where patented inventions in one area can be easily drawn into use at another location, labor market occupational change is fixed to the geographic area by which it is defined. Thus, it should be expected to relate to changes in economic growth in that metropolitan area.

Another important finding is that population growth rates appear to have been inversely correlated with real per capita economic growth during the 1990s, all else constant. Metropolitan economies with higher levels of population growth over this period experienced slower rates of growth in real per capita output. As mentioned above, this was not simply a result of metropolitan population levels growing faster than the level of real GMP. More likely, metropolitan areas with relatively higher rates of 
population growth saw a decline in real per capita economic growth due to some form of congestion externality. One theory is that metropolitan areas with strong population growth failed to maintain adequate public goods and infrastructure consistent with this growth (such as street and highway construction, public utility services, law enforcement, coordination of urban economic development, etc.), thus restraining the rate of growth in real per capita GMP. The lack of adequate public goods and infrastructure for a growing population may play a role in retarding economic growth by reducing productivity throughout the metropolitan economy. Infrastructure buildup may lag behind population growth, so that cities with high population growth do not see real economic growth until some later period when the provision of public goods and services has had a chance to catch up to population increases.

The most important finding revealed in this paper is the relationship found between economic growth and changes in the Gini measure of household income inequality. The design of the present research study was to detect an indirect positive effect, if any, of SBTC on inequality through changes in economic growth. If technological change is skill-biased (as much previous research has suggested) and is a relatively large determinant of economic growth, we should be able to observe a positive relationship between technology-driven economic growth and income inequality, all else constant. In the method employed here, support for this theory could not be established. Additionally, this research study sought to test the theory of an extended or reformulated Kuznets Curve in which economic growth and income inequality might be positively correlated due to structural shifts from an industrial economy to a post-industrial information economy. This theory, too, must be rejected based upon the findings. 
Real per capita GMP growth rates from 1990 to 2000 were found to be inversely correlated with changes in the Gini measure of metropolitan household income inequality over this same period. Thus, the measure of economic growth employed in the present research was found to be significantly related to changes in metropolitan inequality during the 1990s, but in the opposite direction relative to theoretical expectations. While economic growth is found to be a function of technological change, as mentioned above, economic growth reflected in increases in real per capita GMP appears to decrease, not increase, income inequality over the decade investigated here.

These findings prevent support for or confirmation of the theory that SBTC explains rising inequality, at least using the measures employed here. This is not to suggest that we can reject this theory altogether; just that we have failed to confirm it. There are several possible reasons for these results that bear further explanation.

First, SBTC may have no impact on the income or wage distribution through economic growth. Its effect may be distinct from, and in fact in direct opposition to, the effects of economic growth on income inequality. If SBTC does in fact raise income inequality, as many authors argue, it must do so apart from economic growth as defined in the present research. Second, the variables used in this study to operationalize and measure SBTC may be invalid. They may fail to measure the concepts adequately, either because these measures are invalid measures of technological change generally, or because, more specifically, the technological change they capture is skill-neutral rather than skill-biased (i.e., perhaps patented inventions or changes in labor market composition reflect technological change that is, on balance, skill-neutral rather than skill-biased). SBTC may impact both economic growth and income inequality, but 
through measures other than those employed here. Thirdly, even if we concede that the measures of technological change used in this study are valid, they may be so weakly associated with economic growth that their subsequent impact on income inequality is undetectable.

To summarize these points: Both of the two measures of technological change employed in the present study are positively and significantly correlated with economic growth $^{46}$ (although one of them only weakly so). Additionally, the measure of economic growth used in this study is negatively and significantly correlated with the change in metropolitan household income inequality. And, in results not shown here, the two measures of technological change used in this study are found to be uncorrelated with changes in metropolitan household income inequality when controlling for the effects of changes in real per capita GMP. In other words, the measures of technological change used in the present study are not found to be correlated with changes in household income inequality in metropolitan economies in a manner consistent with the SBTC theory of income inequality. It necessarily follows from this evidence, then, that we must reject the hypothesis that SBTC leads to rising income inequality through economic growth. The only way to avoid this conclusion is to argue that the measures of technological change used in the present research are either invalid, or are skill-neutral rather than skill-biased.

\footnotetext{
${ }^{46}$ A repeat of the first-stage regression model (Equation 2, results of which are summarized in Table 4) was conducted using a secondary measure of economic growth (percentage change in real median household income 1990-2000) as the alternative dependent variable. In results not shown here, the impact of technological change on the alternative measure of economic growth was found to be nearly identical to the results presented in Model 1 in Table 4. This further confirms the similarities between the two alternative measures of economic growth employed in this study, and reveals a strong consistency in the relationship between the chosen measures of technological change and the concept of economic growth generally.
} 
Apart from these arguments, we can only conclude that if the SBTC explanation for rising inequality is to be supported, it may need to be demonstrated apart from the effects of economic growth on inequality, and with the use of alternative measures of technological change other than those employed in the present research. Based upon the results found here, a proportionate increase in the metropolitan population in professional-, managerial- and technology-sector occupations raises metropolitan economic growth, and rising metropolitan economic growth subsequently reduces metropolitan household income inequality. This is not implausible. As the percentage of the metropolitan population becomes more professionalized and as the number of jobs in technical sccupations rises, real output and income should also be expected to rise. At the same time, household income dispersion should narrow as the workers in metropolitan populations become more homogeneous and as household income increases. This is perhaps the most important finding in the present research.

An alternative or reformulated Kuznets Curve Hypothesis also cannot be supported by the evidence presented here. The measure of economic growth used in this analysis is negatively correlated with changes in household income inequality, all else constant. Hence, the original Kuznets Hypothesis is at least partially supported: rising economic growth in metropolitan areas tends to result in falling metropolitan household income inequality, all else constant. This is consistent with Kuznets' original growthinequality hypothesis. A reformulated or extended Kuznets Curve Hypothesis, positing a positive relationship between economic growth and income inequality owing to technological and structural changes in a post-industrial information economy cannot be substantiated by the evidence presented here. To the extent that structural and/or 
technological changes raise economic growth, they (apparently) put downward pressure on household income inequality, at least in U.S. metropolitan economies during the 1990s. The quest for a growth-related or technology-related explanation for rising household income inequality during the 1990 s will need to pursue other avenues of research than those presented here. Card and DiNardo (2002) also question the explanatory power of the SBTC theory of rising wage and income inequality, pointing out that wage and income inequality began to stabilize in the 1990 s even as technological change continued to accelerate. One explanation for this may be that technological change has become less skill-biased and more skill-replacing in recent years, particularly as personal computers and other technological advancements have become more "user friendly." If so, this would tend to (moderately) reduce the relative demand for skilled over unskilled labor, restraining the rise in wage and income inequality. This theory has implications for the measures of technological change used in the present research because, as mentioned above (and again below), these measures may not reflect skillbiasedness, and may reflect changes in technology over the 1990s that were instead skillneutral or skill-replacing.

A less important yet interesting finding is the negative relationship found between the population growth rate and the point change in the Gini index of household income inequality from 1990 to 2000 . If the decennial rate of growth in MSA/CMSA population levels is a loose proxy for urbanization, then this finding lends further support to Kuznets' (1955) original theory that late-stage urbanization in advanced industrial economies tends to depress income inequality. When controlling for other factors, population growth appears to (mildly) reduce or suppress changes in household income 
inequality in metropolitan areas, at least during the 1990s. This finding is distinct from previous studies on the metropolitan population-inequality relationship since this line of research began during the 1970s. Most of the previous research exploring the association between urban population and inequality makes use of metropolitan cross-sectional data on population and inequality levels, as opposed to population and inequality growth rates as employed in the present study. Further, the findings in prior research suggest that population levels and/or population growth rates are either uncorrelated or positively correlated with the level of household income inequality in metropolitan areas.

Only the present study tests for the unique relationship between decennial population growth rates and changes in household income inequality from 1990 to 2000 . And, the inverse relationship found between population growth and changes in household income inequality in metropolitan areas contradicts the theory that greater population growth or higher population levels raise inequality. One implication is that there has been a change in the association between these two variables during the 1990s.

The negative and significant association found between these two variables provides a preliminary basis for future research in this area. One possible extension in this line of research would be to control for the effects of population levels in the regression model to determine if population growth remains significantly correlated with changes in household inequality. Additionally, the use of an interaction term between metropolitan population growth rate and population level may provide further evidence on the effect of metropolitan population growth conditional on population levels. In any case, the negative association between metropolitan population growth and household 
income inequality lends further support to Kuznets' (1955) original hypothesis that urbanization in advanced economies would tend to depress inequality.

Two other predictors of changes in metropolitan household income inequality are also important findings in the present research. Holding other factors constant, the measure on educational inequality is positively associated with changes in household income inequality, as we would expect. As the disparity in education levels rises, household income disparity also rises.

This is not an unexpected finding, and much prior research has suggested that educational inequality will lead to wage and income inequality (Glomm \& Ravikumar, 1992; Levy, 1995; Lynch, 1995). Conversely, greater equality of educational opportınity and education levels will tend to lead to greater equality of wages and incomes over the long run (Goldin \& Katz, 2001; Goldin \& Margo, 1992; Margo, 1999). If education and income levels are positively associated, as is widely understood (Bound \& Johnson, 1992; Levy, 1995; Levy \& Murnane, 1992; Murphy \& Welch, 1993), then a rise in the proportion of the population in the extreme tails of the educational distribution (those with graduate or professional degrees plus those with less than a high school diploma) should be expected to lead to an increase in income disparity measured by the household Gini coefficient.

Finally, changes in the racial dissimilarity index measuring racial housing segregation are also positively and significantly correlated with changes in household income inequality in metropolitan economies, as expected. Although this association is weak and barely achieves significance, metropolitan areas with increases in racial housing segregation also tend to experience rising household income inequality. This 
supports the hypothesis that changes in housing segregation along racial lines (which is often a proxy for income segregation as well) may play a minor role in explaining changes in metropolitan household income inequality, controlling for other factors.

This finding lends support to the literature on the spatial mismatch hypothesis (Chakravorty, 1996b; Hill \& Wolman, 1997a; Hill \& Wolman, 1997b; Holzer, 1987; Holzer \& Ihlanfeldt, 1996; Ihlanfeldt \& Sjoquist, 1990; Kain, 1968; Massey \& Denton, 1987; Massey \& Eggers, 1993; Mayer, 1996; O’Regan \& Quigley, 1996; Taylor \& Ong, 1995; Wilson, 1987). Spatial housing segregation between blacks and nonblacks may isolate blacks in urban areas that lack access to information about job opportunities or employment that would match their skill levels. If so, then blacks would tend to have lower incomes than nonblacks, exacerbating overall household income inequality in metropolitan areas. Nonblack households with rising incomes may locate in the suburbs in closer proximity to employment opportunities that match their education level and/or skill set. Additionally, nonblack households may have greater access to private transportation in the form of automobiles than black households (Taylor and Ong), permitting them greater mobility in finding and traveling to and from jobs. Black households, on the other hand, may have lower incomes and lack the means to relocate closer to jobs that fit their education levels or skill sets. This may isolate black households in inner-city neighborhoods where they lack information about job opportunities and also private transportation (an automobile) that could get them this access. In theory, then, spatial mismatch may lead to a combination of rising white household income with falling or stagnant black household income that could, in turn, widen income disparities and lead to a larger rise in income inequality. Based upon the 
findings in Table 6 revealing a positive association between changes in the dissimilarity index and changes in the Gini coefficient, it seems reasonable to conclude that spatial segregation between black and nonblack households (spatial mismatch) plays some limited role in explaining rising household income inequality in metropolitan areas from 1990 to 2000 , all else constant.

\section{Policy Recommendations}

Although these findings do not offer any apparent detailed policy recommendations, and do not necessarily lead us to policy goals that have not been identified before, for those interested in reducing or restraining the rise in income inequality, the findings presented here provide some general direction. It seems clear that, to varying degrees, at least three primary factors explain the changes in household income inequality in metropolitan areas during the 1990s: the growth rate in real per capita GMP, changes in the distribution of educational achievement, and changes in black-nonblack housing segregation.

It should be noted that the policy recommendations offered here are not anticipated to have immediate impacts, but might have some minor impact over the long run. Hence, because they address long-run changes, they are also more speculative. Additionally, these policy proposals may not serve to reduce income inequality in every setting or under all circumstances, and may lead to consequences not foreseen beforehand. We should be very clear in admitting the possibility of such outcomes from the start, and remain humble and modest in our efforts.

First, it seems clear from the present findings that to reduce or restrain household income inequality, efforts could be taken to raise real per capita GMP. Real per capita 
growth (apparently) lifts the household income shares of the households in the bottom quintiles of the income distribution, reducing metropolitan household income inequality. This appears to be the effect over the 1990s as evidenced in this study. As the lowest household incomes rise, and provided they rise more rapidly than households in the upper end of the distribution and/or comprise a larger proportion of the distribution, the overall household income distribution becomes less dispersed and thus less unequal. Again, this is a somewhat counterintuitive finding given the fact that overall inequality during the 1990s appears to have increased, as indicated by the Gini coefficient comparisons in Table 3. However, the independent effect of real per capita economic growth may restrain the rise in household income inequality even as other factors work to increase it. This conclusion is much more plausible when we consider the low $R^{2}$ on Model 4 in Table 6. The variables in this model, including the rate of economic growth, explain less than 13 percent of the variation in household income inequality. Clearly, economic growth may mildly reduce the rise in inequality while some other omitted variable(s) has (have) a much larger counteracting effect.

Policies geared toward income redistribution through direct transfer payments and social programs would apparently do little to achieve greater equality in household incomes based upon the findings in the present research. The growth rate in real per capita transfer payments from 1990 to 2000 was not found to have any impact on the point change in the Gini coefficient of household income inequality over this period, controlling for other factors. ${ }^{47}$ Using additional transfer payments to decrease income

\footnotetext{
${ }^{47}$ It should be noted that the Gini measure of income inequality is less sensitive to changes in the income distribution occurring in the extreme tails of the distribution (Ryscavage, 1999, p. 34). This may explain the absence of a statistically significant finding between the change in transfer payments and changes in the Gini index of household income inequality.
} 
inequality would appear to be a fruitless strategy. The sign on the transfer payment coefficient in Table 6 is in the expected negative direction, suggesting that an increase in per capita transfer payments does tend to reduce household income inequality. However, when controlling for other factors, the effect is not statistically significant. ${ }^{48}$

Better approaches to spurring per capita economic growth, based upon recent research as well as the findings presented in this study, may be to pursue local economic development initiatives that encourage entrepreneurship and innovation (Feldman \& Francis, 2004), attract firms in the science and technology (S\&T) industry that would, in turn, raise the proportion of knowledge workers (Plosila, 2004), increase the proportion of skilled or "creative" labor in technology- and professional-sector employment (Florida, 2004), raise human capital levels through education (Gottlieb \& Fogarty, 2003), and provide labor market training or re-training opportunities for laborers from lowincome households (Blakely \& Bradshaw, 2002; Fitzgerald and Leigh, 2002; Lynch, 1995). It seems clear from the results of the first-stage regression summarized in Table 4 that improvements in the overall skill level, technological orientation and professionalization of the metropolitan population in turn improve the prospects for real per capita economic output. Educational attainment also modestly improves per capita economic growth. Thus, investments in education and training geared toward increasing the proportion of the metropolitan population employed in professional- and technological-sector occupations could have a significant positive impact on per capita growth, in turn reducing or restraining household income inequality. Additionally,

\footnotetext{
${ }^{48}$ In a simple bivariate regression and correlation analysis, the percentage change in metropolitan real per capita transfer payments from 1990 to 2000 was not found to be associated with the growth rate in real per capita GMP over this period. Thus, arguments that transfer payments retard real per capita economic
} 
subsidies to start-up businesses, municipally-financed venture capital lending to entrepreneurs from low-income households, enterprise/empowerment zones in lowincome areas, or business improvement districts may raise real per capita GMP and household income in metropolitan areas. Again, these types of policies would apparently have their greatest impact on reducing or restraining household income inequality if they are designed to attract or retain businesses that 1) employ a relatively higher proportion of technology workers and/or offer professional and managerial employment opportunities, and 2) utilize a relatively higher proportion of employees who hold a fouryear degree or more.

Florida (2004) argues that growing cities are marked by an increasing contingent of professionals who generate new technologies and new ideas through networks of creativity within an urban economy. He suggests that this "creative class" of workers, instilled with a high level of diversity, individuality, intelligence, education, drive, and creativity, are one of the primary forces behind why some urban and regional economies experience rapid development and economic growth. The results found in the present study can be interpreted as a (tentative) confirmation of this theory if we accept that the variable measuring proportionate changes in technical and professional occupations captures some of this "creative class," which is plausible. Thus, policies geared toward attracting elements of this skilled and creative population into metropolitan economies could improve the prospects for economic growth and, in turn, serve to restrain household income inequality. 
One policy proposal at the national level that could increase the levels of skilled and "creative" labor in (some) metropolitan economies is to lift restrictions on the supply of high-skilled, high-education immigrant labor into the United States, especially in an effort to increase the relative levels of scientists, engineers, and other workers in high demand in S\&T sectors (Romer, 2000). By increasing substantially the number of green cards and visas issued to high-skilled and educated immigrants, and by accelerating citizenship for these workers, the supply of high-skilled labor in metropolitan economies could be increased. One implication from the results presented in this paper is that such an increase would improve the prospects of economic growth and in turn reduce household income inequality, all else equal. Further, there is an additional theoretical argument for encouraging high-skilled immigration: an increase in the supply of skilled labor, ceteris paribus, would tend to create wage and income compression as it has apparently done throughout history (Goldin \& Katz, 1996; Goldin \& Margo, 1992; Margo, 1999).

Lynch (1995) argues that employer-provided training may promote gains in wages and household income that would mitigate against rising inequality. Training may play a role in lowering the income gap (or at least preventing it from getting larger) by increasing the supply of skilled labor, raising labor productivity and per capita economic growth, in turn creating some relative wage and income compression as the findings of the present study suggest. However, to raise real per capita growth and simultaneously reduce income inequality, Lynch is careful to point out that labor training efforts must be directed at laborers from low-income households rather than benefiting only employees from middle- and upper-income households as is often the case. Means-tested training 
subsidies or tax credits from local government jurisdictions to local businesses may encourage employer-provided training geared toward low-income labor, although such policies have not always generated the intended results (Blakely \& Bradshaw, 2002).

Second, and closely related, a reduction in educational inequality would likely reduce the level or rate of increase in household income inequality based upon the findings presented here. Policies that increase educational opportunity have historically been found to result in wage compression by increasing the relative supply of skilled labor and reducing or restricting income inequality (Goldin \& Katz, 2001; Goldin \& Margo, 1992). It seems clear that policies promoting educational equality by raising the educational attainment of low-income households serve not only to reduce household income inequality, but should also promote economic growth through improvements in human capital and labor productivity as implied by the findings presented here and elsewhere (Gottlieb \& Fogarty, 2003). Levy (1995) makes just such an argument, claiming that an increase in educational attainment by younger demographic groups (socalled generation $\mathrm{X}$ and generation $\mathrm{Y}$ cohorts) will increase the supply of skilled labor and exert downward pressure on the skilled-unskilled income gap. However, he also predicts that the relative demand for skilled labor will continue to accelerate, leaving overall income inequality roughly unchanged in spite of the increases in educational attainment that he forecasts. Bishop (1996) also argues that the demand for skilled labor (as measured by educational attainment) will not likely abate any time soon. Thus, we are back to Tinbergen's (1975) characterization of rising income inequality as a simple race between the demand for and the supply of skilled labor. 
The question, then, becomes how to accelerate the supply of educated (and thus presumably skilled) labor faster than demand. One method may be to focus on improving the educational attainment of current adult workers rather than simply waiting on the skilled wage premium to induce younger generations to increase their educational attainment. Policies that encourage adult education programs may be the key to compressing the wage and income gaps without simultaneously harming economic growth and development. Presumably, the large bulk of low-skilled workers impacted by structural economic changes are adults ranging in age from 25 to 45 . Thus, education policies must be designed which will provide incentives and access to higher education and skill-development specifically designed for the adult, non-traditional learner. The following combination of policy proposals is suggested as a means of accomplishing this goal.

1) Federal and state personal income tax credits, such as the current federal Lifetime Learning Credit, might be offered (or the benefits increased) for any adult who returns to school to complete a degree, or who begins the pursuit of post-secondary education or vocational training. These tax credits could be designed so that tuition and associated education costs (provided they are verifiable) can be directly deducted from the recipient's adjusted gross income. Additionally, adult learners should be eligible to receive unlimited lifetime income tax credits to provide an incentive for "lifelong learning" and advancement through education or vocational training year after year as market forces demand continuous skill improvements.

2) Federal and state corporate income tax credits could be offered for any firm that hires and employs workers enrolled in higher education or vocational training. Firms of 
any size could receive tax reductions equivalent to a given percentage of their payroll allocated to the wages and salaries of employees enrolled in post-secondary education or vocational training. The intent would be to provide firms with the incentive to hire and retain those employees who are pursuing educational or training/vocational opportunities. This may also further the demand not just for workers who have already completed a degree, but also for workers who are willing to pursue a degree.

3) Federal and state grants might be provided directly to both state universities and private colleges and universities that submit proposals to the Department of Education for the creation of adult-centered education programs that are designed to provide access to working adult students. At a minimum, this would entail the provision of coursework and curriculum designed for adult learners who bring workplace experience into the classroom, and would allow the adult to earn a traditional baccalaureate or advanced degree while also working full-time or part-time. The intent would be to provide institutions of higher learning with incentives to remove the traditional barriers to education (time and location) for working adults with families and occupational responsibilities. Prototypes of such adult education programs typically involve evening classes one or two nights per week structured in an accelerated (non-semester-based) format, or on-line educational delivery through the Internet. ${ }^{49}$

4) Unemployment benefits could be tied directly to the educational pursuits of the recipient as opposed to a percentage of the wages earned on the most recent job. ${ }^{50}$ The

\footnotetext{
${ }^{49}$ The academic integrity and quality of these types of programs may be viewed with some justifiable skepticism. However, as technology permits a wider distribution of knowledge and information in alternative delivery formats, the proliferation of these types of education alternatives seems inevitable. It can only be hoped that competitive pressures, in combination with accreditation standards, will ensure a modicum of academic quality.

${ }^{50}$ The basic concept would be to allow unemployment benefits to be paid according to a fixed proportion of the costs for the level and type of education being pursued by the recipient (vocational training vs.
} 
intent would be for structurally unemployed individuals to seek higher education and/or vocational training programs in order to receive unemployment benefits. Rather than provide proof of having sought employment as a condition for receiving unemployment benefits, the recipient would be required to provide proof of enrollment (or intent to enroll) in a program of higher education or vocational training within a specified time limit. $^{51}$

The combination of these education policies could lead to a more rapid and more fluid transition of labor from low-skilled and low-wage positions to more highly demanded and higher paying occupations, thus potentially reducing the level of household income inequality in metropolitan areas. The novel approach offered here, in comparison to other policies focusing on education, is that these policies would be designed to increase the educational attainment of the current adult working population, not just the educational attainment of future generations passing through the channels of traditional educational institutions. Although the effects of such policies are merely speculative, they may serve to accelerate the supply of skilled labor faster than the demand, thus reducing or at least restraining income inequality over the long run.

Finally, the findings presented here suggest that policies reducing black-nonblack housing segregation in metropolitan areas may also mitigate the rise in household income inequality, although most such policies would have only limited effects given the weak association found in the data. The vast research on spatial mismatch suggests numerous

associates and baccalaureate degrees vs. advanced degrees). Such a policy is ripe for abuse by the recipient who may or may not have any interest in human capital development, so proper guidelines would need to be clearly established and enforced.

${ }^{51}$ Current time limitations on the receipt of unemployment insurance could remain in force, or could be adjusted according to the length of anticipated enrollment in a program of education. However, because of the proven disincentive effects of prolonged unemployment benefits on job search efforts under current law 
policies that might lead to reduced housing segregation along racial lines, and those policy recommendations need not be recounted in detail here (Holzer, 1987; Massey \& Denton, 1987; Mayer, 1996; Taylor \& Ong, 1995; Wilson, 1987). Additionally, the previous policies suggested above that focus on raising real per capita GMP and improving the distribution of education could be equally employed to improve residential assimilation, given that racial segregation is often a proxy for income segregation (Kain \& Singleton, 1996; Massey \& Eggers, 1993; Taylor \& Ong, 1995).

Given the weak association found between changes in household income inequality and changes in black-nonblack housing segregation over the 1990s, suggesting additional spatial mismatch-remedying policies beyond those already widely prom ted would be redundant. As Glaesar and Vigdor (2001) find, the 1990s witnessed a continued decline in black-nonblack segregation levels, and segregation as measured by the dissimilarity index appears to be at its lowest level since the 1920s. The median MSA/CMSA saw a drop of .052 points in the dissimilarity index from 1990 to 2000, as reflected in Table 3. The median dissimilarity index per MSA/CMSA dropped from .5580 in 1990 to .4930 in 2000 , a median drop of 11.6 percent over the decade. Over the past 30 years, time and cultural change reflected in increasing racial tolerance may explain the decline in blacknonblack metropolitan residential segregation as much as any policy intervention. And, while we cannot ignore the residue of racial intolerance that still remains, there is no obvious reason to expect the trend toward increased racial harmony to deviate. Thus, we can tentatively expect that as cultural changes continue to increase tolerance and improve recipient to be active in preparing for re-entry into the labor force rather than consuming leisure. 
black-nonblack residential assimilation, these changes will serve to modestly restrain the rise in metropolitan household income inequality.

\section{Weaknesses and Suggestions for Future Research}

Given the methodology, research design and statistical technique used in this study, there are relatively few threats to validity. The use of secondary unobtrusive cross-sectional MSA data employed in a two-stage least-squares multiple regression analysis eliminates many of the typical threats to validity. ${ }^{52}$ And, because all but sixteen MSAs or CMSAs were included in the analysis, and because the omitted cases appeared to be randomly distributed, the problem of selection bias should be minimized. However, the weaknesses that do exist are significant and deserve careful consideration so that future research on this subject might be improved.

First, the findings presented here cannot be generalized beyond metropolitan areas in the U.S. economy during the 1990s. The generalizability of the results is limited because those results reveal trends and patterns only in large cities (population 50,000 and above) in the United States over a specific ten-year period. While these results might provide some hint of the linkages between technological change, economic growth and inequality in other similar-sized cities in similarly developed economies, we cannot use the findings here presented to make specific predictions about or policy recommendations for those cities. Further, these findings say nothing about the connections between technological change, economic growth and household inequality for smaller cities in the U.S. with populations below 50,000 people. The limited generalizability of the findings

\footnotetext{
${ }^{52}$ For a summary of the potential threats to external and internal validity that plague certain types of research or natural field experiments (such as history, maturation, selection bias, instrumentation, testing,
} 
thus presents opportunities for further research in at least two alternative directions: 1) similar metropolitan areas in other developed economies and 2) the consideration of smaller non-MSA cities in the U.S.

Second, as mentioned earlier in the paper, the validity of the economic growth variable employed in this research may be somewhat questionable due to the methodology used in its calculation. Gross Metropolitan Product (GMP) is computed as a derivative of Gross State Product (GSP) data provided by the Bureau of Economic Analysis. For each state, GSP is allocated by industry to the counties and metropolitan areas within that state. This allocation is done based upon the relative concentrations of these industries in the metropolitan areas as measured by employment and labor market concentrations in these industries and within each county. The distribution of GSP to each county is based upon the employment weighting of each industry in that county according to the first two digits in the SIC occupational categories. Thus, the relative labor concentration of employment in a given industry and county determines the amount of GSP that is appropriated back to each county and/or MSA/CMSA. This approach, while perhaps offering the most plausible estimate of metropolitan per capita output, is not exact and is subject to error. It may not accurately reflect the true amount of output generated by metropolitan economies if the county or metropolitan employment weighting of the GSP number is inaccurate or biased, thereby inflating or deflating the level of economic output for the geographic area. Although it is beyond the scope of this research to suggest specific alternatives, a more improved measure of metropolitan economic growth may be some type of direct measurement of metropolitan production-

time order, imitation, mortality, compensation, competition and demoralization), see Campbell and Stanley, 1966, and Cook and Campbell, 1979. 
and service-sector output rather than the indirect method used by the BEA and Global Insight, Inc.

Third, as mentioned throughout, the validity of the two measures of technological change used in this research may be of some concern. While there is no obvious reason to believe that these measures do not reflect at least some technological innovations for metropolitan economies, we have not tested these measures to see if they are skill-biased, skill-neutral, or skill-replacing. The assumption in this paper, supported by previous literature, has been that the technological measures used are skill-biased. However, at this point, there is no research to test or confirm this assumption, leaving us to conjecture. Thus, one of the vulnerabilities of the present research is that the measures of technological change used, while distinct from those offered in previous studies, may not accurately reflect the concept of skill-biasedness found in the literature on inequality and SBTC. Further, we have found at least one of these measures of technological change to be a weak predictor of real per capita economic growth, and neither measure is directly related to changes in household income inequality over the time period investigated.

While the variable measuring the change in the proportion of the metropolitan population in professional-, managerial- and technology-sector occupations per metropolitan area can plausibly be considered a proxy for change in the skill composition of the labor force, it is not clear whether this change in skill composition is related to technological change or some other factor. An improvement for future research may be to employ a specific variable of technological change that has been found to be explicitly skill-biased in its effect, then to trace its impact on growth and household inequality. Krueger (1993) finds that the percentage increase in personal computer usage in the labor 
force is a skill-biased measure of technological change, and it would be interesting to see if this variable has any relationship to economic growth and/or household inequality in metropolitan economies. However, data on this variable was not found for the specific metropolitan areas used in this study or for the time period investigated for the present research. Locating data of this or similar nature that has been found to be specifically skill-biased, and then pairing it with the units of analysis in the present study provides opportunities for future research and improved findings on the question of technological change, growth and inequality.

Fourth, the household income Gini may not be the best measure of income inequality to test for the effects of SBTC or economic growth on the income distribution. The variation in the household gross income Gini coefficient from 1990 to 2000 is relatively small, and the mean point increase per MSA was just .0138 (see Table 3). Additionally, because this variable is based upon a measure of gross pre-tax and pretransfer income, consumption inequality is less than income inequality. And, as discussed above, household size has declined somewhat between 1990 and 2000, and it is likely that household composition has changed as well (i.e., the average age of households, the average proportion of working members of households, etc.). ${ }^{53}$ Given these realities, a plausible argument can be made that underlying income inequality at the individual level may not have changed all that much during the 1990 s, or that, at the very least, it did not rise as rapidly as it did during the 1980 s, a conclusion reached by much of the research cited in this study. In any case, the household gross income Gini simply cannot reveal these underlying compositional changes occurring within households from 1990 to 2000 . 
As an alternative, Gini coefficients derived from individual earnings data (salary and wages), as opposed to household income data, would arguably be an improved gauge of the overall change in income inequality, and may be a more sensitive measure of the effects of both technological change and economic growth on income dispersion.

Findings from individual earnings inequality, as opposed to household income inequality, may permit more substantive conclusions on the linkages between technological change, economic growth, and the wage distribution. If SBTC is a force that tends to widen the wage and earnings distribution, we would expect to be able to observe this widening more clearly at the level of individual wages and earnings than at the level of household income. If $\varsigma_{0}$ a more precise measure of inequality, such as the change in an individual earnings Gini coefficient, would be an improvement over the change in the household income Gini and could arguably reflect a greater increase in inequality over the decade in question. Because individual-level long-form Census data are not publicly available for Census years 1990 and 2000, and because the household income Gini (as opposed to the individual earnings Gini) is the more widely used measure of inequality in the research literature, data on individual earnings inequality was not used. ${ }^{54}$

Furthermore, there are alternative measures of inequality other than the Gini coefficient which, if used, may also yield different results (Galbraith \& Kum, 2002; Kaplow, 2002; Ryscavage, 1999). To repeat, the household income Gini index was used because it is the most common measure and thus enables the closest comparison to the

\footnotetext{
${ }^{53}$ Credit for these critiques and helpful insights goes to Paul Coomes who read an earlier draft of this paper. ${ }^{54}$ For individual level earnings data, the PUMS (Public Use Micro Sample) data set from the Census Bureau might be used. But, what is gained in terms of individual level data in the PUMS is lost in terms of the number of cases, sample size, and the precise metropolitan geographic definitions available for MSAs. The equivalent unit of analysis in the PUMS data would be a PUMA (Public Use Metropolitan Area). However, PUMAs lack the precise definition of a metropolitan economy because they are geographically
} 
majority of previous research on the question of inequality. However, other measures, such as the $90 / 10$ ratio, 80/20 ratio, Atkinson and Thiel indexes may be more sensitive to changes in inequality at the extremes of the income distribution (Ryscavage, 1999) and thus could be more sensitive to changes in any of the predictor variables used in this study.

Of course, one final critique of any cross-sectional measure of income inequality is that it is necessarily static and does not capture income mobility effects over time and between generations. This criticism applies equally to the present study. Households that comprise the lowest two quintiles of the income distribution in 1990 may no longer be found in these quintiles by 2000 , having risen to higher quintiles. Likewise, households in the upper quintile in 1990 may have fallen into the middle or lower quintiles by 2000 . Thus, if income mobility is high, in the sense that many households change position in the income distribution over time, then cross-sectional measures of household income inequality may be misleading because they give us only a snapshot of the income distribution without revealing how and why changes in the makeup of this distribution might occur. On the other hand, recent studies attempting to measure the degree of income mobility suggest that income mobility over time and across generations, at least in the United States, is not that large, and may be relatively stable (Erikson \& Goldthorpe, 2002; Solon, 2002).

Fifth, it is highly probable that the effects of many of the predictor variables used in the present study operate with a lag. Increases in the rate of patented technologies or skilled labor occupations may not have a simultaneous effect on economic growth as

defined by counties which, in some cases, include large non-metropolitan (rural) areas and households outside MSAs or CMSAs proper. 
assumed in the present research, but may instead operate with a delay. For example, the rate of growth in utility patents or skilled labor during one decade may not impact metropolitan per capita output until a subsequent decade. Likewise, the impact of changes in real per capita economic growth may not coincide strongly with changes in income inequality during the same period, and the effects may be more pronounced in some lagged period. Because the present study does not test for the lagged effects of changes in such measures, and because this study analyzes only simultaneous changes over a single decade, a potential improvement in future studies may be to test for the lagged effects, if any, of technological change on economic growth, and of economic growth on changes in income inequality.

Sixth, one of the most important theoretical explanations offered for rising income inequality (second only to the SBTC hypothesis) has been the effects of increased international trade and immigration, products of increased trade openness and the forces of globalization (Aghion \& Williamson, 1998; Borjas, 1995; Borjas \& Ramey, 1994; Freeman, 1995; Harrigan, 1997, 1998; Irwin, 2002; Johnson \& Stafford, 1993; Lawrence, 1995; Leamer, 1996; Revenga, 1992; Richardson, 1995; Wood, 1995). Due to the limitations of metropolitan-level data on international trade in the 1990 and 2000 census files, the present study was unable to control for the effects of international trade on metropolitan household income inequality. A potential variable that may be able to control for this effect would be the percentage of real GMP comprised of net exports from local metropolitan economies to foreign economies outside the U.S. Some measure of local net exports might serve as a proxy for the effects of international trade on income or earnings inequality, permitting us to control for these effects in future research. 
Additionally, a measure of the impact of metropolitan immigration on

metropolitan household income inequality was prevented due to limitations in the census data. It might have been helpful to control for the effects of changes in metropolitan immigration, and in particular Hispanic immigration, on changes in metropolitan household income inequality over the 1990 s, especially since this has been another widely accepted explanation for the rise in inequality (and the plateau in median household income) in recent decades (Brookings Institution, 2001). However, while the 2000 Census data permit a highly refined classification of metropolitan population in terms of both racial and ethnic categories, the 1990 Census data are much less parsimonious, offering only broad categories of race. Because the present study was designed to measure changes in numerous variables over the entire decade, and because the 1990 and 2000 Census race and ethnicity data are dissimilar, controlling for the effects of metropolitan Hispanic immigration was not possible using the present data sets and methodology. Future research may be able to make use of a lesser number of cases (PUMAs) found in the PUMS data sets to control for the effects of immigration.

Finally, as the results in Table 6 clearly indicate, most of the variation in metropolitan household income inequality as measured by the household Gini coefficient remains unexplained. The low $R^{2}$ in Model 4 suggests that the present study leaves largely unidentified important factors that could potentially explain changes in income inequality in metropolitan economies. Some of this residual effect might be accounted for by the additional variables proposed above for future research in this section, while other variables remain as yet unidentified. Where possible, it would certainly be important to control for other factors widely believed to have had some role in raising 
income inequality in recent decades, particularly the effects of international trade, immigration, and the decline in the role of labor market institutions such as unions and the real value of the minimum wage.

Overall, this study has attempted to detect the indirect effect of skill-biased technological change (SBTC) on inequality through changes in the rate of per capita economic growth over the 1990s. The findings presented here, based upon MSA level data from 1990 to 2000 , suggest that 1) further work must be done to substantiate the SBTC explanation for rising income inequality, 2) the effects of technological change may have little or no impact on inequality through economic growth, 3 ) the original Kuznets Curve Hypothesis appears to hold true even during periods of apparent structural change in an advanced post-industrial economy, and 4) numerous additional factors not identified by this study must be responsible for the variations in metropolitan household income inequality over the decade in question. Future research may address these challenges and questions through lines of inquiry similar to those suggested above. 


\section{REFERENCES}

Acemoglu, D. (2002a). Technical change, inequality, and the labor market. Journal of Economic Literature, 40(1), 7-72.

Acemoglu, D. (2002b). Cross-country inequality trends. National Bureau of Economic Research (Cambridge, MA), Working Paper No. 8832.

Adelman, I. \& Robinson, S. (1989). Income distribution and development. In H. Chenery \& T.N. Srinivisan (Eds.), Handbook of Development Economics, 2, 9491003.

Aghion, P., Caroli, E., \& Garcia-Penalosa, C. (1999). Inequality and economic growth: The perspective of the new growth theories. Journal of Economic Literature, 37(4), 1615-1660.

Aghion, P. \& Williamson, J.G. (1998). Growth, inequality and globalization: Theory, history and policy. Cambridge: Cambridge University Press.

Aigner, D.J. \& Heins, A.J. (1967). On the determinants of income equality. The American Economic Review, 57(1), 175-184.

Alesina, A. \& Rodrik, D. (1994). Distributive politics and economic growth. Quarterly Journal of Economics, 109(2), 465-490.

Alperovich, G. (1995). The relationship between income inequality and city size: A general equilibrium model of an open system of cities approach. Urban Studies, $\underline{32}(6), 853-862$.

Al-Samarrie, A. \& Miller, H.P. (1967). State differentials in income concentration. The American Economic Review, 57(1), 59-72.

Anand, S. \& Kanbur, S.M.R. (1993). The Kuznets process and the inequalitydevelopment relationship. Journal of Development Economics, 40(1), 25-52.

Asher, M.A. \& DeFina, R.H. (1995). Has deunionization led to higher earnings inequality? Federal Reserve Bank of Philadelphia Business Review (November/December), 3-12.

Austen, S. (1999). Norms of inequality. Journal of Economic Issues, 33(2), 435. 
Autor, D.H., Katz, L.F, \& Krueger, A.B. (1998). Computing inequality: Have computers changed the labor market? Quarterly Journal of Economics, 113(4), 1169-1213.

Barro, R.J. (2000). Inequality and growth in a panel of countries. Journal of Economic Growth, 5, 5-32.

Barro, R.J. (2001). Human capital: Growth, history, and policy. The American Economic Review, 91(2), 12-17.

Becker, G. (1961). Human capital: A theoretical and empirical analysis. Chicago: University of Chicago Press.

Berman, E., Bound, J., \& Griliches, Z. (1994). Changes in the demand for skilled labor within U.S. manufacturing: Evidence from the annual survey of manufacturers. Quarterly Journal of Economics, 109(2), 367-397.

Berman, E., Bound, J., \& Machin, S. (1998). Implications of skill-biased technologial change: International evidence. Quarterly Journal of Economics, 113(4), 12451279 .

Berry, W.D. (1993). Understanding regression assumptions. Newberry Park, CA: Sage Publications, Inc.

Betz, D. M. (1972). The city as a system generating income equality. Social Forces, 51, 192-198.

Bhagwati, J. (1995). Trade and wages: Choosing among alternative explanations. Federal Reserve Bank of New York Economic Policy Review (January), 42-46.

Bishop, J.H. (1996). Is the market for college graduates headed for a bust? Demand and supply responses to rising college wage premiums. Federal Reserve Bank of Boston New England Economic Review (May/June), 116-138.

Blakely, E.J. \& Bradshaw, T.K. (2002). Planning local economic development: Theory and practice, $3^{\text {rd }}$ ed. Thousand Oaks, CA: Sage Publications.

Block, W. (2000). Is inequality harmful for growth? Humanomics, 16(2), 52-58.

Borjas, G. J. (1995). The internationalization of the U.S. labor market and the wage structure. Federal Reserve Bank of New York Economic Policy Review (January), 3-8.

Borjas, G. J. \& Ramey, V.A. (1994). Time-series evidence on the sources of trends in wage inequality. The American Economic Review, 84(2), 10-16. 
Bound, J. \& Johnson, G. (1992). Changes in the structure of wages in the 1980's: An evaluation of alternative explanations. The American Economic Review, 82(3), 371-392.

Bound, J. \& Johnson, G. (1995). What are the causes of rising wage inequality in the United States? Federal Reserve Bank of New York Economic Policy Review (January), 9-17.

Brauer, D.A. \& Hickok, S. (1995). Explaining the growing inequality in wages across skill levels. Federal Reserve Bank of New York Economic Policy Review (January), 61-75.

Brookings Institution Center on Urban and Metropolitan Policy. (2001). Racial and ethnic change in the nation's largest cities: Evidence from the 2000 Census. In Census 2000 and the New Urban Dynamic. The Brookings Institution Survey Series.

Brynjolfsson, E. \& Hitt, L.M. (2000). Beyond computation: Information technology, organizational transformation and business performance. The Journal of Economic Perspectives, 14(4), 23-48.

Burns, L.S. (1975). The urban income distribution: A human capital explanation. Regional Science and Urban Economics, 5, 465-482.

Campbell, D.T. \& Stanley, J.C. (1966). Experimental and quasi-experimental designs for research. Chicago: Rand McNally.

Cappelli, P. (1996). Technology and skill requirements: Implications for establishment wage structure. Federal Reserve Bank of Boston New England Economic Review (May/June), 139-156.

Card, D. \& DiNardo, J.E. (2002). Skill biased technological change and rising wage inequality: Some problems and puzzles. National Bureau of Economic Research (Cambridge, MA), Working Paper No. 8769.

Carlino, G.A. (2001). Knowledge spillovers: Cities' role in the new economy. Federal Reserve Bank of Philadelphia Business Review ( $4^{\text {th }}$ Quarter $), 17-26$.

Caselli, F. \& Coleman II, W.J. (2001). Cross-country technology diffusion: The case of computers. The American Economic Review, 91(2), 328-335.

Chakravorty, S. (1996a). Urban inequality revisited: The determinants of income distribution in U.S. metropolitan areas. Urban Affairs Review, 31(6), 759.

Chakravorty, S. (1996b). A measurement of spatial disparity: The case of income inequality. Urban Studies, 33(9), 1671-1686. 
Chang, R. (1994). Income inequality and economic growth: Evidence and recent theories. Federal Reserve Bank of Atlanta Economic Review (July/August), 1-10.

Cloutier, N.R. (1997). Metropolitan income inequality during the 1980s: The impact of urban development, industrial mix, and family structure. Journal of Regional Science, 37(3), 459-478.

Conerly, W.B. (2003a). Is extending unemployment benefits a good idea? National Center for Policy Analysis (Dallas, TX), Brief Analysis No. 426.

Conerly, W.B. (2003b). The effect of extended benefits for the unemployed. American Institute for Full Employment. Retrieved April 10, 2003, from http://www.fullemployment.org/extendingunemployment.html.

Cook, T.D. \& Campbell, D.T. (1979). Quasi-experimentation: Design and analysis issues for field settings. Chicago: Rand McNally.

Danziger, S. (1976). Determinants of the level and distribution of family income in metropolitan areas, 1969. Land Economics, 52(4), 467-478.

Deininger, K. \& Squire, L. (1997, March). Economic growth and income inequality: Reexamining the links. Finance and Development. 38-41.

De Nardi, M., Ren, L. \& Wei, C. (2000). Income inequality and redistribution in five countries. Federal Reserve Bank of Chicago Economic Perspectives, 25(2), 2-20.

Dieckmann, O. (1996). Income inequality and economic growth in an open economy. International Advances in Economic Research, 2(3), 270-279.

Dollar, D. \& Kraay, A. (2001). Growth is good for the poor. Development Research Group of The World Bank (Washington, D.C.), Working Paper No. 2587. Retrieved from http://econ.worldbank.org/files/1696 wps2587.pdf.

Drennan, M.P., Tobier, E. \& Lewis, J. (1996). The interruption of income convergence and income growth in large cities in the 1980s. Urban Studies, 33(1), 63-82.

Duranton, G. \& Puga, D. (2001). Nursery cities: Urban diversity, process innovation, and the life cycle of products. The American Economic Review, 91(5), 1454-1477.

Erikson, R. \& Goldthorpe, J.H. (2002). Intergenerational inequality: A sociological perspective. The Journal of Economic Perspectives, 16 (3), 31-44.

Farbman, M. (1975). The size distribution of family income in U.S. SMSAs, 1959. The Review of Income and Wealth, 2 , 217-237. 
Feldman, M.P. \& Francis, J.L. (2004). Homegrown solutions: Fostering cluster formation. Economic Development Quarterly, 18(2), 127-137.

Feldstein, M. (1998). Overview: Is income inequality really a problem? In Income Inequality: Issues and Policy Options, a symposium of The Federal Reserve Bank of Kansas City, 357-390.

Fitzgerald, J. \& Leigh, N.G. (2002). Economic revitalization: Cases and strategies for city and suburb. Thousand Oaks, CA: Sage Publications.

Florida, R. (2004). The rise of the creative class: And how it's transforming work, leisure, community and everyday life. New York: Basic Books (paperback edition with updates).

Forbes, K.J. (2000). A reassessment of the relationship between inequality and economic growth. The American Economic Review, 90(4), 869-887.

Fortin, N.M. \& Lemieux, T. (1997). Institutional changes and rising wage inequality: Is there a linkage? The Journal of Economic Perspectives. 11 (2), 75-96.

Freeman, D.G. (2003). Trickling down the rising tide: New estimates of the link between poverty and the macroeconomy. Southern Economic Journal, 70(2), 359-373.

Freeman, R.B. (1995). Are your wages set in Beijing? The Journal of Economic Perspectives, 9(3), 15-32.

Freeman, R.B. (1996). Labor market institutions and earnings inequality. Federal Reserve Bank of Boston New England Economic Review (May/June), 157-171.

Furman, J \& Stiglitz, J.E. (1998). Economic consequences of income inequality. In Income Inequality: Issues and Policy Options, a symposium of the Federal Reserve Bank of Kansas City, 221-263.

Galbraith, J.K. \& Kum, H. (2002). Inequality and economic growth: Data comparisons and econometric tests. The University of Texas Inequality Project (Austin, TX), Working Paper No. 21.

Galor, O. \& Moav, O. (2000). Ability-biased technological transition, wage inequality, and economic growth. Quarterly Journal of Economics, 115(2), 469.

Galor, O. \& Tsiddon, D. (1997). Technological progress, mobility, and economic growth. The American Economic Review, 87(3), 363-382.

Galster, G.C. (1989). Metropolitan population size and economic well-being. Urban Affairs Quarterly, 24(4), 597-614. 
Garofalo, G. \& Fogarty, M.S. (1979). Urban income distribution and the urban hierarchyequality hypothesis. The Review of Economics and Statistics, 61(3), 381-388.

Gastwirth, J.L. (1972). The estimation of the Lorenz curve and Gini index. The Review of Economics and Statistics, 54(3), 306-316.

Glaeser, E.L. \& Mare, D.C. (2001). Cities and skills. Journal of Labor Economics, 19(2), 316-342.

Glaeser, E. L. \& Vigdor, J.L. (2001). Racial segregation in the 2000 census: Promising news. In Census 2000 and the New Urban Dynamic. The Brookings Institution Survey Series.

Glomm, G. (1997). Whatever happened to the Kuznets curve? Is it really upside down? Journal of Income Distribution, 7(1), 63-87.

Glomm, G. \& Ravikumar, B. (1992). Public versus private investment in human capital: Endogenous growth and income inequality. The Journal of Political Economy, $100(4), 818-834$

Goldin, C. \& Katz, L.F. (1996). Technology, skill, and the wage structure: Insights from the past. The American Economic Review, 86(2), 252-257.

Goldin, C. \& Katz, L.F. (1998). The origins of technology-skill complimentarity. The Quarterly Journal of Economics, 113(3), 693-732.

Goldin, C. \& Katz, L.F. (2001). The legacy of U.S. educational leadership: Notes on distribution and economic growth in the $20^{\text {th }}$ century. The American Economic Review, 91(2), 18-23.

Goldin, C. \& Margo, R.A. (1992). The great compression: The wage structure in the United States at mid-century. Quarterly Journal of Economics, 107(1), 1-34.

Gordon, R.J. (2000). Does the "new economy" measure up to the great inventions of the past? The Journal of Economic Perspectives, 14(4), 49-74.

Gottlieb, P.D. \& Fogarty, M. (2003). Educational attainment and metropolitan growth. Economic Development Quarterly, 17(4), 325-336.

Gottschalk, P. (1993). Changes in inequality of family income in seven industrialized countries. The American Economic Review, 83(2), 136-142.

Gottschalk, P. (1997). Inequality, income growth, and mobility: The basic facts. The Journal of Economic Perspectives, 11(2), 21-40. 
Gottschalk, P. \& Smeeding, T.M. (1997). Cross-national comparisons of earnings and income inequality. Journal of Economic Literature, 35(2), 633-687.

Greenwood, J. (1999). The third industrial revolution: Technology, productivity, and income inequality. Federal Reserve Bank of Cleveland Economic Review, 35(2), $2-12$

Greenwood, J. \& Jovanovic, B. (1990). Financial development, growth, and the distribution of income. The Journal of Political Economy, 98(5), 1076-1107.

Griliches, Z. (1990). Patent statistics as economic indicators: A survey. Journal of Economic Literature, 28(4), 1661-1707.

Gritz, M.R. \& MaCurdy, T. (1997). Measuring the influence of unemployment insurance on unemployment experiences. Journal of Business and Economic Statistics, $\underline{15}(2)$.

Gujarati, D. N. (1995). Basic econometrics, $3^{\text {rd }}$ ed. New York, NY: McGraw-Hill.

Harrigan, J. (1997). Technology, factor supplies, and international specialization: Estimating the neoclassical model. The American Economic Review, 87(4), 475494.

Harrigan, J. (1998). International trade and American wages in general equilibrium, 1967-1995. Paper presented at the NBER conference on "The Impact of International Trade on Wages," Monterey, CA, February 27-28.

Haslag, I., Fomby, T. \& Slottje, D.J. (1988). A study of the relationship between economic growth and inequality: The case of Mexico. Federal Reserve Bank of Dallas Economic Review (May).

Hausman, J.A. (1976). Specification tests in econometrics. Econometrica, 46, 1251-1271.

Haworth, C.T., Long, J.E., \& Rasmussen, D.W. (1978). Income distribution, city size, and urban growth. Urban Studies, 15(1), 1-7.

Haworth, C.T., Long, J.E., \& Rasmussen, D.W. (1979). Income distribution, city size, and urban growth: A reply. Urban Studies, 16, 345-347.

Higgs, R. (1971). American inventiveness, 1870-1920. The Journal of Political Economy, 79(3), 661-667.

Hill, E.W. \& Wolman, H.L. (1997a). City-suburban income disparities and metropolitan area employment: Can tightening labor markets reduce wage gaps? Urban Affairs Review, 32(4), 558-582. 
Hill, E.W. \& Wolman, H.L. (1997b). Accounting for the change in income disparities between U.S. central cities and their suburbs from 1980 to 1990. Urban Studies, $\underline{34}(1), 43-60$.

Hirsch, B.T. (1982). Income distribution, city size and urban growth: A final reexamination. Urban Studies, 19, 71-74.

Hoch, I. (1972). Income and city size. Urban Studies, 9, 299-328.

Holzer, H.J. (1987). Informal job search and black youth unemployment. The American Economic Review, 77(3), 446-452.

Holzer, H.J. \& Ihlanfeldt, K.R. (1996). Spatial factors and the employment of blacks at the firm level. Federal Reserve Bank of Boston New England Economic Review (May/June), 65-86.

Hyclak, T. (1996). Structural changes in labor demand and unemployment in local labor markets. Journal of Regional Science, 36(4), 653-663.

Hyclak, T. (2000). Rising wage inequality: The 1980s experience in urban labor markets. Kalamazoo, MI: W.E. Upjohn Institute for Employment Research.

Hyslop, D. R. (2001). Rising U.S. earnings inequality and family labor supply: The covariance structure of intrafamily earnings. The American Economic Review, 91(4), -777

Ihlanfeldt, K.R. \& Sjoquist, D.L. (1990). Job accessibility and racial differences in youth employment rates. The American Economic Review, 80(1), 267-276.

Irwin, D.A. (2002). Free trade under fire. Princeton, NJ: Princeton University Press.

Jaffe, A.B., Trajtenberg, M., \& Henderson, R. (1993). Geographic localization of knowledge spillovers as evidenced by patent citations. The Quarterly Journal of Economics, 108(3), 577-598.

Johnson, G.E. (1997). Changes in earnings inequality: The role of demand shifts. The Journal of Economic Perspectives, 11(2) 41-54.

Johnson, G.E. \& Stafford, F.P. (1993). International competition and real wages. The American Economic Review, 83(2), 127-130.

Juhn, C. \& Murphy, K.M. (1995). Inequality in labor market outcomes: Contrasting the 1980s and earlier decades. Federal Reserve Bank of New York Economic Policy Review (January), 26-32. 
Juhn, C., Murphy, K.M., \& Pierce, B. (1993). Wage inequality and the rise in returns to skill. The Journal of Political Economy, 101(3), 410-442.

Kain, J.F. (1968). Housing segregation, negro employment, and metropolitan decentralization. Quarterly Journal of Economics, 82(2), 175-197.

Kain, J.F. \& Singleton, K. (1996). Equality of educational opportunity revisited. Federal Reserve Bank of Boston New England Economic Review (May/June), 87-114.

Kane, T.J. \& Rouse, C.E. (1995). Labor-market returns to two- and four-year college. The American Economic Review, 85(3), 600-614.

Kaplow, L. (2002). Why measure inequality? National Bureau of Economic Research (Cambridge, MA), Working Paper No. 9342.

Katz, L.F. \& Murphy, K.M. (1992). Changes in relative wages, 1963-1987: Supply and demand factors. Quarterly Journal of Economics, 107(1), 35-78.

Keefer, P. \& Knack, S. (2002). Polarization, politics and property rights: Links between inequality and growth. Public Choice, 111, 127-154.

Kennedy, P. (1997). A guide to econometrics, $3^{\text {rd }}$ ed. Cambridge, MA: The MIT Press.

Kennedy, T. E. \& Nord, S. (1984). The effect of city size on the urban income distribution through time: 1950-70. Applied Economics, 16, 717-728.

Kiley, M.T. (1997). The supply of skilled labor and skill-biased technological progress. FEDS Paper 1997-45, Division of Research and Statistics, Federal Reserve Board (Washington, D.C.).

Kodrzycki, Y.K. (1996). Labor markets and earnings inequality: A status report. Federal Reserve Bank of Boston New England Economic Review (May/June), 11-25.

Konow, J. (2003). Which is the fairest one of all? A positive analysis of justice theories. Journal of Economic Literature, 41(4), 1188-1239.

Krueger, A.B. (1993). How computers have changed the wage structure: Evidence from microdata, 1984-1989. Quarterly Journal of Economics, 108(1), 33-60.

Kuznets, S. (1955). Economic growth and income inequality. The American Economic Review, 45(1), 1-28.

Lawrence, R.Z. (1995). U.S. wage trends in the 1980s: The role of international factors. Federal Reserve Bank of New York Economic Policy Review(January), 18-25. 
Leamer, E.E. (1996). Wage inequality from international competition and technological change: Theory and country experience. The American Economic Review, 86(2), 309-314.

Lee, W. \& Roemer, J. (1998). Income distribution, redistributive politics, and economic growth. Journal of Economic Growth, 3, 217-240.

Levy, F. (1995). The future path and consequences of the U.S. earnings/education gap. Federal Reserve Bank of New York Economic Policy Review(January), 35-41.

Levy, F. \& Murnane, R.J. (1992). U.S. earnings levels and earnings inequality: A review of recent trends and proposed explanations. Journal of Economic Literature, $\underline{30}(3), 1333-1381$.

Levy, F. \& Murnane, R.J. (1996). With what skills are computers a complement? The American Economic Review, 86(2), 258-262.

Li, H. \& Zou, H. (1998). Income inequality is not harmful for growth: Theory and evidence. Review of Development Economics, 2(3), 31 8-334.

Lindbeck, A. (1998). How can economic policy strike a balance between economic efficiency and income inequality. In Income Inequality: Issues and Policy Options, a symposium of The Federal Reserve Bank of Kansas City, 295-356.

Lindbeck, A. \& Snower, D. (1996). Reorganization of firms and labor-market inequality. The American Economic Review, 86(2), 315-321.

List, J.A. \& Gallett, C.A. (1999). The Kuznets curve: What happens after the inverted-U? Review of Development Economics, 3(2), 200-206.

Long, J.E., Rasmussen, D.W., \& Haworth, C.T. (1977). Income inequality and city size. The Review of Economics and Statistics, 59(2), 244-246.

Lucas, Jr., R.E. (1988). On the mechanics of economic development. Journal of Monetary Economics, 22(1), 3-42.

Lucas, Jr. R.E. (2004). The Industrial Revolution: Past and future. Federal Reserve Bank of Minneapolis The Region 18(1) (May), 4-21.

Lynch, L.M. (1995). The growing wage gap: Is training the answer? Federal Reserve Bank of New York Economic Policy Review (January), 54-58.

Madden, J.F. (2000). Changes in income inequality within U.S. metropolitan areas. Kalamazoo, MI: W.E. Upjohn Institute for Employment Research. 
Margo, R.A. (1999). The history of wage inequality in America, 1820-1970. The Jerome Levy Economics Institute of Bard College (Annendale-on-Hudson, NY), Working Paper No. 286.

Massey, D.S. \& Denton, N. (1987). Trends in the residential segregation of blacks, Hispanics, and Asians: 1970-1980. American Sociological Review, 52(?), 802825.

Massey, D.S. \& Eggers, M.L. (1993). The spatial concentration of affluence and poverty during the 1970s. Urban Affairs Quarterly, 29(2), 299-315.

Mayer, C.J. (1996). Does location matter? Federal Reserve Bank of Boston New England Economic Review (May/June), 26-40.

Meyer, B.D. (1990). Unemployment insurance and unemployment spells. Econometrica, 58(4), 757-782.

Mills, E.S. \& Hamilton, B.W. (1994). Urban Economics, $5^{\text {th }}$ ed. New York, NY: Addison Wesley.

Moomaw, R. \& Shatter, A.M.. (1996). Urbanization and economic development: A bias toward large cities? Journal of Urban Economics, 40(1), 13-37.

Mooney, J.D. (1967). Urban Poverty and Labor Force Participation. The American Economic Review, 57(1), 104-119.

Moore, T.S. \& Laramore, A. (1990). Industrial change and urban joblessness: An assessment of the mismatch hypothesis. Urban Affairs Quarterly, 25(4), 640-658.

Mulligan, C.B., Gil, R. \& Sala-i-Martin, X. (2004). Do democracies have different public policies than nondemocracies? The Journal of Economic Perspectives, $\underline{18}(1), 51-74$.

Murphy, K.M. \& Welch, F. (1992). The structure of wages. Quarterly Journal of Economics, 107(1), 285-326.

Murphy, K.M. \& Welch, F. (1993a). Inequality and relative wages. The American Economic Review, 83(2), 104-109.

Murphy, K.M. \& Welch, F. (1993b). Occupational change and the demand for skill, 1940-1990. The American Economic Review, 83(2), 122-126.

Murray, B.B. (1969). Metropolitan interpersonal income inequality. Land Economics, 45(1), 125-128. 
Nakamura, L.I. (2000). Economics and the new economy: The invisible hand meets creative destruction. Federal Reserve Bank of Philadelphia Business Review (July/August), 15-30.

Nelson, J.I, \& Lorence, J. (1985). Employment in service activities and inequality in metropolitan areas. Urban Affairs Quarterly, 21(1), 106-125.

Nelson, J.I. \& Lorence, J. (1988). Metropolitan earnings inequality and service sector employment. Social Forces, 67(2), 492-511.

Nickell, S. \& Bell, B. (1996). Changes in the distribution of wages and unemployment in OECD countries. The American Economic Review, 86(2), 302-308.

Nord, S. (1980a). An empirical analysis of income inequality and city size. Southern Economic Journal, 46, 863-872.

Nord, S. (1980b). Income inequality and city size: An examination of alternative hypotheses for large and small cities. The Review of Economics and Statistics, 62(4), $502 \cdots 508$.

Nunn, S. \& Worgan, A. (2002). Spaces of innovation: Patent activity in Indiana metropolitan areas, 1990 to 1998. Economic Development Quarterly, 16(3), 237250.

Nunn, S. \& Worgan, A. (2001). Spaces of innovation: Patent activity in Indiana metropolitan areas, 1990-98. Center for Urban Policy and the Environment (Indianapolis, IN). Monograph.

O'hUallachain, B. (1999). Patent places: Size matters. Journal of Regional Science, 39(4), 613-636.

Okun, A.M. (1975). Equality and efficiency: The big tradeoff. Washington, D.C.: The Brookings Institution.

Oliner, S.D. \& Sichel, D.E. (2000). The resurgence of growth in the late 1990s: Is information technology the story? The Journal of Economic Perspectives, 14(4), $3-22$.

O'Regan, K.M. \& Quigley, J.M. (1996). Spatial effects upon employment outcomes: The case of New Jersey teenagers. Federal Reserve Bank of Boston New England Economic Review (May/June), 41-64.

Panizza, U. (2002). Income inequality and economic growth: Evidence from American data. Journal of Economic Growth, 7, 25-41. 
Partridge, M.D. (1997). Is inequality harmful for growth? Comment. The American Economic Review, 87(5), p. 1019.

Persson, T. \& Tabellini, G. (1994). Is inequality harmful for growth? The American Economic Review, 84(3), 600-621.

Plosila, W.H. (2004). State science- and technology-based economic development policy: History, trends and developments, and future directions. Economic Development Quarterly, 18(2), 113-126.

Rawls, J. (1971). A theory of justice. New York: Belknap.

Revenga, A.L. (1992). Exporting jobs?: The impact of import competition on employment and wages in U.S. manufacturing. Quarterly Journal of Economics, $\underline{107}(1), 255-284$.

Richardson, J.D. (1995). Income inequality and trade: How to think, what to conclude. The Journal of Economic Perspectives, 9(3), 33-55.

Rodriguez, C.B. (2000). An empirical test of the institutionalist view on income inequality: Economic growth within the United States. American Journal of Economics and Sociology, 59(2), 303.

Romer, P.M. (1986). Increasing returns and long-run growth. The Journal of Political Economy, 94(5), 1002-1037.

Romer, P.M. (2000). Should the government subsidize supply or demand in the market for scientists and engineers? National Bureau of Economic Research (Cambridge, MA), Working Paper No. 7723.

Ryscavage, P. (1999). Income inequality in America: An analysis of trends. Armonk, NY: M.E. Sharpe, Inc.

Schmookler, J. (1954). The level of inventive activity. Review of Economics and Statistics, 36(2), 183-190.

Schmookler, J. (1957). Inventors past and present. Review of Economics and Statistics, $\underline{39}(3), 321-333$.

Schumpeter, J. A. (1976). Capitalism, socialism, and democracy ( $3^{\text {rd }}$ ed.). New York, NY: Harper and Row Publishers.

Siegal, D.S. (1999). Skill-biased technological change: Evidence from a firm-level survey. Kalamazoo, MI: W.E. Upjohn Institute for Employment Research. 
Snower, D.J. (1998). Causes of changing earnings inequality. In Income Inequality: Issues and Policy Options, a symposium of The Federal Reserve Bank of Kansas City, 69-158.

Solon, G. (2002). Cross-country differences in intergenerational earnings mobility. The Journal of Economic Perspectives, 16(3), 59-66.

Solow, R. (1956). A contribution to the theory of economic growth. Quarterly Journal of Economics, $70(1), 65-94$.

Solow, R. (1957). Technical change and the aggregate production function. Review of Economics and Statistics, 39(3), 312-320.

Stiroh, K.J. (2001a). Information technology and the U.S. productivity revival: What do the industry data say? Federal Reserve Bank of New York Staff Reports, No. 115 (January).

Stiroh, K.J. (2001b). Investing in information technology: Productivity payoffs for U.S. industries. Federal Reserve Bank of New York Current Issues in Economics and Finance, $7(6), 1-6$.

Sylwester, K. (1999). An empirical analysis of income inequality, education expenditures, and growth. The Journal of Economics, 25(2), 1-15.

Sylwester, K. (2000). Income inequality, education expenditures, and growth. Journal of Development Economics, 63, 379-398.

Tabachnick, B.G. and Fidell, L.S. (2001). Using multivariate statistics, $4^{\text {th }}$ ed. Needham Heights, MA: Allyn and Bacon.

Taylor, B.D. \& Ong, P.M. (1995). Spatial mismatch or automobile mismatch? An examination of race, residence and commuting in U.S. metropolitan areas. Urban Studies, 32(9), 1453-1473.

Thornton, J. (2001). The Kuznets inverted-U hypothesis: Panel data evidence from 96 countries. Applied Economic Letters, 8, 15-16.

Tinbergen, J. (1975). Income difference: Recent research. Amsterdam: North-Holland.

Topel, R.H. (1997). Factor proportions and relative wages: The supply-side determinants of wage inequality. The Journal of Economic Perspectives, 11(2), 55-74. 
U.S. Conference of Mayors. (2001). Conference of mayors president launches nationwide "Competitive Cities Tour:" Releases new report showing many U.S. metro areas outpace states, even nations, in economic output. Press Release of the U.S. Conference of Mayors (Washington, D.C.) dated July 10. Retrieved December 22, 2003, from http://www.usmayors.org/uscm/news/press releases/documents/ npe_071001.asp.

U.S. Department of Commerce, Bureau of Economic Analysis (2003). News release: National Income and Product Accounts comprehensive revision dated December 10. Retrieved May 20, 2004, from http://www.bea.doc.gov/bea/newsrel/ $2003 \mathrm{cr}$ newsrelease.htm.

U.S. Department of Labor, Bureau of Labor Statistics. (2003). Public data query. Retrieved May 20, 2004, from http://data.bls.gov/cgi-bin/surveymost?pr.

Vincente, J. \& Borge, L. (2000). Inequality and growth: Inverted and uninverted Ushapes. Applied Economics Letters, 7(8), 497-501.

Walker B (1979). Income distribution, city size, and urban growth A reply Urban Studies, 16, 341-343.

Welch, F. (1999). In defense of inequality. The American Economic Review, 89(2), 1-17.

Wessel, D.W. (2003, December 11). The link between patents and prosperity. The Wall Street Journal, p. A2.

Wheeler, C.H. (2004). On the distributional aspects of urban growth. Journal of Urban Economics, 55(2), 371-397.

Wilson, W.J. (1987). The truly disadvantaged: The inner city, the underclass and public policy. Chicago: University of Chicago Press.

Wolff, E.N. (1985). The magnitude and causes of the recent productivity slowdown in the U.S. In W. Baumol \& K. McClennan (Eds.), Productivity growth and U.S. competitiveness, 29-57.

Wolff, E.N. (1996). The productivity slowdown: The culprit at last? Follow-up on Hulten and Wolff. The American Economic Review, 86(5), 1239-1252.

Wood, A. (1995). How trade hurt unskilled workers. The Journal of Economic Perspectives, 9(3), 57-80.

Worgan, A. \& Nunn, S. (2002). Exploring a complicated labyrinth: Some tips on using patent data to measure urban and regional innovation. Economic Development Quarterly, 16(3), 229-236. 
Yinger, J. \& Danziger, S. (1978). An equilibrium model of urban population and the distribution of income. Urban Studies, 15(2), 201-214. 


\section{APPENDIX A}

Table 7: Summary of regression coefficients estimating changes in the metropolitan household Gini index, 1990-2000, including the direct effects of the measures of technological change (standard errors are in parentheses, $t$-values in brackets)

\begin{tabular}{|c|c|c|}
\hline & Model 6 & Model 7 \\
\hline$y$-intercept (constant) & .0243 & .0233 \\
\hline \multirow[t]{3}{*}{$\% \Delta$ actual per capita real GMP $1990-2000$} & -.0001 & \\
\hline & $(.000)$ & \\
\hline & {$[-1.475]$} & \\
\hline \multirow[t]{3}{*}{ proportionate $\Delta$ in educational inequality $1990-2000$} & $.0013^{* * *}$ & $.0013^{* * *}$ \\
\hline & $(.000)$ & $(.000)$ \\
\hline & [2.632] & [2.683] \\
\hline \multirow[t]{3}{*}{ point change in dissimilarity index $1990-2000$} & $.0247^{*}$ & $.0270^{* *}$ \\
\hline & $(.013)$ & $(.013)$ \\
\hline & [1.925] & {$[2.120]$} \\
\hline \multirow{3}{*}{$\% \Delta$ in per capita total real transfer payments $1990-2000$} & -.0001 & -.0001 \\
\hline & $(.000)$ & $(.000)$ \\
\hline & {$[-.416]$} & {$[-.612]$} \\
\hline \multirow[t]{3}{*}{$\Delta$ in proportion of black population $1990-2000$} & -.0004 & -.0004 \\
\hline & $(.001)$ & $(.001)$ \\
\hline & {$[-.594]$} & {$[-.561]$} \\
\hline \multirow[t]{3}{*}{$\Delta$ in ratio of female heads-of-household to population $1990-2000$} & .0011 & .0009 \\
\hline & $(.003)$ & $(.003)$ \\
\hline & [.384] & {$[.298]$} \\
\hline \multirow[t]{3}{*}{$\Delta$ in proportion of elderly population age $65+1990-2000$} & .0010 & .0012 \\
\hline & $(.001)$ & $(.001)$ \\
\hline & [1.215] & [1.356] \\
\hline \multirow[t]{3}{*}{ dummy for South census region } & .0008 & .0008 \\
\hline & $(.002)$ & $(.002)$ \\
\hline & {$[.444]$} & {$[.434]$} \\
\hline \multirow[t]{3}{*}{$\%$ population growth rate $1990-2000$} & $-.0002^{* * *}$ & $-.0002^{* *}$ \\
\hline & $(.000)$ & $(.000)$ \\
\hline & {$[-2.630]$} & {$[-2.554]$} \\
\hline \multirow[t]{3}{*}{$\% \Delta$ per capita utility patent approvals $1990-2000$} & -.0001 & -.0001 \\
\hline & $(.000)$ & $(.000)$ \\
\hline & {$[-.272]$} & {$[-.432]$} \\
\hline$\Delta$ in proportion of population in prof. / mgmt. / tech. jobs $1990-$ & -.0007 & -.0012 \\
\hline \multirow[t]{2}{*}{2000} & $(.001)$ & $(.001)$ \\
\hline & {$[-.817]$} & {$[-1.578]$} \\
\hline$F$ & 3.343 & 3.444 \\
\hline$R^{2}$ & .129 & .122 \\
\hline adjusted $R^{2}$ & .091 & .086 \\
\hline$n$ & 260 & 260 \\
\hline
\end{tabular}


The primary focus of the present research is on the direct relationship between technology-driven per capita economic growth and changes in household income inequality, the growth-inequality relationship. If technological change is positively associated with economic growth and is also a determinant of growing income inequality, then we might expect a positive relationship between growth and changes in income inequality. This study has shown otherwise, namely that economic growth tends to moderately reduce (or at least restrain) income inequality when controlling for other factors.

However, some curious readers may be interested in the direct impact of the measures of technological change on the changes in household income inequality when controlling for other factors. Table 7, above, is included as a satisfaction of this curiosity. Model 6 is a repeat of Model 4 with the additional inclusion of the two measures of technological change: per capita patent approval growth rates and change in the share of MSA population in technical- and professional-sector occupations. Model 7 excludes the per capita growth rate to determine if the measures of technological change play any role in explaining changes in MSA household income inequality.

As both Models 6 and 7 reveal, the measures of technological change employed in this study indicate no direct relationship with the changes in MSA household income inequality from 1990 to 2000 . If we assume that these measures of technological change are skill-biased, this finding further undermines the SBTC theory of widening income inequality, at least at the metropolitan economy level. Further, as indicated in Model 6, when the measures of technological change are included in the regression, the coefficient on per capita economic growth rate fails the test of significance, indicating that the 
relationship between income inequality and per capita economic growth rates is highly sensitive to the inclusion of these other variables, even though they are not themselves significantly related to changes in household income inequality. As in the previous findings highlighted in this research paper, both models exhibit relatively low $R^{2}$ values, indicating that much of the variation in household income inequality still remains unexplained. 


\section{CURRICULUM VITAE}

\section{Thomas Eric Lehman}

Department of Economics, College of Arts and Sciences Indiana Wesleyan University 4201 S. Washington St.

Marion, IN 46952

tom.1ehman@indwes.edu (765) 673-0658 (Residence) (765) 677-2602 (Office)

DOB: Fort Wayne, Indiana - December 2, 1967

\section{Education}

M.A. Ball State University 1994

Political Science

- Emphases: public policy and public administration, policy analysis, research methods and statistics

- Masters thesis: "The Politics of Christianity: An Analysis of the Economic and Social Views of the Christian Right"

B.S. Indiana Wesleyan University 1992

Economics

- Triple major: 1) Economics 2) Political Science 3) History

- Graduated cum laude GPA: $3.4 / 4.0$

- Voted by faculty as the Outstanding Economics Student of the graduating class of 1992

- Recipient, Alan Bowman Political Science Scholarship Award, 1991

\section{Academic Employment History}

2002-present: Assistant Professor, Economics, Indiana Wesleyan University, Department of Economics, CAS and College of APS

See below for faculty teaching load and courses taught

1994-2002: $\quad$ Administrative / Adjunct Faculty, Economics and Business, Indiana Wesleyan University, College of APS and CAS 
1999-2002: $\quad$ Program Chair, Business and Management, Baccalaureate Degree Programs, Indiana Wesleyan University, College of APS

Responsible for and provide oversight to all bachelors degree programs in the Department of Business and Management, including student advising, faculty hiring, orientation and development, and curriculum revision and design; combined full-time and part-time faculty of over 500 active instructors

1998-1999: $\quad$ Director, Faculty Recruitment, Indiana Wesleyan University, APS Responsible for all faculty recruitment in the Adult and Professional Studies program; managed a team of five faculty recruiters and staff, and a budget of $\$ 50,000$

1997-1998: $\quad$ Coordinator of Faculty Services, Indiana Wesleyan University, APS Responsible for the recruitment of faculty for the Business and Management Department of the Adult and Professional Studies programs. Developed networking contacts with educational, professional, and business organizations throughout Indiana; conducted initial faculty candidate interviews; responsible for organizing and coordinating fulltime and part-time faculty search committee interviews; made faculty hiring recommendations to program directors; conducted faculty orientation and development for new adjunct faculty

\section{Non-Academic Employment History}

1993-1997: $\quad$ Assistant Branch Manager and Financial Consultant, American General Finance, Inc.

Responsible for consumer lending decisions, loan approval, and debt collection administration for $\$ 10$ million accounts receivables; managed staff of seven and $\$ 10$ million in financial assets; financial consultant to borrowers in need of home mortgage loans, automobile financing, personal property loans, debt consolidation, insurance services, and bankruptcy relief or Consumer Credit Counseling debt relief

1991-1994: Insurance Agent and Financial Consultant, Primerica Financial Services, Inc. (now Citigroup)

Independent licensed insurance agent in property and casualty, life and health; financial consultant and mutual fund broker for PFS 
Faculty Teaching Load, Indiana Wesleyan University*

\begin{tabular}{|c|c|}
\hline ECO 211 & Introduction to Economics ( $1 \mathrm{x}$ semester) \\
\hline ECO 212 & Microeconomics (1 $\mathrm{x}$ semester) \\
\hline ECO 213 & Macroeconomics ( $1 \mathrm{x}$ semester) \\
\hline BUS320 & Business Statistics (every other year) \\
\hline $\mathrm{ECO} 365$ & Public Administration and Finance (every other year) \\
\hline $\mathrm{ECO} 320$ & American Economic History (once annually) \\
\hline ECO 205 & Basic Economics (1-2 times annually) \\
\hline ECO 330 & Applied Microeconomics (2-3 times annually) \\
\hline ECO 331 & Applied Macroeconomics (2-3 times annually) \\
\hline BUS 150 & Personal Finance (less than once annually) \\
\hline HST 180 & Western Civilization (less than once annually) \\
\hline
\end{tabular}

*Teaching evaluations and course syllabi available upon request

\section{Current Professional and Academic Associations / Memberships}

American Fconomic Association (AEA)

\section{Professional Assignments, Administrative Appointments, and Activities}

Indiana Wesleyan University Administrative Appointments:

- Faculty Development Committee, CAS and College of APS 1999-2002 Implemented faculty rank improvement processes and guidelines; developed faculty peer review evaluation instruments and processes; responsible for faculty development workshop scheduling and programming; ongoing faculty portfolio review and evaluation for faculty rank improvement

- Administrative/Academic Committee, College of APS 1998-2002

Provide oversight for new academic initiatives such as new online degree programs, new on-site satellite campus development, and faculty hiring and development; enrollment management and growth policies debated and voted upon; student and faculty service issues considered; implementation of academic quality initiatives

Scholarship: Popular Articles, Presentations, Papers, and Research

Scholarly Articles:

2004 (in press) "Why rents rise." Chapter 4 in Invisible City: Power, Place and Poverty, John Gilderbloom, Ed., 2004. (Co-authored with John Gilderbloom, Zhenfeng Pan and Stephen Roosa). 


\section{Popular Articles:}

2004 "Critics don't really understand free trade." Guest economics column for the Chronicle-Tribune newspaper (Marion, IN) published Thursday, May 6, 2004.

2004 "The public should not be fooled: Outsourcing is good for the economy." Guest economics column for the Chronicle-Tribune newspaper (Marion, $\mathbb{N}$ ) published Tuesday, March 2, 2004.

2003 "Economics prof offers ideas to help county." Guest economics column for the Chronicle-Tribune newspaper (Marion, IN) published Sunday, September 28, 2003.

2003 "In defense of payday lending." The Free Market. (September).

2003 "Believe it or not, unemployment can help." Guest economics column for the Chronicle-Tribune newspaper (Marion, IN) published Sunday, June 22, 2003.

1995. "Coming to America: The Benefits of Open Immigration." Ideas on Liberty. (December).

1993. "How Three Screw Machine Companies are Tapping Human Productivity Through Gainsharing." Employment Relations Today. (Winter) (co-authored with and ghost-published under the name of Tom McGrath of Jackson Gainsharing Co., Inc.)

Scholarly and Popular Presentations:

"Comparative local economic development strategies: Options for Marion and Grant County." Synergy 2004. Indiana Wesleyan University. May 2004.

"Why Rents Vary Across Cities and Over Time, 1970-2000." Presentation at a symposium for Indiana Wesleyan University Scholarship Day, April 2003.

" $4^{\text {th }}$ and Oak Street Economic Revitalization Proposal" (Louisville, KY). Presentation to Louisville area Economic Development Corporation, Louisville Chapter of the Shalom Group, and business and government leaders in Louisville, December 2002 (team / class project for UPA640 Economic Development).

“TL's Time-Tidy Tips for Effective Time Management." In-service training for Indiana Wesleyan University staff and hourly employees, June 2002.

"Libertarians and Conservatives: Strange Bedfellows or Political Allies?" Paper presented to the Opportunity Project of Indiana, March 1997.

Unpublished Research:

2003 "Why Rents Vary Across Cities: Understanding the Causes and Solutions of the Nation's Housing Crisis." (co-authored with John Gilderbloom and Zhenfeng Pan). 
2003 "Inter-City Rent Prices in the Larger U.S. Market 1990-2000." (co-authored with John Gilderbloom, Zhenfeng Pan and Stephen Roosa).

2003 "Why Rents Vary: Understanding the Roots of the Housing Crisis" (co-authored with John Gilderbloom and Zhenfeng Pan).

2002. "The Determinants of Adult Student Academic Performance in Nontraditional Degree Programs: Program Effects or Grade Inflation? A Case Study." (The statistical findings of this research were presented at a seminar for the faculty of Indiana Wesleyan University's College of APS, May 2002.)

Master's Thesis: "The politics of Christianity: An analysis of the economic and social views of the Christian Right." Ball State University, 1994.

\section{Other Professional and Personal Activities}

- Panel discussant, MacNeil/Lehrer By the People: America in the World, "Globalization and free trade: Making the local connection." May 24, 2004. Indiana Wesleyan University (Marion, IN).

- Guest economist on Conversations with Joy Cardin, The Ideas Network of Wisconsin Public Radio (Madison, WI). Radio call-in discussion topic: "The Payday Lending Industry." (January 20, 2004).

- Nominated and included in "Who's Who Among America's Teachers, 20032004."

- Frequent guest on the Tim Rush radio program Good Morning Grant County (WGOM/WBAT-AM). Recent topics of discussion include: local/county governance and policy (October 2002), fiscal policy and the Bush tax cuts (January 2003), and local economic development opportunities for Marion and Grant County (August 2003). 